DESY-07-102

July 2007

\title{
Three- and four-jet final states in photoproduction at HERA
}

\author{
ZEUS Collaboration
}

\begin{abstract}
Three- and four-jet final states have been measured in photoproduction at HERA using the ZEUS detector with an integrated luminosity of $121 \mathrm{pb}^{-1}$. The results are presented for jets with transverse energy $E_{T}^{\text {jet }}>6 \mathrm{GeV}$ and pseudorapidity $\left|\eta^{\text {jet }}\right|<2.4$, in the kinematic region given by the virtuality of the photon $Q^{2}<$ $1 \mathrm{GeV}^{2}$ and the inelasticity $0.2 \leq y \leq 0.85$ and in two mass regions defined as $25 \leq M_{n j}<50 \mathrm{GeV}$ and $M_{n j} \geq 50 \mathrm{GeV}$, where $M_{n j}$ is the invariant mass of the $n$-jet system. The four-jet photoproduction cross section has been measured for the first time and represents the highest-order process studied at HERA. Both the three- and four-jet cross sections have been compared with leading-logarithmic parton-shower Monte Carlo models, with and without multi-parton interactions. The three-jet cross sections have been compared to an $\mathcal{O}\left(\alpha \alpha_{s}^{2}\right)$ perturbative QCD calculation.
\end{abstract}




\section{The ZEUS Collaboration}

S. Chekanov ${ }^{1}$, M. Derrick, S. Magill, B. Musgrave, D. Nicholass ${ }^{2}$, J. Repond, R. Yoshida Argonne National Laboratory, Argonne, Illinois 60439-4815, USA ${ }^{n}$

M.C.K. Mattingly

Andrews University, Berrien Springs, Michigan 49104-0380, USA

M. Jechow, N. Pavel ${ }^{\dagger}$, A.G. Yagües Molina

Institut für Physik der Humboldt-Universität zu Berlin, Berlin, Germany

S. Antonelli, P. Antonioli, G. Bari, M. Basile, L. Bellagamba, M. Bindi, D. Boscherini,

A. Bruni, G. Bruni, L. Cifarelli, F. Cindolo, A. Contin, M. Corradi, S. De Pasquale,

G. Iacobucci, A. Margotti, R. Nania, A. Polini, G. Sartorelli, A. Zichichi

University and INFN Bologna, Bologna, Italy $^{e}$

D. Bartsch, I. Brock, H. Hartmann, E. Hilger, H.-P. Jakob, M. Jüngst, O.M. Kind ${ }^{3}$, A.E. Nuncio-Quiroz, E. Paul ${ }^{4}$, R. Renner ${ }^{5}$, U. Samson, V. Schönberg, R. Shehzadi, M. Wlasenko Physikalisches Institut der Universität Bonn, Bonn, Germany ${ }^{b}$

N.H. Brook, G.P. Heath, J.D. Morris

H.H. Wills Physics Laboratory, University of Bristol, Bristol, United Kingdom ${ }^{m}$

M. Capua, S. Fazio, A. Mastroberardino, M. Schioppa, G. Susinno, E. Tassi

Calabria University, Physics Department and INFN, Cosenza, Italy ${ }^{e}$

J.Y. $\mathrm{Kim}^{6}$, K.J. Ma

Chonnam National University, Kwangju, South Korea ${ }^{g}$

Z.A. Ibrahim, B. Kamaluddin, W.A.T. Wan Abdullah

Jabatan Fizik, Universiti Malaya, 50603 Kuala Lumpur, Malaysia ${ }^{r}$

Y. Ning, Z. Ren, F. Sciulli

Nevis Laboratories, Columbia University, Irvington on Hudson, New York 10027o

J. Chwastowski, A. Eskreys, J. Figiel, A. Galas, M. Gil, K. Olkiewicz, P. Stopa, L. Zawiejski

The Henryk Niewodniczanski Institute of Nuclear Physics, Polish Academy of Sciences, Cracow, Poland ${ }^{i}$

L. Adamczyk, T. Bołd, I. Grabowska-Bołd, D. Kisielewska, J. Łukasik, M. Przybycień,

L. Suszycki

Faculty of Physics and Applied Computer Science, AGH-University of Science and Technology, Cracow, Poland ${ }^{p}$

A. Kotański ${ }^{8}$, W. Słomiński ${ }^{9}$

Department of Physics, Jagellonian University, Cracow, Poland 
V. Adler ${ }^{10}$, U. Behrens, I. Bloch, C. Blohm, A. Bonato, K. Borras, R. Ciesielski, N. Coppola, A. Dossanov, V. Drugakov, J. Fourletova, A. Geiser, D. Gladkov, P. Göttlicher ${ }^{11}$, J. Grebenyuk, I. Gregor, T. Haas, W. Hain, C. Horn ${ }^{12}$, A. Hüttmann, B. Kahle, I.I. Katkov, U. Klein ${ }^{13}$, U. Kötz, H. Kowalski, E. Lobodzinska, B. Löhr, R. Mankel, I.-A. MelzerPellmann, S. Miglioranzi, A. Montanari, T. Namsoo, D. Notz, L. Rinaldi, P. Roloff, I. Rubinsky, R. Santamarta, U. Schneekloth, A. Spiridonov ${ }^{14}$, H. Stadie, D. Szuba ${ }^{15}$, J. Szuba ${ }^{16}$, T. Theedt, G. Wolf, K. Wrona, C. Youngman, W. Zeuner

Deutsches Elektronen-Synchrotron DESY, Hamburg, Germany

W. Lohmann, S. Schlenstedt

Deutsches Elektronen-Synchrotron DESY, Zeuthen, Germany

G. Barbagli, E. Gallo, P. G. Pelfer

University and INFN Florence, Florence, Italy ${ }^{e}$

A. Bamberger, D. Dobur, F. Karstens, N.N. Vlasov ${ }^{17}$

Fakultät für Physik der Universität Freiburg i.Br., Freiburg i.Br., Germany ${ }^{b}$

P.J. Bussey, A.T. Doyle, W. Dunne, M. Forrest, D.H. Saxon, I.O. Skillicorn

Department of Physics and Astronomy, University of Glasgow, Glasgow, United Kingdom $^{m}$

I. Gialas ${ }^{18}$, K. Papageorgiu

Department of Engineering in Management and Finance, Univ. of Aegean, Greece

T. Gosau, U. Holm, R. Klanner, E. Lohrmann, H. Salehi, P. Schleper, T. Schörner-Sadenius,

J. Sztuk, K. Wichmann, K. Wick

Hamburg University, Institute of Exp. Physics, Hamburg, Germany ${ }^{b}$

C. Foudas, C. Fry, K.R. Long, A.D. Tapper

Imperial College London, High Energy Nuclear Physics Group, London, United Kingdom ${ }^{m}$

M. Kataoka ${ }^{19}$, T. Matsumoto, K. Nagano, K. Tokushuku ${ }^{20}$, S. Yamada, Y. Yamazaki ${ }^{21}$ Institute of Particle and Nuclear Studies, KEK, Tsukuba, Japan ${ }^{f}$

A.N. Barakbaev, E.G. Boos, N.S. Pokrovskiy, B.O. Zhautykov

Institute of Physics and Technology of Ministry of Education and Science of Kazakhstan, Almaty, Kazakhstan

V. Aushev ${ }^{1}$, M. Borodin, A. Kozulia, M. Lisovyi

Institute for Nuclear Research, National Academy of Sciences, Kiev and Kiev National University, Kiev, Ukraine

D. Son

Kyungpook National University, Center for High Energy Physics, Daegu, South Korea ${ }^{g}$ 
J. de Favereau, K. Piotrzkowski

Institut de Physique Nucléaire, Université Catholique de Louvain, Louvain-la-Neuve, Belgium $^{q}$

F. Barreiro, C. Glasman², M. Jimenez, L. Labarga, J. del Peso, E. Ron, M. Soares, J. Terrón, M. Zambrana

Departamento de Física Teórica, Universidad Autónoma de Madrid, Madrid, Spain ${ }^{l}$

F. Corriveau, C. Liu, R. Walsh, C. Zhou

Department of Physics, McGill University, Montréal, Québec, Canada H3A 2T8 a

T. Tsurugai

Meiji Gakuin University, Faculty of General Education, Yokohama, Japan ${ }^{f}$

A. Antonov, B.A. Dolgoshein, V. Sosnovtsev, A. Stifutkin, S. Suchkov

Moscow Engineering Physics Institute, Moscow, Russia ${ }^{j}$

R.K. Dementiev, P.F. Ermolov, L.K. Gladilin, L.A. Khein, I.A. Korzhavina, V.A. Kuzmin, B.B. Levchenko ${ }^{23}$, O.Yu. Lukina, A.S. Proskuryakov, L.M. Shcheglova, D.S. Zotkin, S.A. Zotkin

Moscow State University, Institute of Nuclear Physics, Moscow, Russia ${ }^{k}$

I. Abt, C. Büttner, A. Caldwell, D. Kollar, W.B. Schmidke, J. Sutiak

Max-Planck-Institut für Physik, München, Germany

G. Grigorescu, A. Keramidas, E. Koffeman, P. Kooijman, A. Pellegrino, H. Tiecke, M. Vázquez ${ }^{19}$, L. Wiggers

NIKHEF and University of Amsterdam, Amsterdam, Netherlands ${ }^{h}$

N. Brümmer, B. Bylsma, L.S. Durkin, A. Lee, T.Y. Ling

Physics Department, Ohio State University, Columbus, Ohio $43210^{n}$

P.D. Allfrey, M.A. Bell, A.M. Cooper-Sarkar, R.C.E. Devenish, J. Ferrando, B. Foster, K. Korcsak-Gorzo, K. Oliver, S. Patel, V. Roberfroid ${ }^{24}$, A. Robertson, P.B. Straub, C. Uribe-Estrada, R. Walczak

Department of Physics, University of Oxford, Oxford United Kingdom ${ }^{m}$

P. Bellan, A. Bertolin, R. Brugnera, R. Carlin, F. Dal Corso, S. Dusini, A. Garfagnini, S. Limentani, A. Longhin, L. Stanco, M. Turcato

Dipartimento di Fisica dell' Università and INFN, Padova, Italy ${ }^{e}$

B.Y. Oh, A. Raval, J. Ukleja ${ }^{25}$, J.J. Whitmore ${ }^{26}$

Department of Physics, Pennsylvania State University, University Park, Pennsylvania $16802^{\circ}$

Y. Iga

Polytechnic University, Sagamihara, Japan ${ }^{f}$ 
G. D'Agostini, G. Marini, A. Nigro

Dipartimento di Fisica, Università 'La Sapienza' and INFN, Rome, Italy ${ }^{e}$

J.E. Cole, J.C. Hart

Rutherford Appleton Laboratory, Chilton, Didcot, Oxon, United Kingdom ${ }^{m}$

H. Abramowicz ${ }^{27}$, A. Gabareen, R. Ingbir, S. Kananov, A. Levy

Raymond and Beverly Sackler Faculty of Exact Sciences, School of Physics, Tel-Aviv University, Tel-Aviv, Israel ${ }^{d}$

M. Kuze, J. Maeda

Department of Physics, Tokyo Institute of Technology, Tokyo, Japan ${ }^{f}$

R. Hori, S. Kagawa ${ }^{28}$, N. Okazaki, S. Shimizu, T. Tawara

Department of Physics, University of Tokyo, Tokyo, Japan ${ }^{f}$

R. Hamatsu, H. Kaji ${ }^{29}$, S. Kitamura ${ }^{30}$, O. Ota, Y.D. Ri

Tokyo Metropolitan University, Department of Physics, Tokyo, Japan ${ }^{f}$

M.I. Ferrero, V. Monaco, R. Sacchi, A. Solano

Università di Torino and INFN, Torino, Italy ${ }^{e}$

M. Arneodo, M. Ruspa

Università del Piemonte Orientale, Novara, and INFN, Torino, Italy ${ }^{e}$

S. Fourletov, J.F. Martin

Department of Physics, University of Toronto, Toronto, Ontario, Canada M5S 1A7 a

S.K. Boutle ${ }^{18}$, J.M. Butterworth, C. Gwenlan ${ }^{31}$, T.W. Jones, J.H. Loizides, M.R. Sutton ${ }^{31}$, M. Wing

Physics and Astronomy Department, University College London, London, United Kingdom $^{m}$

B. Brzozowska, J. Ciborowski ${ }^{32}$, G. Grzelak, P. Kulinski, P. Łużniak ${ }^{33}$, J. Malka ${ }^{33}$, R.J. Nowak, J.M. Pawlak, T. Tymieniecka, A. Ukleja, A.F. Żarnecki

Warsaw University, Institute of Experimental Physics, Warsaw, Poland

M. Adamus, P. Plucinski ${ }^{34}$

Institute for Nuclear Studies, Warsaw, Poland

Y. Eisenberg, I. Giller, D. Hochman, U. Karshon, M. Rosin

Department of Particle Physics, Weizmann Institute, Rehovot, Israel ${ }^{c}$

E. Brownson, T. Danielson, A. Everett, D. Kçira, D.D. Reeder ${ }^{4}$, P. Ryan, A.A. Savin, W.H. Smith, H. Wolfe

Department of Physics, University of Wisconsin, Madison, Wisconsin 53706, USA ${ }^{n}$

S. Bhadra, C.D. Catterall, Y. Cui, G. Hartner, S. Menary, U. Noor, J. Standage, J. Whyte Department of Physics, York University, Ontario, Canada M3J 1P3 ${ }^{a}$ 
${ }^{1}$ supported by DESY, Germany

2 also affiliated with University College London, UK

${ }^{3}$ now at Humboldt University, Berlin, Germany

${ }^{4}$ retired

5 self-employed

${ }^{6}$ supported by Chonnam National University in 2005

7 supported by a scholarship of the World Laboratory Björn Wiik Research Project

8 supported by the research grant no. 1 P03B 04529 (2005-2008)

9 This work was supported in part by the Marie Curie Actions Transfer of Knowledge project COCOS (contract MTKD-CT-2004-517186)

${ }^{10}$ now at Univ. Libre de Bruxelles, Belgium

11 now at DESY group FEB, Hamburg, Germany

12 now at Stanford Linear Accelerator Center, Stanford, USA

13 now at University of Liverpool, UK

14 also at Institut of Theoretical and Experimental Physics, Moscow, Russia

15 also at INP, Cracow, Poland

16 on leave of absence from FPACS, AGH-UST, Cracow, Poland

17 partly supported by Moscow State University, Russia

18 also affiliated with DESY

19 now at CERN, Geneva, Switzerland

20 also at University of Tokyo, Japan

${ }^{21}$ now at Kobe University, Japan

${ }^{22}$ Ramón y Cajal Fellow

23 partly supported by Russian Foundation for Basic Research grant no. 05-02-39028NSFC-a

${ }^{24}$ EU Marie Curie Fellow

25 partially supported by Warsaw University, Poland

26 This material was based on work supported by the National Science Foundation, while working at the Foundation.

27 also at Max Planck Institute, Munich, Germany, Alexander von Humboldt Research Award

${ }^{28}$ now at KEK, Tsukuba, Japan

${ }^{29}$ now at Nagoya University, Japan

30 Department of Radiological Science

${ }^{31}$ PPARC Advanced fellow

32 also at Eódź University, Poland

33 Łódź University, Poland

34 supported by the Polish Ministry for Education and Science grant no. 1 P03B 14129

$\dagger$ deceased 
a supported by the Natural Sciences and Engineering Research Council of Canada (NSERC)

$b$ supported by the German Federal Ministry for Education and Research (BMBF), under contract numbers HZ1GUA 2, HZ1GUB 0, HZ1PDA 5, HZ1VFA 5

c supported in part by the MINERVA Gesellschaft für Forschung GmbH, the Israel Science Foundation (grant no. 293/02-11.2) and the U.S.-Israel Binational Science Foundation

$d$ supported by the German-Israeli Foundation and the Israel Science Foundation

$e$ supported by the Italian National Institute for Nuclear Physics (INFN)

$f \quad$ supported by the Japanese Ministry of Education, Culture, Sports, Science and Technology (MEXT) and its grants for Scientific Research

$g$ supported by the Korean Ministry of Education and Korea Science and Engineering Foundation

$h$ supported by the Netherlands Foundation for Research on Matter (FOM)

$i$ supported by the Polish State Committee for Scientific Research, grant no. 620/E-77/SPB/DESY/P-03/DZ 117/2003-2005 and grant no. 1P03B07427/2004-2006

${ }^{j}$ partially supported by the German Federal Ministry for Education and Research $(\mathrm{BMBF})$

$k$ supported by RF Presidential grant N 8122.2006.2 for the leading scientific schools and by the Russian Ministry of Education and Science through its grant Research on High Energy Physics

$l$ supported by the Spanish Ministry of Education and Science through funds provided by CICYT

$m$ supported by the Particle Physics and Astronomy Research Council, UK

$n$ supported by the US Department of Energy

$o$ supported by the US National Science Foundation. Any opinion, findings and conclusions or recommendations expressed in this material are those of the authors and do not necessarily reflect the views of the National Science Foundation.

$p \quad$ supported by the Polish Ministry of Science and Higher Education as a scientific project (2006-2008)

$q$ supported by FNRS and its associated funds (IISN and FRIA) and by an Inter-University Attraction Poles Programme subsidised by the Belgian Federal Science Policy Office

$r$ supported by the Malaysian Ministry of Science, Technology and Innovation/Akademi Sains Malaysia grant SAGA 66-02-03-0048 


\section{Introduction}

In photoproduction at HERA, a quasi-real photon, emitted by the incoming electron ${ }^{1}$, interacts with the proton. Hard photoproduction [1-10] may be categorised at leading order (LO) as being either direct, if the photon interacts as a point-like particle, or resolved, if it fluctuates into a partonic system, and subsequently transfers only a fraction of its momentum to the hard interaction.

Photoproduction collisions at HERA can lead to final states with multiple jets. Multi-jet events are of particular interest as they are produced by processes that are manifestly beyond LO in the strong coupling constant, $\alpha_{s}$. Presently, predictions from perturbative quantum chromodynamics (pQCD) pertaining to multi-jet final states in photoproduction are only available up to $\mathcal{O}\left(\alpha \alpha_{s}^{2}\right)$, where $\alpha$ is the fine structure constant.

The hadron-like structure of the photon in resolved processes gives rise to the possibility of multi-parton interactions (MPIs) at HERA. In the MPI picture, more than one pair of partons takes part in the hard interaction. A schematic of an MPI event is shown in Fig. 1. The secondary scatters generate additional hadronic energy flow in the event, the topology and magnitude of which is poorly understood theoretically. Potentially, this energy flow may lead to the formation of jets and so MPIs may constitute a source of multi-jets in the final state. Multi-parton interactions have been studied before at the Tevatron [11-14], in dijet photoproduction events at HERA $[15,16]$ and are expected to be prevalent at the LHC $[17,18]$.

Three-jet photoproduction events have been studied before at HERA in the $M_{3 j} \geq$ $50 \mathrm{GeV}[19]$ region of three-jet invariant mass. Multi-jet final states have also been studied in deep inelastic scattering (DIS) at HERA [20-23]. In this paper, differential cross sections are presented for the three-jet photoproduction final state, in a wider $M_{3 j}$ region and with over seven times the luminosity of the previous ZEUS publication [19]. The four-jet photoproduction cross sections are presented here for the first time. Also examined is the description of the data by two Monte Carlo (MC) models and whether or not it is improved by the introduction of simulated MPIs. In addition, an $\mathcal{O}\left(\alpha \alpha_{s}^{2}\right)$ prediction has been compared to the three-jet data.

\section{Experimental conditions}

The data were collected using the ZEUS detector during the 1996 to 2000 running periods. In 1996 and 1997, HERA collided positrons with protons, with energies of $E_{e}=27.5 \mathrm{GeV}$

\footnotetext{
${ }^{1}$ From now on the word "electron" is used as a generic term for electrons and positrons, unless stated otherwise.
} 
and $E_{p}=820 \mathrm{GeV}$, respectively, corresponding to a beam centre-of-mass energy, $\sqrt{s}$, of $300 \mathrm{GeV}$. From 1998 onwards the proton beam energy was raised to $E_{p}=920 \mathrm{GeV}$ $(\sqrt{s}=318 \mathrm{GeV})$. Furthermore, a subsample of these later data consists of electron-proton collisions. The total sample corresponds to an integrated luminosity of $(121 \pm 2) \mathrm{pb}^{-1}$, of which $82 \mathrm{pb}^{-1}$ were collected at $\sqrt{s}=318 \mathrm{GeV}$. A detailed description of the ZEUS detector can be found elsewhere $[24,25]$. A brief outline of the components that are of most relevance to this analysis is given below.

The high-resolution uranium-scintillator calorimeter (CAL) [26] consists of three parts: the forward, the barrel and the rear calorimeters. Each part is subdivided transversely into towers and longitudinally into one electromagnetic and either one (in the rear) or two (in the barrel and forward) hadronic sections. The smallest subdivision of the calorimeter is called a cell. The CAL relative energy resolutions, as measured under test-beam conditions, are $0.18 / \sqrt{E}$ for electrons and $0.35 / \sqrt{E}$ for hadrons, with $E$ in $\mathrm{GeV}$.

Charged particles are measured in the central tracking detector (CTD) [27], which operates in a magnetic field of $1.43 \mathrm{~T}$ provided by a thin superconducting coil. The CTD covers the polar-angle ${ }^{2}$ region $15^{\circ}<\theta<164^{\circ}$. The relative transverse-momentum resolution for full-length tracks is $\sigma_{p_{T}} / p_{T}=0.0058 p_{T} \oplus 0.0065 \oplus 0.0014 / p_{T}$, with $p_{T}$ in GeV. Both tracking and calorimetry were used to reconstruct the transverse energy and direction of jets as described in Section 3.

The luminosity was measured from the rate of the bremsstrahlung process $e p \rightarrow e \gamma p$, where the photon is detected in a lead-scintillator calorimeter [28] placed in the HERA tunnel at $Z=-107 \mathrm{~m}$.

\section{Event reconstruction and selection}

A three-level trigger system was used to select events online [25,29]. At the first two levels, general characteristics of photoproduction collisions were required and background from beam-gas events was rejected. At the third level, jets were reconstructed by applying a cone jet algorithm to the CAL cells. Events with at least two jets satisfying $E_{T}^{\text {jet }} \geq$ $4.5 \mathrm{GeV}$ and $\eta^{\text {jet }} \leq 2.5$ were accepted, where $E_{T}^{\text {jet }}$ and $\eta^{\text {jet }}$ are the transverse energy and pseudorapidity of the jet evaluated in the laboratory frame.

In the offline analysis, the hadronic final state was reconstructed using energy-flow objects $[30,31]$ (EFOs), which are formed from a combination of track and calorimeter infor-

\footnotetext{
${ }^{2}$ The ZEUS coordinate system is a right-handed Cartesian system, with the $Z$ axis pointing in the proton beam direction, referred to as the "forward direction", and the $X$ axis pointing left towards the centre of HERA. The coordinate origin is at the nominal interaction point.
} 
mation. This approach optimises the energy resolution and the one-to-one correspondence between the detector-level objects and the hadrons. The EFOs were corrected $[32,33]$ to account for energy losses in the dead material and were forced to be massless by setting the energy component equal to the magnitude of the three-momentum.

The jets were reconstructed using the $k_{T}$ cluster algorithm [34] in the longitudinally invariant inclusive mode [35] using the $p_{T}^{2}$ recombination scheme. At the detector level, jets were formed from the EFOs. The energy and angular reconstruction of the detectorlevel jets exhibited no systematic bias with respect to those defined at the hadron level.

The data sample was selected by requiring the following:

- the longitudinal position of the reconstructed vertex was in the range $\left|Z_{\mathrm{vtx}}\right| \leq 40 \mathrm{~cm}$;

- $y_{\mathrm{JB}} \geq 0.2$, to reduce the contamination from beam-gas events, where $y_{\mathrm{JB}}$ is the Jacquet-Blondel estimator [36] of the inelasticity, $y$, the fraction of the incoming electron momentum carried by the photon;

- no scattered electron was observed in the CAL with $y_{e} \leq 0.85$, to remove background due to DIS, where $y_{e}$ is the electron-method estimator of $y$;

- $y_{\mathrm{JB}} \leq 0.85$, which further removed contamination from DIS;

- $P_{T}^{\text {miss }} / \sqrt{E_{T}} \leq 2 \mathrm{GeV}^{1 / 2}$, where $P_{T}^{\text {miss }}$ is the missing transverse momentum and $E_{T}$ is the total transverse energy. This removed any background from charged current, cosmic and halo-muon events;

- at least three (or four, depending on the specific sample) jets were found with $\left|\eta^{\text {jet }}\right| \leq$ 2.4 and $E_{T}^{\mathrm{jet}} \geq 6 \mathrm{GeV}$.

Furthermore, the three- and four-jet analyses were conducted in low- and high-mass regions given by $25 \leq M_{n j} \leq 50 \mathrm{GeV}$ and $M_{n j} \geq 50 \mathrm{GeV}$, respectively, where $M_{n j}$ is the invariant mass of the $n$-jet system.

After all of the selection criteria had been applied, the low- and high-mass, three-jet data samples had 291646 and 38098 events, respectively, while the equivalent four-jet data samples had 31533 and 12525 events.

Photoproduction events are characterised by the low virtuality, $Q^{2}$, of the quasi-real exchanged photon, where $Q^{2}$ is the negative of the photon four-momentum squared. The kinematics are specified by $y$ and $x_{\gamma}$, the fraction of the photon momentum taking part in the interaction. The variable $x_{\gamma}$ can be approximated using the observable $x_{\gamma}^{\text {obs }}$, defined as

$$
x_{\gamma}^{\mathrm{obs}}=\frac{\sum_{i=1}^{\mathrm{n}} E_{T, i}^{\mathrm{jet}} \exp \left(-\eta_{i}^{\mathrm{jet}}\right)}{2 y E_{e}},
$$

where the sum runs over the $n$-jets considered in the event and $E_{e}=27.5 \mathrm{GeV}$ denotes the energy of the incoming electron. 
An angular variable used to analyse three-jet events is $\psi_{3}$ [37], which, as shown in Fig. 2, is the angle in the three-jet centre-of-mass frame between the plane containing the highest energy jet and the beam, and the plane containing the three jets. The beam is described by the three-vector $\boldsymbol{p}_{\text {beam }}=\boldsymbol{p}_{p}-\boldsymbol{p}_{e}$, where $\boldsymbol{p}_{p}$ and $\boldsymbol{p}_{e}$ are the momenta of the proton and electron beams, respectively. The variable may be written as

$$
\cos \left(\psi_{3}\right)=\frac{\left(\boldsymbol{p}_{\text {beam }} \times \boldsymbol{p}_{3}\right) \cdot\left(\boldsymbol{p}_{4} \times \boldsymbol{p}_{5}\right)}{\left|\boldsymbol{p}_{\text {beam }} \times \boldsymbol{p}_{3}\right|\left|\boldsymbol{p}_{4} \times \boldsymbol{p}_{5}\right|},
$$

where it is conventional to number the three jets, 3,4 and 5 , in order of decreasing energy. The $\psi_{3}$ angle reflects the orientation of the lowest-energy jet. In the case where this jet arises from initial-state gluon radiation, the coherence property of QCD will tend to orient the third jet close to the incoming proton or photon direction. The two planes shown in Fig. 2 will therefore tend to coincide leading to a $\psi_{3}$ distribution that peaks toward 0 and $\pi$.

\section{Monte Carlo models}

Two MC generators were used to simulate photoproduction events, HeRwIG 6.505 [38] and Pythia 6.206 [39]. Both models include the LO $(2 \rightarrow 2)$ matrix elements, approximate higher-order processes using initial-state and final-state parton showers and simulate hadronisation. Direct and resolved photoproduction samples were generated separately. The implementation of the parton-showers and hadronisation models in the generators differs [39-42]. Hadronisation in HERWIG is simulated using the cluster model [43] while Pythia uses the Lund string model $[44,45]$.

\subsection{Underlying-event models}

In the HERwIG samples, MPIs were simulated using a separate program called JimmY 4.0 [46-49]. The latter is based on a simple eikonal model that approximates the interacting hadrons as disks that are extended in the transverse plane. An impact parameter quantifies the degree to which the two disks overlap during the collision.

The Pythia MPI model that was used in this paper is known as the "simple model" [39]. It estimates the average number of MPIs per event, $\bar{n}$, as $\bar{n}=\sigma_{H}\left(\hat{p}_{T}^{\min }\right) / \sigma_{\mathrm{ND}}(s)$, where $\sigma_{H}$ and $\sigma_{\mathrm{ND}}$ are the inclusive-hard and non-diffractive, inelastic cross sections, respectively, and $\hat{p}_{T}^{\min }$ is a minimal constraint applied to the $p_{T}$ of the partonic collision. The number of MPIs is assumed to obey a Poisson distribution. The probability that the secondary collisions occur with transverse momentum $p_{T}$ is given by $P\left(p_{T}\right)=\left(1 / \sigma_{\mathrm{ND}}(s)\right)\left(\mathrm{d} \sigma_{H} / \mathrm{d} p_{T}\right)$. 
The simple model proceeds by ordering the secondary interactions in terms of $p_{T}$ and then calculates the probability of each successive scatter.

\subsection{Monte Carlo samples}

The MC samples were used for two purposes: to correct the data for detector effects and to compare to the measured hadron-level cross sections. The MC samples used to correct the data included a full GEANT 3.13 [50] simulation of the ZEUS detector and three-level trigger. The resolved and direct $\mathrm{MC}$ samples were combined in the ratio that gave the best fit to the $x_{\gamma}^{\text {obs }}$ distribution in the data, significantly improving the overall description of the data by the MC. The resolved and direct samples used to compare to the measured cross sections, however, were combined in the ratio predicted by the MC models.

The HeRwig samples that were compared to the data were generated with $\hat{p}_{T}^{\min }$ set to $4 \mathrm{GeV}$ and with the CTEQ5L [51] and GRV-G LO [52] parameterisations for the proton and photon parton density functions (PDFs), respectively. All other HERwIG parameters were set to default. To simulate the Herwig MPIs, the JimmY model was run with the minimum $p_{T}$ of the secondary scatters, $\hat{p}_{T}^{\text {mpi }}$, set to $2.2 \mathrm{GeV}$, the probability that the photon would resolve via a large hadron-like fluctuation set to $1 / 340$ and the effective transverse radius of the photon squared was increased by a factor of 4 from its default value. These adjusted MPI settings were the result of simultaneous tuning to the threeand four-jet $x_{\gamma}^{\text {obs }}$ cross sections measured in this analysis, in the low- and high-mass regions.

The Pyтнia samples that were compared to the data were generated with $\hat{p}_{T}^{\min }=4.5 \mathrm{GeV}$, $\hat{p}_{T}^{\text {mpi }}=1.9 \mathrm{GeV}$, which is the default value, and with the CTEQ5L and GRV-G LO parameterisations for the proton and photon PDFs, respectively. All other PYTHIA and simple-model parameters were set to default.

\subsection{Monte Carlo scaling factors}

Both LO MC simulations underestimated the magnitude of the measured cross sections. To compare with the shape of the differential cross sections, the MC predictions were either area normalised to the equivalent data set or scaled by the factor required to area normalise the high-mass MC cross sections to the high-mass data, where MPIs are expected to be less influential. The choice of normalisation procedure will be clearly stated in Section 8 and in the figure captions.

The scaling factors that were applied to the HERWIG and PYTHIA cross sections are shown in Table 1. The scaling factors for the PYTHIA model were significantly larger than for 
HeRWIG. Within each model, the factors applied to the three-jet predictions were similar whether MPIs were included or not, indicating that both models expect relatively little effect from MPIs in the high-mass three-jet sample. In the four-jet case, however, the scaling factors for the high-mass MPI samples were significantly smaller than those for the nominal samples, showing that both models predict a sizable contribution from MPIs in the high-mass four-jet sample.

\section{The $\mathcal{O}\left(\alpha \alpha_{s}^{2}\right)$ pQCD calculation}

The three-jet differential cross sections were calculated at $\mathcal{O}\left(\alpha \alpha_{s}^{2}\right)$ using the program by Klasen, Kleinwort and Kramer [53,54]. The calculation is LO for this process. The renormalisation, $\mu_{r}$, and factorisation, $\mu_{f}$, scales were set to $\mu_{r}=\mu_{f}=\mu=E_{T}^{\max }$, the $E_{T}$ of the hardest parton. The theoretical scale uncertainty was evaluated by varying $\mu$, setting it to $2^{ \pm 1} E_{T}^{\max }$. The value of $\alpha_{s}$ was calculated with one-loop precision and assuming five active flavours. A value of $\Lambda_{\overline{\mathrm{MS}}}^{(5)}=181 \mathrm{MeV}$ was taken. The CTEQ6L [55] proton and GRV-G LO [56] photon PDFs were used for the calculation.

The theoretical calculations were corrected for both hadronisation and MPI effects. The correction factors were obtained using the Herwig and PyTHIA models. The hadronisation corrections, $\mathcal{C}_{\text {had }}$, were calculated by taking the bin-by-bin ratio of the MC cross sections at the hadron $\left(\sigma_{\mathrm{HL}}\right)$ and parton levels $\left(\sigma_{\mathrm{PL}}\right), \mathcal{C}_{\mathrm{had}}=\sigma_{\mathrm{HL}} / \sigma_{\mathrm{PL}}$. To obtain $\sigma_{\mathrm{PL}}$, the $k_{T}$ cluster algorithm was run over all partons produced by the parton shower, prior to hadronisation. The MPI corrections, $\mathcal{C}_{\mathrm{MPI}}$, were calculated by taking the bin-by-bin ratio of the

hadron-level cross sections, with $\left(\sigma_{\mathrm{HL}}^{\mathrm{MPI}}\right)$ and without MPIs $\left(\sigma_{\mathrm{HL}}^{\mathrm{noMPI}}\right), \mathcal{C}_{\mathrm{MPI}}=\sigma_{\mathrm{HL}}^{\mathrm{MPI}} / \sigma_{\mathrm{HL}}^{\mathrm{noMPI}}$. The hadronisation and MPI corrections that were applied to the calculation represented the average corrections taken from the two MC models. A symmetric uncertainty was associated with the correction factors equal to half the difference between the predictions of the two MC models. The hadronisation corrections were found to typically reduce the cross section by $\mathcal{O}(20 \%)$, whereas the MPI corrections increased the cross section by $\mathcal{O}(50 \%)$ in the low-mass region and by $\mathcal{O}(10 \%)$ in the high-mass sample. The uncertainty associated with the MPI corrections was larger than that estimated for the hadronisation factors.

\section{Acceptance corrections}

Detector effects and trigger inefficiencies were accounted for by applying bin-by-bin correction factors, $\mathcal{C}_{\mathrm{det}}=\sigma_{\mathrm{HL}} / \sigma_{\mathrm{DL}}$, where $\sigma_{\mathrm{DL}}$ is the predicted detector-level cross section. 
The correction factors were extracted separately from the HERWIG and PyTHIA MC samples with MPIs. Before calculating the corrections, the resolved components of the MC samples were reweighted in $y_{\mathrm{JB}}$ to improve the overall description of the data [57]. The typical bin-by-bin corrections applied to the low- and high-mass three-(four-)jet data were approximately $0.75(0.45)$ and $1.3(0.95)$, respectively. The largest correction factors were found in the lowest $E_{T}^{\text {jet }}$ and the extreme $\eta^{\text {jet }}$ bins.

Once corrected to the hadron level, the measured cross sections, $\sigma_{\sqrt{\mathrm{s}}}$, at $\sqrt{s}=300 \mathrm{GeV}$ and $\sqrt{s}=318 \mathrm{GeV}$ were combined using the following formula:

$$
\sigma=\frac{\sigma_{300} \cdot\left(\sigma_{318}^{\mathrm{mc}} / \sigma_{300}^{\mathrm{mc}}\right) \cdot \mathcal{L}_{300}+\sigma_{318} \cdot \mathcal{L}_{318}}{\mathcal{L}_{300}+\mathcal{L}_{318}}
$$

where $\mathcal{L}_{\sqrt{\mathrm{s}}}$ is the integrated luminosity and $\sigma_{\sqrt{\mathrm{s}}}^{\mathrm{mc}}$, the predicted cross section at $\sqrt{s}$. As such, the measured cross sections presented here correspond to $\sqrt{s}=318 \mathrm{GeV}$. The $\sigma_{318}^{\mathrm{mc}} / \sigma_{300}^{\mathrm{mc}}$ ratios were $\sim 1.1$ for all but the low-mass four-jet sample, where it was around $10 \%$ larger.

The results presented here represent the average hadron-level cross sections obtained when the data is treated with HeRwig or PYTHIA, with half the spread interpreted as symmetric systematic uncertainty. This systematic uncertainty was added in quadrature to those described below.

\section{$7 \quad$ Systematic uncertainties}

A detailed study of the sources of systematic uncertainty associated with the measurement was performed using the HERWIG MC sample [57]. The sources contributing to the quoted systematic uncertainties are,

- the CAL energy scale uncertainty is $\pm 3 \%$. The energy scale was changed in the MC simulation accordingly;

- the uncertainty due to the dependence of the measured cross sections on the detectorlevel selection criteria, which were varied up and down by the detector resolution for the data and the MC samples together. More specifically,

- the $E_{T}^{\text {jet }}$ cut on each of the jets was changed by $\pm 1 \mathrm{GeV}$;

- the $\left|\eta^{\text {jet }}\right|$ cut on each of the jets was changed by \pm 0.04 ;

- the $M_{n j}$ selection criteria were changed by $\pm 10 \%$;

- the lower and upper cut on $y_{\mathrm{JB}}$ was changed by \pm 0.03 and \pm 0.05 , respectively; 
- the cut on $y_{e}$, used to differentiate between real and fake scattered-electron candidates, was changed by \pm 0.05 .

In addition, it was verified that the bin-by-bin acceptance corrections were not sensitive to variations in the relative amount of direct and resolved events or the exact shape of the $y_{\mathrm{JB}}$ distribution in the combined MC sample.

All the systematic uncertainties were added in quadrature except that associated with the CAL energy scale. The CAL energy scale uncertainty is highly correlated between bins and is displayed separately in the plots presented here.

The largest systematic uncertainty in the cross sections, except for the high-mass threejet case, was that associated with the CAL energy scale, which led to an uncertainty of approximately $\pm 10 \%$ in both the low- and high-mass three-jet cross sections, and $\pm 20 \%$ and $\pm 15 \%$ in the low- and high-mass four-jet cross sections, respectively. The largest uncertainty in the high-mass three-jet cross section came from the choice of MC model used to calculate the acceptance corrections and was approximately $\pm 10 \%$. In the low-mass three-jet sample, the uncertainty due to the $\mathrm{MC}$ model was $\pm 5 \%$ and in the four-jet low- and high-mass samples the values were $\pm 3 \%$ and $\pm 4 \%$, respectively. Another significant source of systematic uncertainty in the low-mass samples was that associated with the $E_{T}^{\text {jet }}$ selection criteria, which generated a $\pm 4 \%$ and $\pm 8 \%$ effect in the three- and four-jet cases, respectively. In the high-mass samples, varying the $M_{n j}$ selection criteria generated a $\pm 8 \%$ and $\pm 6 \%$ effect in the three- and four-jet cross sections, respectively. The high-mass four-jet cross section was also sensitive to varying the $E_{T}^{\text {jet }}$ cut, which changed its value by about $\pm 4 \%$.

\section{Results and discussion}

The three- and four-jet photoproduction cross sections are presented here at the hadron level for jets with $E_{T}^{\text {jet }} \geq 6 \mathrm{GeV}$ and $\left|\eta^{\text {jet }}\right| \leq 2.4$, in the kinematic region given by $Q^{2}<1 \mathrm{GeV}^{2}$ and $0.2 \leq y \leq 0.85$, and in low- $\left(25 \leq M_{n j}<50 \mathrm{GeV}\right)$ and high-mass $\left(M_{n j} \geq 50 \mathrm{GeV}\right)$ regions.

\subsection{The $\mathrm{d} \sigma / \mathrm{d} M_{n j}$ cross section}

The three- and four-jet cross sections are given as a function of $M_{n j}$ in Fig. 3 and Tables 2 and 3. In general, both cross sections decrease exponentially with increasing $M_{n j}$. Also shown in Fig. 3 are the HeRWIG and Pyтhia predictions without MPIs, normalised to the high-mass region $\left(M_{n j} \geq 50 \mathrm{GeV}\right)$. Both models incorrectly describe the $M_{n j}$ dependence 
of the cross section and significantly underestimate the low mass data. The discrepancy is larger in the four-jet case. With the inclusion of MPIs, both scaled MC predictions give a reasonably good description of the data over the full $M_{n j}$ ranges.

\subsection{The $\mathrm{d} \sigma / \mathrm{d} x_{\gamma}^{\mathrm{obs}}$ cross section}

The three- and four-jet cross sections are given as a function of $x_{\gamma}^{\text {obs }}$ for the low- and highmass samples in Fig. 4 and Tables 4 and 5. The distributions exhibit a peak at $x_{\gamma}^{\text {obs }} \approx 0.9$ in all but the low-mass four-jet sample. The low-mass cross sections show enhancement at low $x_{\gamma}^{\text {obs }}$ compared to those at high-mass, which is a consequence of the tighter kinematic constraints at high mass. The degree to which the low $x_{\gamma}^{\text {obs }}$ region is enhanced is larger in the four-jet case. Shown also in Fig. 4 are the scaled MC predictions compared to the data.

The MC predictions show that, in the absence of MPIs, the three- and four-jet cross sections are expected to decrease with decreasing $x_{\gamma}^{\text {obs }}$ in both mass regions. Moreover, the low- $x_{\gamma}^{\text {obs }}$ suppression is expected to be marginally stronger in the four-jet case. The low-mass data, however, are in contradiction to both predictions. These data therefore suggest that some mechanism in addition to the processes modelled in the MC without MPIs, is contributing to the low-mass cross sections. One possible mechanism is MPIs.

A comparison of the data with the MC predictions, normalised to the high-mass data, shows that both those with and without MPIs are in reasonable agreement with the highmass cross sections (Figs. 4b and $4 \mathrm{~d}$ ). In the low-mass low- $x_{\gamma}^{\text {obs }}$ regions that are poorly described by the nominal MC models, the introduction of MPIs to the simulations aids the description of the data. More specifically, the HERwIG prediction with tuned MPIs describes the data reasonably well in all of the samples. The default PYTHIA model tends to overestimate the data in the mid- $x_{\gamma}^{\text {obs }}$ region $\left(0.4 \lesssim x_{\gamma}^{\text {obs }} \lesssim 0.8\right)$ in the low-mass samples but describes the cross section reasonably well elsewhere.

Shown also in Fig. 4 is the contribution to the HERwIG predictions attributed to direct processes, as defined in that LO model with parton showers. In all four samples, direct events are predicted to be found solely at high $x_{\gamma}^{\text {obs }}$, although resolved processes are expected to make a significant, and in the four-jet case dominant, contribution even at high $x_{\gamma}^{\text {obs }}$. This is in contrast to the behaviour of dijet photoproduction, where the high$x_{\gamma}^{\text {obs }}$ region is dominated by direct events [15]. 


\subsection{The $\mathrm{d} \sigma / \mathrm{d} y$ cross section}

The three- and four-jet cross sections are given as a function of $y$ in the low- and high-mass samples in Fig. 5 and Tables 6 and 7. The cross sections are observed to increase steeply with $y$ in all but the low-mass three-jet sample where it is approximately constant. The shapes of the distributions are governed by the available kinematic phase space and the energy distribution of the photon flux: while the phase space increases with $y$, the photon flux decreases with increasing $y$.

Also shown in Fig. 5 are the predictions from Herwig and PythiA, with and without MPIs, which have been area normalised to the data. At high mass, the predictions with and without MPIs are similar and describe the data well. In the low-mass samples, MPIs are predicted to cause a more steeply increasing cross section. However, the data are not precise enough to differentiate between the various models and all of the MC predictions roughly describe the data.

\subsection{The $\mathrm{d} \sigma / \mathrm{d} E_{T}^{\mathrm{jet}}$ and $\mathrm{d} \sigma / \mathrm{d} \eta^{\text {jet }}$ cross sections}

The cross sections are given as a function of the $E_{T}^{\text {jet }}$ of each of the jets in both three-jet samples in Fig. 6 and Tables 8 to 10 and in both four-jet samples in Fig. 7 and Tables 11 to 14. Similarly, the $\mathrm{d} \sigma / \mathrm{d} \eta^{\text {jet }}$ cross sections are given in Figs. 8 and 9 and Tables 15 to 21. In each case the jets have been ordered in descending $E_{T}^{\text {jet }}$.

The $E_{T}^{\text {jet }}$ distributions of all of the jets in all of the samples are observed to fall off approximately exponentially with increasing $E_{T}^{\text {jet }}$. All of the samples are similarly distributed when binned in terms of $\eta^{\text {jet}}$, regardless of the position of the jet in the $E_{T}^{\text {jet }}$ ordering. The generic trend is an increasing cross section from $\eta^{\text {jet }} \approx-1.4$ followed by a plateau and, in the high-mass samples, a continued rise above $\eta^{\text {jet }} \approx 1$.4. In the low-mass samples, the plateaux begin at $\eta^{\text {jet }} \approx 0.6$ and extend to the upper edge of the measured $\eta$ region. In the high-mass samples, the lower bounds of the $\eta^{\text {jet }}$ ranges covered by the plateaux decrease with decreasing $E_{T}^{\text {jet }}$, while the upper bounds all lie at $\eta^{\text {jet }} \approx 1.4$.

Shown also in Figs. 6 and 7 are $\mathrm{d} \sigma / \mathrm{d} E_{T}^{\text {jet }}$ predictions from the PythiA and HerwiG models, with and without MPIs, normalised to the data. The description of the data by each of the MC models is generally good for all of the jets in all of the samples, although the MC predictions do vary somewhat. In all four samples, the PYTHIA cross sections without MPIs give the poorest description, in particular of $\mathrm{d} \sigma / \mathrm{d} E_{T}^{\mathrm{jet} 2}$. Overall, the description of the data is improved by the inclusion of MPIs.

Figures 8 and 9 show the comparison between $\mathrm{d} \sigma / \mathrm{d} \eta^{\text {jet }}$ in the data and as predicted by the MC models. Each MC model largely describes both sets of high-mass data. The 
best description of the low-mass data is given by the HERWIG model with tuned MPIs. The Pythia prediction with default MPIs also generally describes the data. The poorest description is of the three-jet $\eta^{\text {jet1 }}$ distribution. The introduction of MPIs into the simulations certainly aids the description. In general, the MC models without MPIs predict a cross section that falls off at high $\eta^{\text {jet }}$ but MPIs reduce this effect in line with what is observed.

\subsection{The $\mathrm{d} \sigma / \mathrm{d} \cos \left(\psi_{3}\right)$ cross section}

The three-jet cross section is given as a function of $\cos \left(\psi_{3}\right)$ for the low- and high-mass samples in Fig. 10 and Table 22. The $\cos \left(\psi_{3}\right)$ cross section has a similar shape in both the low- and high-mass samples; relatively flat in the central $\cos \left(\psi_{3}\right)$ region and increasing rapidly as $\left|\cos \left(\psi_{3}\right)\right| \rightarrow 1$. Also shown in Fig. 10 is a comparison of the MC models with the data. All of the area normalised MC predictions describe the data well.

\subsection{The $\mathrm{d} \sigma / \mathrm{d} M_{3 j}$ cross section compared with $\mathcal{O}\left(\alpha \alpha_{s}^{2}\right)$ pQCD}

Figure 11 shows an $\mathcal{O}\left(\alpha \alpha_{s}^{2}\right)$ prediction, corrected for hadronisation effects and MPIs, compared to the measured $\mathrm{d} \sigma / \mathrm{d} M_{3 j}$ cross section. The hadronisation and MPI corrections, including their estimated uncertainties, are given in Fig. 11b and in Table 2. The hadronisation corrections are constant in $M_{3 j}$, while the MPI corrections increase significantly towards low $M_{3 j}$. The theoretical uncertainties on both the MPI corrections and the pQCD predictions are large. The magnitude and shape of the calculation is consistent with the data within the large theoretical uncertainties. This is best seen in the data over theory ratio shown in Fig. 11c. The level of consistency between data and theory would be far worse at low $M_{3 j}$ if it were not for the large MPI corrections.

\subsection{The $\mathrm{d} \sigma / \mathrm{d} E_{T}^{\mathrm{jet}}$ cross section compared with $\mathcal{O}\left(\alpha \alpha_{s}^{2}\right)$ pQCD}

Figure 12 shows the comparison between the measured and predicted $\mathrm{d} \sigma / \mathrm{d} E_{T}^{\mathrm{jet}}$ cross sections at $\mathcal{O}\left(\alpha \alpha_{s}^{2}\right)$ for each jet in the low- and high-mass three-jet samples. The pQCD predictions have been corrected for hadronisation effects and MPIs, which are detailed in Tables 8 to 10 (not shown in Fig. 12). Hadronisation is predicted to decrease the partonlevel cross sections at low $E_{T}^{\text {jet }}$, whereas the MPIs are expected to do the reverse in the low-mass region: at high mass they are small.

The calculation is largely consistent, within the large uncertainties, with both the lowand high-mass data. The exception to this is the rapid predicted falloff of the $E_{T}^{\text {jet1 }}$ cross 
section at high $E_{T}^{\text {jet1 }}$ in the low-mass sample, which is not observed in the data. This effect is due to the three-parton kinematics within the theory, which precludes the highest momentum parton from carrying more than half of the total centre-of-mass energy. Thus, for the low-mass sample, the $M_{n j}<50 \mathrm{GeV}$ criterium translates into an $E_{T}<25 \mathrm{GeV}$ constraint for the partons in the theory, as indeed observed.

\subsection{The $\mathrm{d} \sigma / \mathrm{d} \eta^{\text {jet }}$ cross section compared with $\mathcal{O}\left(\alpha \alpha_{s}^{2}\right)$ pQCD}

Figure 13 shows the comparison between the measured and predicted $\mathrm{d} \sigma / \mathrm{d} \eta^{\text {jet }}$ cross sections at $\mathcal{O}\left(\alpha \alpha_{s}^{2}\right)$ for each jet in the low- and high-mass three-jet samples. The hadronisation and MPI correction factors are given in Tables 15 to 17 (not shown in Fig. 13). Hadronisation is predicted to cause an overall decrease in the parton-level cross sections, most significantly at low $\eta^{\text {jet }}$. The MPIs in the low-mass sample are predicted to cause a small increase in the cross section at low $\eta^{\text {jet }}$, becoming larger as $\eta^{\text {jet }}$ increases. The calculation is consistent with the $\eta^{\text {jet }}$ distributions. There is some indication of a difference in shape at lower masses, however, the uncertainties are again large. The description of the low-mass data would be worse if it were not for the MPI corrections.

\subsection{The $\mathrm{d} \sigma / \mathrm{d} \cos \left(\psi_{3}\right)$ cross section compared with $\mathcal{O}\left(\alpha \alpha_{s}^{2}\right)$ pQCD}

The comparison between the measured and the predicted $\mathrm{d} \sigma / \mathrm{d} \cos \left(\psi_{3}\right)$ cross sections at $\mathcal{O}\left(\alpha \alpha_{s}^{2}\right)$ is shown for the low-mass sample in Fig. 14 and for the high-mass region in Fig. 15. The ratio of the low-mass data divided by the calculation is shown along with the hadronisation and MPI corrections, which are also given in Table 22. In both low- and high-mass regions, the QCD calculation is consistent with the data. There is some indication of a difference in shape at low masses; however, the theory has large uncertainties.

\section{Summary}

Three- and four-jet states have been measured in hard $\gamma p$ collisions at HERA, using an integrated luminosity of $121 \mathrm{pb}^{-1}$. The three- and four-jet cross sections have been measured for jets with $E_{T}^{\text {jet }}>6 \mathrm{GeV}$ and $\left|\eta^{\text {jet }}\right|<2.4$, in the kinematic region given by $Q^{2}<1 \mathrm{GeV}^{2}$ and $0.2 \leq y \leq 0.85$ and in two mass regions defined as $25 \leq M_{n j}<50 \mathrm{GeV}$ and $M_{n j} \geq 50 \mathrm{GeV}$. The three-jet events have been measured with over seven times the luminosity of the previous ZEUS publication and in a wider $M_{3 j}$ region. The four-jet process described here has been measured for the first time at HERA. 
In the high-mass regions, the shape of the three- and four-jet cross sections are reasonably well described by both the Pythia and Herwig models without MPIs. In the low-mass region, the MC models without MPIs underestimate the data when normalised to the measured high-mass cross section. When MPIs are added to the MC simulations, the agreement between the models and data is generally improved. Although the data have large uncertainties, the measured cross sections are potentially useful in the testing and tuning of MPI and underlying-event models.

The $\mathcal{O}\left(\alpha \alpha_{s}^{2}\right)$ pQCD calculation was compared to the three-jet data and is consistent within the large uncertainties. The MPI corrections typically improved the description of the data by the pQCD calculation. This data will provide a testing ground for higher-order calculations in photoproduction.

\section{Acknowledgments}

The support and encouragement of the DESY Directorate has been invaluable and we are indebted to the HERA machine group for their diligent efforts. The design, construction and installation of the ZEUS detector involved many people both in and outside of DESY that are not listed as authors here but their contributions are acknowledged with great appreciation nonetheless. 


\section{References}

[1] C.H. Llewellyn Smith, Phys. Lett. B79, 83 (1978).

[2] I. Kang and C.H. Llewellyn Smith, Nucl. Phys. B166, 413 (1980).

[3] J.F. Owens, Phys. Rev. D21, 54 (1980).

[4] M. Fontannaz, A. Mantrach and D. Schiff, Z. Phys. C6, 241 (1980).

[5] W.J. Stirling and Z. Kunszt, Proc. HERA Workshop, R.D. Peccei (ed.), Vol. 2, p. 331. DESY, Hamburg, Germany (1987).

[6] M. Drees and F. Halzen, Phys. Rev. Lett. 61, 275 (1988).

[7] M. Drees and R.M. Godbole, Phys. Rev. Lett. 61, 682 (1988).

[8] M. Drees and R.M. Godbole, Phys. Rev. D39, 169 (1989).

[9] H. Baer, J. Ohnemus and J.F. Owens, Z. Phys. C42, 657 (1989).

[10] H. Baer, J. Ohnemus and J.F. Owens, Phys. Rev. D40, 2844 (1989).

[11] CDF Collab., F. Abe et al., Phys. Rev. D47, 4857 (1993).

[12] CDF Collab., F. Abe et al., Phys. Rev. Lett. 79, 584 (1997).

[13] CDF Collab., F. Abe et al., Phys. Rev. D56, 3811 (1997).

[14] D0 Collab., V. M. Abazov et al., Phys. Rev. D67, 052001 (2003).

[15] ZEUS Coll., M. Derrick et al., Phys. Lett. B348, 665 (1995).

[16] H1 Collab., S. Aid et al., Z. Phys. C70, 17 (1996).

[17] A. Del Fabbro and D. Treleani, hep-ph/0301178 (unpublished).

[18] D. Acosta et al., CERN-CMS-NOTE-2006-067 (unpublished).

[19] ZEUS Coll., J. Breitweg et al., Phys. Lett. B443, 394 (1998).

[20] H1 Coll., I. Abt et al., Z. Phys. C61, 59 (1994).

[21] H1 Coll., C. Adloff et al., Phys. Lett. B515, 17 (2001).

[22] ZEUS Coll., S. Chekanov et al., Eur. Phys. J C44, 183 (2005).

[23] ZEUS Coll., S. Chekanov et al., Phys. Lett. B516, 273 (2002).

[24] ZEUS Coll., M. Derrick et al., Phys. Lett. B 297, 404 (1992).

[25] ZEUS Coll., U. Holm (ed.), The ZEUS Detector. Status Report (unpublished), DESY (1993), available on http://www-zeus.desy.de/bluebook/bluebook.html. 
[26] M. Derrick et al., Nucl. Inst. Meth. A 309, 77 (1991);

A. Andresen et al., Nucl. Inst. Meth. A 309, 101 (1991);

A. Bernstein et al., Nucl. Inst. Meth. A 336, 23 (1993);

A. Caldwell et al., Nucl. Inst. Meth. A 321, 356 (1992).

[27] N. Harnew et al., Nucl. Inst. Meth. A 279, 290 (1989);

B. Foster et al., Nucl. Phys. Proc. Suppl. B 32, 181 (1993);

B. Foster et al., Nucl. Inst. Meth. A 338, 254 (1994).

[28] J. Andruszków et al., Preprint DESY-92-066, DESY, 1992 (unpublished);

ZEUS Coll., M. Derrick et al., Z. Phys. C 63, 391 (1994).

[29] ZEUS Coll., J. Breitweg et al., Eur. Phys. J. C 1, 109 (1998).

[30] ZEUS Coll., J. Brietweg et al., Eur. Phys. J. C6, 43 (1999).

[31] G.M. Briskin. PhD. Thesis, Tel Aviv University, Israel, 1998 (unpublished).

[32] ZEUS Coll., J. Brietweg et al., Eur. Phys. J. C11, 35 (1999).

[33] ZEUS Coll. S. Chekanov et al., Eur. Phys. J. C23, 615 (2002).

[34] S. Catani et al., Nucl. Phys. B406, 187 (1993).

[35] S.D. Ellis and D.E. Soper, Phys. Rev. D48, 3160 (1993).

[36] F. Jacquet and A. Blondel, Proceedings of the Study for an ep Facility for Europe, U. Amaldi (ed.), p. 391. Hamburg, Germany (1979). Also in preprint DESY 79/48.

[37] S. Geer and T. Asakawa, Phys. Rev. D53, 4793 (1996).

[38] G. Corcella et al., HERWIG 6.5 Manual, 2000, available on http://hepwww.rl.ac.uk/theory/seymour/herwig/;

G. Corcella et al., HERWIG 6.5 Release Note, 2001, available on http://hepwww.rl.ac.uk/theory/seymour/herwig/;

G. Marchesini et al., Comput. Phys. Commun. 67, 465 (1992).

[39] T. Sjöstrand et al., PYTHIA 6.206 Manual, 2002, available on http://www.thep.lu.se/ torbjorn/Pythia.html;

T. Sjöstrand et al., Comput. Phys. Commun. 135, 238 (2001).

[40] G. Marchesini and B.R. Webber, Nucl. Phys. B310, 461 (1988).

[41] I.G. Knowles, Nucl. Phys. B310, 571 (1988).

[42] I.G. Knowles, Comput. Phys. Commun. 58, 271 (1990).

[43] B.R. Webber, Nucl. Phys B238, 492 (1984).

[44] B. Andersson et al., Phys. Rep. 97, 31 (1983).

[45] T. Sjöstrand, Phys. Lett. B142, 420 (1984). 
[46] J.M. Butterworth, J.R. Forshaw and M.H. Seymour, Z. Phys. C72, 637 (1996).

[47] J.M. Butterworth and J.R. Forshaw, J. Phys. G19, 1657 (1993).

[48] J.M. Butterworth et al., J. Phys. G22, 883 (1996).

[49] J.M. Butterworth and M.H. Seymour, JIMMY4: Multiparton Interactions in HERWIG for the LHC (unpublished), 2005, available on http://hepforge. cedar.ac.uk/jimmy/.

[50] R. Brun et al., Geant3, CERN-DD/EE/84-1, 1987 (unpublished).

[51] CTEQ Coll., H.L. Lai et al., Eur. Phys. J. C12, 375 (2000).

[52] M. Gluck, E. Reya and A. Vogt, Z. Phys. C53, 127 (1992).

[53] M. Klasen, T. Kleinwort and G. Kramer, Eur. Phys. J. direct C1, 1 (1998).

[54] M. Klasen, Eur. Phys. J. C7, 225 (1999).

[55] J. Pumplin et al., JHEP 0602, 032 (2006).

[56] M. Gluck, E. Reya and A. Vogt, Phys. Rev. D45, 3986 (1992).

[57] T. Namsoo. PhD. Thesis, University of Bristol, UK, 2006 (unpublished). 


\begin{tabular}{|c|c|c|c|}
\hline \multicolumn{5}{|c|}{ HERWIG scaling factors } \\
\hline 3-jet no MPIs & 3-jet with MPIs & 4-jet no MPIs & 4-jet with MPIs \\
\hline 1.7 & 1.7 & 3.1 & 2.1 \\
\hline \hline \multicolumn{4}{|c|}{ PYTHIA scaling factors } \\
\hline 3-jet no MPIs & 3-jet with MPIs & 4-jet no MPIs & 4-jet with MPIs \\
\hline 3.8 & 3.1 & 9.2 & 5.3 \\
\hline
\end{tabular}

Table 1: The scaling factors applied to the HeRwig and Pythia $x_{\gamma}^{\text {obs }}$ and $M_{n j}$ cross sections.

\begin{tabular}{|c|c|c|c|c|c|c|c|c|c|c|}
\hline \multicolumn{3}{|c|}{$\begin{array}{c}M_{3 j} \text { range } \\
(\mathrm{GeV})\end{array}$} & \multirow{2}{*}{$\begin{array}{l}d \sigma / d M_{3 j} \\
94\end{array}$} & \multicolumn{2}{|c|}{$\begin{array}{c} \pm \text { stat. } \quad \pm \text { syst. } \\
(\mathrm{pb} / \mathrm{GeV})\end{array}$} & \pm E-scale & \multicolumn{2}{|c|}{ had. corr. } & \multicolumn{2}{|c|}{ MPI corr. } \\
\hline 25 & & 32 & & \pm 0 & $\begin{array}{l}+10 \\
-9\end{array}$ & $\begin{array}{l}+12 \\
-12\end{array}$ & 0.793 & \pm 0.004 & 1.88 & \pm 0.37 \\
\hline 32 & - & 41 & 80.4 & \pm 0.3 & $\begin{array}{l}+8.5 \\
{ }_{-8.2}\end{array}$ & $\begin{array}{l}+9.5 \\
{ }_{-9.5}\end{array}$ & 0.805 & \pm 0.010 & 1.44 & \pm 0.23 \\
\hline 41 & - & 50 & 48.4 & \pm 0.3 & $\begin{array}{l}+5.5 \\
-5.4\end{array}$ & $\begin{array}{l}+5.6 \\
{ }_{-5.6}\end{array}$ & 0.815 & \pm 0.015 & 1.25 & \pm 0.16 \\
\hline 50 & - & 59 & 25.2 & \pm 0.2 & $\begin{array}{l}+3.1 \\
-3.1\end{array}$ & $\begin{array}{l}+2.5 \\
-2.5\end{array}$ & 0.815 & \pm 0.017 & 1.15 & \pm 0.13 \\
\hline 59 & - & 70 & 10.7 & \pm 0.1 & $\begin{array}{l}+1.9 \\
{ }_{-1.4}\end{array}$ & $\begin{array}{l}+1.2 \\
{ }_{-1.2}\end{array}$ & 0.817 & \pm 0.008 & 1.09 & \pm 0.10 \\
\hline 70 & - & 82 & 4.00 & \pm 0.08 & $\begin{array}{l}+0.56 \\
{ }_{-0.52}\end{array}$ & $\begin{array}{l}+0.50 \\
{ }_{-0.50}\end{array}$ & 0.810 & \pm 0.009 & 1.07 & \pm 0.08 \\
\hline 82 & - & 95 & 1.44 & \pm 0.04 & ${ }_{-0.27}^{+0.24}$ & $\begin{array}{l}+0.20 \\
{ }_{-0.20}\end{array}$ & 0.808 & \pm 0.007 & 1.04 & \pm 0.05 \\
\hline 95 & . & 109 & 0.61 & \pm 0.02 & $\begin{array}{l}+0.28 \\
-0.21\end{array}$ & $\begin{array}{l}+0.07 \\
-0.07\end{array}$ & 0.811 & \pm 0.014 & 1.03 & \pm 0.05 \\
\hline 109 & - & 124 & 0.179 & \pm 0.012 & $\begin{array}{l}+0.084 \\
{ }_{-0.066}\end{array}$ & $\begin{array}{l}+0.023 \\
-0.023\end{array}$ & 0.840 & \pm 0.019 & 1.03 & \pm 0.05 \\
\hline 124 & - & 140 & 0.066 & \pm 0.008 & $\begin{array}{l}+0.022 \\
{ }_{-0.019}\end{array}$ & $\begin{array}{l}+0.014 \\
{ }_{-0.014}\end{array}$ & 0.798 & \pm 0.008 & 1.00 & \pm 0.04 \\
\hline 140 & - & 160 & 0.023 & \pm 0.005 & $\begin{array}{l}+0.019 \\
{ }_{-0.010}^{+}\end{array}$ & $\begin{array}{l}+0.012 \\
{ }_{-0.012}\end{array}$ & 0.809 & \pm 0.012 & 1.00 & \pm 0.06 \\
\hline
\end{tabular}

Table 2: The measured three-jet differential cross-section $d \sigma / d M_{3 j}$. The statistical, systematic and calorimeter energy scale (E-scale) uncertainties are shown separately. Also shown are the hadronisation and MPI corrections that were applied to the $\mathcal{O}\left(\alpha \alpha_{s}^{2}\right)$ prediction. 


\begin{tabular}{|c|c|c|c|c|c|c|}
\hline \multicolumn{3}{|c|}{$\begin{array}{c}M_{4 j} \text { range } \\
(\mathrm{GeV})\end{array}$} & $d \sigma / d M_{4 j}$ & $\begin{array}{l} \pm \text { stat. } \\
\qquad(\mathrm{pb} / \mathrm{C}\end{array}$ & $\begin{array}{l} \pm \text { syst. } \\
\text { eV) }\end{array}$ & \pm E-scale \\
\hline 25 & & 32 & 1.16 & \pm 0.04 & $\begin{array}{l}+0.29 \\
-0.20\end{array}$ & $\begin{array}{l}+0.28 \\
-0.28\end{array}$ \\
\hline 32 & & 41 & 5.8 & \pm 0.1 & ${ }_{-0.7}^{+0.6}$ & ${ }_{-1.1}^{+1.1}$ \\
\hline 41 & - & 50 & 6.3 & \pm 0.1 & ${ }_{-0.7}^{+0.7}$ & ${ }_{-1.1}^{+1.1}$ \\
\hline 50 & - & 59 & 4.49 & \pm 0.09 & $\begin{array}{l}+0.65 \\
{ }_{-0.48}\end{array}$ & $\begin{array}{l}+0.73 \\
{ }_{-0}\end{array}$ \\
\hline 59 & - & 70 & 2.85 & \pm 0.07 & $\begin{array}{l}{ }_{-0.59}^{+0.43} \\
-\end{array}$ & $\begin{array}{l}+0.43 \\
-0.43\end{array}$ \\
\hline 70 & - & 82 & 1.25 & \pm 0.05 & $\begin{array}{l}+0.27 \\
{ }_{-0.20}\end{array}$ & $\begin{array}{l}+0.22 \\
{ }_{-0.22}\end{array}$ \\
\hline 82 & - & 95 & 0.488 & \pm 0.027 & $\begin{array}{l}+0.064 \\
{ }_{-0.063}\end{array}$ & $\begin{array}{l}+0.087 \\
+0.087\end{array}$ \\
\hline 95 & . & 109 & 0.237 & \pm 0.018 & $\begin{array}{l}+0.052 \\
{ }_{-0.068}\end{array}$ & $\begin{array}{l}+0.042 \\
-0.042\end{array}$ \\
\hline 109 & - & 124 & 0.060 & \pm 0.009 & $\begin{array}{l}+0.019 \\
{ }_{-0.013}\end{array}$ & $\begin{array}{l}+0.010 \\
{ }_{-0.010}\end{array}$ \\
\hline 124 & 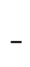 & 140 & 0.027 & \pm 0.006 & $\begin{array}{l}+0.019 \\
{ }_{-0.015}\end{array}$ & ${ }_{-0.006}^{+0.006}$ \\
\hline 140 & - & 160 & 0.0024 & \pm 0.0016 & $\begin{array}{l}+0.0053 \\
-0.0019\end{array}$ & $\begin{array}{l}{ }_{-0.0012}^{+0.0012} \\
-0.0012\end{array}$ \\
\hline
\end{tabular}

Table 3: The measured four-jet differential cross-section $d \sigma / d M_{4 j}$. Other details as described in the caption to Table 2. 


\begin{tabular}{|c|c|c|c|c|c|}
\hline \multicolumn{2}{|c|}{$x_{\gamma}^{\text {obs }}$ range } & $d \sigma / d x_{\gamma}^{\mathrm{ob}}$ & \multicolumn{2}{|c|}{$\begin{array}{c} \pm \text { stat. } \pm \text { syst } \\
\text { (pb) }\end{array}$} & \pm E-scale \\
\hline \multicolumn{6}{|c|}{$25 \leq M_{3 j}<50 \mathrm{GeV}$} \\
\hline 0.00 & -0.11 & 109 & \pm 7 & $\begin{array}{l}+66 \\
-53\end{array}$ & $\begin{array}{l}+31 \\
-31\end{array}$ \\
\hline 0.11 & $\begin{array}{l}-\quad 0.22 \\
-\end{array}$ & 1449 & \pm 15 & $\begin{array}{l}+334 \\
{ }_{-324}\end{array}$ & $\begin{array}{l}+289 \\
-289\end{array}$ \\
\hline 0.22 & - 0.33 & 2102 & \pm 15 & $\begin{array}{l}+240 \\
-230\end{array}$ & $\begin{array}{l}+361 \\
{ }_{-361}^{361}\end{array}$ \\
\hline 0.33 & - $\quad 0.47$ & 1989 & \pm 13 & $\begin{array}{l}+128 \\
{ }_{-119}\end{array}$ & $\begin{array}{l}+292 \\
{ }_{-292}\end{array}$ \\
\hline 0.47 & $\begin{array}{l}-\quad 0.62 \\
-\end{array}$ & 1774 & \pm 12 & ${ }_{-97}^{+117}$ & $\begin{array}{l}+234 \\
{ }_{-234}\end{array}$ \\
\hline 0.62 & - 0.75 & 1752 & \pm 13 & ${ }_{-99}^{+115}$ & $\begin{array}{l}+199 \\
{ }_{-199}\end{array}$ \\
\hline 0.75 & - $\quad 0.85$ & 2579 & \pm 19 & $\begin{array}{l}+204 \\
-184\end{array}$ & $\begin{array}{l}+253 \\
{ }_{-253}\end{array}$ \\
\hline 0.850 & $-\quad 0.935$ & 3803 & \pm 26 & $\begin{array}{l}+672 \\
{ }_{-600}\end{array}$ & $\begin{array}{l}+227 \\
-227\end{array}$ \\
\hline 0.935 & $\begin{array}{l}-\quad 1.000 \\
\end{array}$ & 730 & \pm 12 & $\begin{array}{l}+203 \\
-194 \\
\end{array}$ & $\begin{array}{l}+22 \\
-22\end{array}$ \\
\hline \multicolumn{6}{|c|}{$M_{3 j} \geq 50 \mathrm{GeV}$} \\
\hline 0.11 & -0.22 & 6.9 & \pm 1.0 & $\begin{array}{l}+8.0 \\
-5.0\end{array}$ & $\begin{array}{l}+2.0 \\
{ }_{-2.0}\end{array}$ \\
\hline 0.22 & - 0.33 & 51 & \pm 3 & ${ }_{-13}^{+10}$ & ${ }_{-10}^{+10}$ \\
\hline 0.33 & $\begin{array}{l}-\quad 0.47 \\
\end{array}$ & 153 & \pm 4 & $\begin{array}{l}+42 \\
{ }_{-42}\end{array}$ & ${ }_{-21}^{+21}$ \\
\hline 0.47 & - $\quad 0.62$ & 310 & \pm 6 & ${ }_{-75}^{+87}$ & ${ }_{-40}^{+40}$ \\
\hline 0.62 & - $\quad 0.75$ & 504 & \pm 8 & $\begin{array}{l}+93 \\
{ }_{-86}\end{array}$ & $\begin{array}{l}+60 \\
-60\end{array}$ \\
\hline 0.75 & -0.85 & 871 & \pm 12 & $\begin{array}{l}+101 \\
{ }_{-113}\end{array}$ & $\begin{array}{l}+100 \\
-100\end{array}$ \\
\hline 0.850 & - 0.935 & 1695 & \pm 18 & ${ }_{-211}^{+202}$ & ${ }_{-161}^{+161}$ \\
\hline 0.935 & $\begin{array}{l}-\quad 1.000 \\
\end{array}$ & 666 & \pm 14 & $\begin{array}{l}+169 \\
{ }_{-164}\end{array}$ & $\begin{array}{l}+52 \\
{ }_{-52}\end{array}$ \\
\hline
\end{tabular}

Table 4: The measured three-jet differential cross-section $d \sigma / d x_{\gamma}^{\mathrm{obs}}$ in both the low- and high-mass regions. Other details as described in the caption to Table 2. 


\begin{tabular}{|c|c|c|c|c|c|}
\hline$x_{\gamma}^{\mathrm{ob}}$ & range & $d \sigma / d x_{\gamma}^{\mathrm{obs}}$ & \multicolumn{2}{|c|}{$\begin{array}{c} \pm \text { stat. } \pm \text { syst. } \\
(\mathrm{pb})\end{array}$} & \pm E-scale \\
\hline \multicolumn{6}{|c|}{$25 \leq M_{4 j}<50 \mathrm{GeV}$} \\
\hline 0.00 & -0.11 & 4.9 & \pm 1.7 & $\begin{array}{l}+5.1 \\
-3.0\end{array}$ & $\begin{array}{l}+1.4 \\
-1.4\end{array}$ \\
\hline 0.11 & $\begin{array}{l}-\quad 0.22 \\
-\end{array}$ & 100 & \pm 4 & $\begin{array}{l}+44 \\
-37\end{array}$ & $\begin{array}{l}+21 \\
-21\end{array}$ \\
\hline 0.22 & -0.33 & 210 & \pm 5 & $\begin{array}{l}+46 \\
-45\end{array}$ & $\begin{array}{l}+53 \\
-53\end{array}$ \\
\hline 0.33 & - $\quad 0.47$ & 177 & \pm 4 & ${ }_{-18}^{+31}$ & $\begin{array}{l}+38 \\
{ }_{-38}\end{array}$ \\
\hline 0.47 & - $\quad 0.62$ & 136 & \pm 3 & ${ }_{-13}^{+21}$ & $\begin{array}{l}+29 \\
-29\end{array}$ \\
\hline 0.62 & - $\quad 0.75$ & 94 & \pm 3 & $\begin{array}{l}+27 \\
-17\end{array}$ & $\begin{array}{l}+14 \\
-14\end{array}$ \\
\hline 0.75 & -0.85 & 113 & \pm 3 & $\begin{array}{l}+42 \\
-35\end{array}$ & $\begin{array}{l}+15 \\
-15\end{array}$ \\
\hline 0.850 & - $\quad 0.935$ & 125 & \pm 4 & $\begin{array}{l}+28 \\
{ }_{-33}^{2}\end{array}$ & $\begin{array}{l}+9 \\
-9\end{array}$ \\
\hline 0.935 & - 1.000 & 22 & \pm 2 & $\begin{array}{l}+6 \\
-13 \\
\end{array}$ & $\begin{array}{l}+3 \\
-3 \\
\end{array}$ \\
\hline \multicolumn{6}{|c|}{$M_{4 j} \geq 50 \mathrm{GeV}$} \\
\hline 0.11 & -0.22 & 0.4 & \pm 0.2 & $\begin{array}{l}+2.3 \\
-0.2\end{array}$ & $\begin{array}{l}+0.2 \\
-0.2\end{array}$ \\
\hline 0.22 & - $\quad 0.33$ & 25 & \pm 2 & ${ }_{-12}^{+14}$ & $\begin{array}{l}+9 \\
-9\end{array}$ \\
\hline 0.33 & - $\quad 0.47$ & 64 & \pm 3 & ${ }_{-23}^{+26}$ & ${ }_{-11}^{+11}$ \\
\hline 0.47 & - 0.62 & 103 & \pm 3 & $\begin{array}{l}+26 \\
{ }_{-30}\end{array}$ & $\begin{array}{l}+19 \\
-19\end{array}$ \\
\hline 0.62 & $-\quad 0.75$ & 126 & \pm 4 & $\begin{array}{l}+18 \\
-24\end{array}$ & $\begin{array}{l}+21 \\
-21\end{array}$ \\
\hline 0.75 & -0.85 & 170 & \pm 5 & $\begin{array}{l}+31 \\
{ }_{-27}\end{array}$ & $\begin{array}{l}+24 \\
-24\end{array}$ \\
\hline 0.850 & - $\quad 0.935$ & 307 & \pm 8 & $\begin{array}{l}+39 \\
{ }_{-40}\end{array}$ & $\begin{array}{l}+35 \\
{ }_{-35}\end{array}$ \\
\hline 0.935 & $\begin{array}{l}-\quad 1.000 \\
\end{array}$ & 122 & \pm 5 & $\begin{array}{l}+69 \\
{ }_{-37}\end{array}$ & $\begin{array}{l}+7 \\
{ }_{-7}\end{array}$ \\
\hline
\end{tabular}

Table 5: The measured four-jet differential cross-section $d \sigma / d x_{\gamma}^{\text {obs }}$ in both the lowand high-mass regions. Other details as described in the caption to Table 2. 


\begin{tabular}{|c|c|c|c|c|c|c|}
\hline \multicolumn{3}{|c|}{$y$ range } & $d \sigma / d y$ & \pm stat & $\begin{array}{l} \pm \text { sys } \\
\text { b) }\end{array}$ & \pm E-scale \\
\hline \multicolumn{7}{|c|}{$25 \leq M_{3 j}<50 \mathrm{GeV}$} \\
\hline 0.200 & - & 0.272 & 2264 & \pm 22 & $\begin{array}{l}+400 \\
-392\end{array}$ & $\begin{array}{l}+152 \\
{ }_{-152}\end{array}$ \\
\hline 0.272 & - & 0.344 & 2794 & \pm 22 & $\begin{array}{l}+491 \\
-382\end{array}$ & $\begin{array}{l}+286 \\
-286\end{array}$ \\
\hline 0.344 & - & 0.417 & 2854 & \pm 22 & $\begin{array}{l}+390 \\
-282\end{array}$ & $\begin{array}{l}+321 \\
-321\end{array}$ \\
\hline 0.417 & - & 0.489 & 2900 & \pm 22 & $\begin{array}{l}+288 \\
-238\end{array}$ & $\begin{array}{l}+340 \\
-340\end{array}$ \\
\hline 0.489 & - & 0.561 & 2973 & \pm 22 & $\begin{array}{l}+270 \\
{ }_{-261}\end{array}$ & $\begin{array}{l}+361 \\
-361\end{array}$ \\
\hline 0.561 & - & 0.633 & 2918 & \pm 22 & $\begin{array}{l}+268 \\
-242\end{array}$ & $\begin{array}{l}+363 \\
-363\end{array}$ \\
\hline 0.633 & - & 0.706 & 2833 & \pm 22 & $\begin{array}{l}+232 \\
-218\end{array}$ & $\begin{array}{l}+366 \\
-366\end{array}$ \\
\hline 0.706 & - & 0.778 & 2739 & \pm 22 & $\begin{array}{l}+250 \\
-216\end{array}$ & $\begin{array}{l}+380 \\
-380\end{array}$ \\
\hline 0.778 & - & 0.850 & 2797 & \pm 23 & $\begin{array}{l}+340 \\
-326 \\
\end{array}$ & $\begin{array}{l}+415 \\
-415 \\
\end{array}$ \\
\hline \multicolumn{7}{|c|}{$M_{3 j} \geq 50 \mathrm{GeV}$} \\
\hline 0.200 & - & 0.272 & 156 & \pm 7 & $\begin{array}{l}+24 \\
-38\end{array}$ & $\begin{array}{l}+16 \\
-16\end{array}$ \\
\hline 0.272 & - & 0.344 & 271 & \pm 7 & $\begin{array}{l}+28 \\
-13\end{array}$ & ${ }_{-24}^{+24}$ \\
\hline 0.344 & - & 0.417 & 455 & \pm 10 & $\begin{array}{l}+78 \\
-65\end{array}$ & $\begin{array}{l}+43 \\
-43\end{array}$ \\
\hline 0.417 & - & 0.489 & 565 & \pm 11 & $\begin{array}{l}+59 \\
{ }_{-91}^{+}\end{array}$ & $\begin{array}{l}+52 \\
-52\end{array}$ \\
\hline 0.489 & - & 0.561 & 684 & \pm 12 & $\begin{array}{l}+134 \\
-108\end{array}$ & $\begin{array}{l}+67 \\
-67\end{array}$ \\
\hline 0.561 & - & 0.633 & 768 & \pm 13 & ${ }_{-131}^{+111}$ & $\begin{array}{l}+81 \\
-81\end{array}$ \\
\hline 0.633 & - & 0.706 & 905 & \pm 14 & $\begin{array}{l}+171 \\
{ }_{-199}\end{array}$ & ${ }_{-100}^{+100}$ \\
\hline 0.706 & - & 0.778 & 961 & \pm 15 & $\begin{array}{l}+201 \\
-206\end{array}$ & $\begin{array}{l}+113 \\
{ }_{-113}\end{array}$ \\
\hline 0.778 & - & 0.850 & 1058 & \pm 16 & $\begin{array}{r}+259 \\
-224 \\
\end{array}$ & $\begin{array}{l}+130 \\
-130 \\
\end{array}$ \\
\hline
\end{tabular}

Table 6: The measured three-jet differential cross-section $d \sigma / d y$ in both the lowand high-mass regions. Other details as described in the caption to Table 2. 


\begin{tabular}{|c|c|c|c|c|c|c|}
\hline \multicolumn{3}{|c|}{$y$ range } & $d \sigma / d y$ & \pm stat. & $\begin{array}{l} \pm \text { sys } \\
\text { b) }\end{array}$ & \pm E-scale \\
\hline \multicolumn{7}{|c|}{$25 \leq M_{4 j}<50 \mathrm{GeV}$} \\
\hline 0.200 & - & 0.272 & 90 & \pm 4 & $\begin{array}{l}+30 \\
-25\end{array}$ & $\begin{array}{l}+8 \\
-8\end{array}$ \\
\hline 0.272 & - & 0.344 & 113 & \pm 4 & $\begin{array}{l}+23 \\
-14\end{array}$ & $\begin{array}{l}+18 \\
-18\end{array}$ \\
\hline 0.344 & - & 0.417 & 154 & \pm 5 & $\begin{array}{l}+28 \\
-24\end{array}$ & $\begin{array}{l}+29 \\
+29\end{array}$ \\
\hline 0.417 & - & 0.489 & 171 & \pm 5 & $\begin{array}{l}+30 \\
-17\end{array}$ & $\begin{array}{l}+33 \\
{ }_{-33}\end{array}$ \\
\hline 0.489 & - & 0.561 & 186 & \pm 5 & $\begin{array}{l}+15 \\
{ }_{-23}\end{array}$ & $\begin{array}{l}+37 \\
{ }_{-37}\end{array}$ \\
\hline 0.561 & - & 0.633 & 210 & \pm 5 & $\begin{array}{l}+30 \\
{ }_{-27}\end{array}$ & $\begin{array}{l}+39 \\
-39\end{array}$ \\
\hline 0.633 & - & 0.706 & 215 & \pm 5 & $\begin{array}{l}+31 \\
-28\end{array}$ & $\begin{array}{l}+42 \\
-42\end{array}$ \\
\hline 0.706 & - & 0.778 & 218 & \pm 6 & $\begin{array}{l}+23 \\
-24\end{array}$ & $\begin{array}{l}+44 \\
-44\end{array}$ \\
\hline 0.778 & - & 0.850 & 246 & \pm 7 & $\begin{array}{l}+37 \\
{ }_{-43} \\
\end{array}$ & $\begin{array}{l}+52 \\
{ }_{-52}\end{array}$ \\
\hline \multicolumn{7}{|c|}{$M_{4 j} \geq 50 \mathrm{GeV}$} \\
\hline 0.200 & - & 0.272 & 16.8 & \pm 2.4 & $\begin{array}{l}+5.3 \\
-6.8\end{array}$ & $\begin{array}{l}+3.1 \\
-3.1\end{array}$ \\
\hline 0.272 & - & 0.344 & 40 & \pm 3 & $\begin{array}{l}+13 \\
-13\end{array}$ & $\begin{array}{l}+6 \\
-6\end{array}$ \\
\hline 0.344 & - & 0.417 & 81 & \pm 4 & $\begin{array}{l}+13 \\
-7\end{array}$ & $\begin{array}{l}+9 \\
{ }_{-9}\end{array}$ \\
\hline 0.417 & - & 0.489 & 108 & \pm 5 & $\begin{array}{l}+8 \\
-9\end{array}$ & ${ }_{-15}^{+15}$ \\
\hline 0.489 & - & 0.561 & 136 & \pm 5 & $\begin{array}{l}+13 \\
-16\end{array}$ & $\begin{array}{l}+17 \\
-17\end{array}$ \\
\hline 0.561 & - & 0.633 & 171 & \pm 6 & $\begin{array}{l}+28 \\
-17\end{array}$ & $\begin{array}{l}+24 \\
-24\end{array}$ \\
\hline 0.633 & - & 0.706 & 228 & \pm 7 & $\begin{array}{l}+33 \\
{ }_{-47}\end{array}$ & $\begin{array}{l}+33 \\
{ }_{-33}\end{array}$ \\
\hline 0.706 & - & 0.778 & 266 & \pm 8 & $\begin{array}{l}+54 \\
-66\end{array}$ & $\begin{array}{l}+40 \\
{ }_{-40}\end{array}$ \\
\hline 0.778 & - & 0.850 & 266 & \pm 8 & $\begin{array}{l}+60 \\
-51 \\
\end{array}$ & $\begin{array}{l}+47 \\
-47 \\
\end{array}$ \\
\hline
\end{tabular}

Table 7: The measured four-jet differential cross-section do/dy in both the lowand high-mass regions. Other details as described in the caption to Table 2. 


\begin{tabular}{|c|c|c|c|c|c|c|c|c|c|c|}
\hline \multicolumn{3}{|c|}{$\begin{array}{c}E_{T}^{\text {jet1 }} \text { range } \\
(\mathrm{GeV})\end{array}$} & \multirow[t]{2}{*}{$d \sigma / d E_{T}^{\mathrm{jet} 1}$} & \multirow{2}{*}{\multicolumn{3}{|c|}{$\begin{array}{c}\begin{array}{c} \pm \text { stat. } \quad \pm \text { syst. } \quad \pm \text { E-scale } \\
(\mathrm{pb} / \mathrm{GeV})\end{array} \\
25 \leq M_{3 j}<50 \mathrm{GeV}\end{array}$}} & \multicolumn{2}{|c|}{ had. corr. } & \multicolumn{2}{|c|}{ MPI corr. } \\
\hline \multicolumn{7}{|c|}{$25 \leq M_{3 j}<50 \mathrm{GeV}$} & & & & \\
\hline 6.0 & 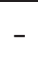 & 8.5 & 107 & \pm 1 & $\begin{array}{l}+19 \\
-17\end{array}$ & $\begin{array}{l}+11 \\
-11\end{array}$ & 0.744 & \pm 0.026 & 2.09 & \pm 0.70 \\
\hline 8.5 & - & 11.2 & 248 & \pm 1 & $\begin{array}{l}+20 \\
-20\end{array}$ & $\begin{array}{l}+29 \\
-29\end{array}$ & 0.791 & \pm 0.012 & 1.67 & \pm 0.34 \\
\hline 11.2 & - & 14.2 & 169 & \pm 1 & $\begin{array}{l}+11 \\
-10\end{array}$ & $\begin{array}{l}+21 \\
-21\end{array}$ & 0.819 & \pm 0.009 & 1.38 & \pm 0.17 \\
\hline 14.2 & - & 17.6 & 75.2 & \pm 0.6 & $\begin{array}{l}+6.9 \\
{ }_{-7.2}\end{array}$ & $\begin{array}{l}+9.7 \\
{ }_{-9.7}\end{array}$ & 0.842 & \pm 0.003 & 1.24 & \pm 0.12 \\
\hline 17.6 & - & 21.5 & 19.9 & \pm 0.3 & $\begin{array}{l}+2.6 \\
-2.3\end{array}$ & $\begin{array}{l}+2.6 \\
-2.6\end{array}$ & 0.834 & \pm 0.017 & 1.17 & \pm 0.09 \\
\hline 21.5 & - & 26.0 & 2.54 & \pm 0.09 & $\begin{array}{l}+0.38 \\
-0.32\end{array}$ & ${ }_{-0.37}^{+0.37}$ & 0.774 & \pm 0.064 & 1.16 & \pm 0.11 \\
\hline 26.0 & - & 31.2 & 0.200 & \pm 0.022 & $\begin{array}{l}+0.071 \\
{ }_{-0.077}\end{array}$ & $\begin{array}{l}+0.040 \\
{ }_{-0.040}\end{array}$ & 0.725 & \pm 0.080 & 1.21 & \pm 0.20 \\
\hline \multicolumn{11}{|c|}{$M_{3 j} \geq 50 \mathrm{GeV}$} \\
\hline 6.0 & 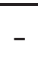 & 8.5 & 2.7 & \pm 0.2 & $\begin{array}{l}+1.3 \\
-1.0\end{array}$ & $\begin{array}{l}+0.6 \\
-0.6\end{array}$ & 0.515 & \pm 0.052 & 1.42 & \pm 0.29 \\
\hline 8.5 & 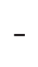 & 11.2 & 14.4 & \pm 0.4 & $\begin{array}{l}+5.8 \\
-4.7\end{array}$ & $\begin{array}{l}+1.5 \\
-1.5\end{array}$ & 0.646 & \pm 0.044 & 1.28 & \pm 0.20 \\
\hline 11.2 & - & 14.2 & 24.5 & \pm 0.4 & $\begin{array}{l}+5.5 \\
-5.6\end{array}$ & ${ }_{-2.5}^{+2.5}$ & 0.759 & \pm 0.024 & 1.17 & \pm 0.16 \\
\hline 14.2 & - & 17.6 & 27.8 & \pm 0.4 & $\begin{array}{l}+4.7 \\
-4.0\end{array}$ & $\begin{array}{l}+2.7 \\
{ }_{-2.7}\end{array}$ & 0.839 & \pm 0.018 & 1.13 & \pm 0.13 \\
\hline 17.6 & - & 21.5 & 23.1 & \pm 0.3 & $\begin{array}{l}+2.2 \\
-2.1\end{array}$ & $\begin{array}{l}+2.2 \\
{ }_{-2.2}\end{array}$ & 0.878 & \pm 0.007 & 1.09 & \pm 0.09 \\
\hline 21.5 & - & 26.0 & 14.1 & \pm 0.2 & $\begin{array}{l}+1.5 \\
-1.3\end{array}$ & $\begin{array}{l}+1.5 \\
-1.5\end{array}$ & 0.864 & \pm 0.016 & 1.07 & \pm 0.08 \\
\hline 26.0 & - & 31.2 & 6.07 & \pm 0.12 & $\begin{array}{l}+0.59 \\
-0.58\end{array}$ & ${ }_{-0.72}^{+0.72}$ & 0.859 & \pm 0.025 & 1.06 & \pm 0.07 \\
\hline 31.2 & - & 37.0 & 2.06 & \pm 0.07 & $\begin{array}{l}+0.19 \\
{ }_{-0.18}\end{array}$ & $\begin{array}{l}+0.32 \\
{ }_{-0.32}\end{array}$ & 0.848 & \pm 0.034 & 1.04 & \pm 0.05 \\
\hline 37.0 & 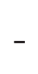 & 43.9 & 0.79 & \pm 0.04 & $\begin{array}{l}+0.63 \\
-0.16\end{array}$ & $\begin{array}{l}+0.22 \\
-0.22\end{array}$ & 0.838 & \pm 0.032 & 1.02 & \pm 0.04 \\
\hline 43.9 & - & 51.8 & 0.246 & \pm 0.020 & $\begin{array}{l}+0.044 \\
-0.046\end{array}$ & $\begin{array}{l}+0.066 \\
-0.066\end{array}$ & 0.847 & \pm 0.045 & 1.04 & \pm 0.07 \\
\hline 51.8 & - & 60.8 & 0.067 & \pm 0.007 & $\begin{array}{l}+0.021 \\
-0.031\end{array}$ & $\begin{array}{l}+0.013 \\
-0.013\end{array}$ & 0.881 & \pm 0.039 & 1.00 & \pm 0.04 \\
\hline 60.8 & - & 71.0 & 0.035 & \pm 0.004 & $\begin{array}{l}+0.019 \\
-0.019 \\
\end{array}$ & $\begin{array}{l}{ }_{-0.001}^{+0.001} \\
\end{array}$ & 0.870 & \pm 0.001 & 1.02 & \pm 0.07 \\
\hline
\end{tabular}

Table 8: The measured three-jet differential cross-section $d \sigma / d E_{T}^{\mathrm{jet} 1}$ in both the low-and high-mass regions. Other details as described in the caption to Table 2. 


\begin{tabular}{|c|c|c|c|c|c|c|c|c|c|c|}
\hline \multicolumn{3}{|c|}{$\begin{array}{c}E_{T}^{\mathrm{jet} 2} \text { range } \\
(\mathrm{GeV}) \\
\end{array}$} & \multirow[t]{2}{*}{$d \sigma / d E_{T}^{\text {jet2 }}$} & \multicolumn{3}{|c|}{$\begin{array}{c} \pm \text { stat. } \quad \pm \text { syst. } \pm \text { E-scale } \\
(\mathrm{pb} / \mathrm{GeV})\end{array}$} & \multicolumn{2}{|c|}{ had. corr. } & \multicolumn{2}{|c|}{ MPI corr. } \\
\hline \multicolumn{10}{|c|}{$25 \leq M_{3 j}<50 \mathrm{GeV}$} & \\
\hline 6.0 & . & 8.5 & 383 & \pm 1 & $\begin{array}{l}+48 \\
-47\end{array}$ & $\begin{array}{l}+43 \\
-43\end{array}$ & 0.772 & \pm 0.023 & 1.68 & \pm 0.39 \\
\hline 8.5 & - & 11.2 & 229 & \pm 1 & $\begin{array}{l}+10 \\
-9\end{array}$ & $\begin{array}{l}+28 \\
-28\end{array}$ & 0.829 & \pm 0.010 & 1.41 & \pm 0.18 \\
\hline 11.2 & - & 14.2 & 59.0 & \pm 0.5 & $\begin{array}{l}+3.7 \\
{ }_{-2.7}\end{array}$ & $\begin{array}{l}+7.4 \\
-7.4\end{array}$ & 0.868 & \pm 0.018 & 1.25 & \pm 0.10 \\
\hline 14.2 & - & 17.6 & 10.4 & \pm 0.2 & $\begin{array}{l}+1.3 \\
-1.0\end{array}$ & $\begin{array}{l}+1.3 \\
-1.3\end{array}$ & 0.869 & \pm 0.005 & 1.19 & \pm 0.06 \\
\hline 17.6 & - & 21.5 & 0.84 & \pm 0.05 & $\begin{array}{l}+0.42 \\
-0.23 \\
\end{array}$ & $\begin{array}{l}+0.11 \\
-0.11 \\
\end{array}$ & 0.861 & \pm 0.042 & 1.16 & \pm 0.09 \\
\hline \multicolumn{11}{|c|}{$M_{3 j} \geq 50 \mathrm{GeV}$} \\
\hline 6.0 & - & 8.5 & 22.2 & \pm 0.5 & $\begin{array}{l}+9.0 \\
-8.0\end{array}$ & $\begin{array}{l}+2.6 \\
{ }_{-2.6}\end{array}$ & 0.626 & \pm 0.027 & 1.26 & \pm 0.22 \\
\hline 8.5 & - & 11.2 & 40 & \pm 1 & $\begin{array}{l}+11 \\
-9\end{array}$ & $\begin{array}{l}+4 \\
-4\end{array}$ & 0.759 & \pm 0.019 & 1.16 & \pm 0.15 \\
\hline 11.2 & - & 14.2 & 34.3 & \pm 0.4 & $\begin{array}{l}+4.1 \\
-4.0\end{array}$ & $\begin{array}{l}+3.6 \\
-3.6\end{array}$ & 0.861 & \pm 0.005 & 1.11 & \pm 0.12 \\
\hline 14.2 & - & 17.6 & 21.6 & \pm 0.3 & $\begin{array}{l}+1.5 \\
-1.4\end{array}$ & $\begin{array}{l}+2.3 \\
{ }_{-2.3}\end{array}$ & 0.891 & \pm 0.008 & 1.08 & \pm 0.09 \\
\hline 17.6 & - & 21.5 & 11.5 & \pm 0.2 & $\begin{array}{l}+0.7 \\
-0.6\end{array}$ & $\begin{array}{l}+1.3 \\
-1.3\end{array}$ & 0.898 & \pm 0.011 & 1.07 & \pm 0.07 \\
\hline 21.5 & - & 26.0 & 4.48 & \pm 0.12 & $\begin{array}{l}+0.49 \\
-0.54\end{array}$ & ${ }_{-0.47}^{+0.47}$ & 0.888 & \pm 0.015 & 1.06 & \pm 0.07 \\
\hline 26.0 & - & 31.2 & 1.57 & \pm 0.07 & $\begin{array}{l}+0.18 \\
-0.12\end{array}$ & $\begin{array}{l}+0.16 \\
-0.16\end{array}$ & 0.881 & \pm 0.010 & 1.06 & \pm 0.07 \\
\hline 31.2 & - & 37.0 & 0.558 & \pm 0.035 & $\begin{array}{l}+0.065 \\
-0.091\end{array}$ & $\begin{array}{l}+0.077 \\
-0.077\end{array}$ & 0.892 & \pm 0.028 & 1.03 & \pm 0.05 \\
\hline 37.0 & - & 43.9 & 0.214 & \pm 0.021 & $\begin{array}{l}{ }_{-0.053}^{+0.046} \\
\end{array}$ & $\begin{array}{l}+0.025 \\
-0.025\end{array}$ & 0.898 & \pm 0.003 & 1.01 & \pm 0.03 \\
\hline 43.9 & - & 51.8 & 0.071 & \pm 0.013 & $\begin{array}{l}+0.026 \\
{ }_{-0.020}\end{array}$ & $\begin{array}{l}+0.008 \\
{ }_{-0.008}\end{array}$ & 0.898 & \pm 0.028 & 1.00 & \pm 0.05 \\
\hline 51.8 & - & 60.8 & 0.042 & \pm 0.009 & $\begin{array}{l}+0.022 \\
-0.025 \\
\end{array}$ & $\begin{array}{l}+0.004 \\
-0.004 \\
\end{array}$ & 0.765 & \pm 0.092 & 1.02 & \pm 0.10 \\
\hline
\end{tabular}

Table 9: The measured three-jet differential cross-section $d \sigma / d E_{T}^{\mathrm{jet} 2}$ in both the low-and high-mass regions. Other details as described in the caption to Table 2. 


\begin{tabular}{|c|c|c|c|c|c|c|c|c|c|c|}
\hline \multicolumn{3}{|c|}{$\begin{array}{c}E_{T}^{\text {jet3 }} \text { range } \\
(\mathrm{GeV})\end{array}$} & $d \sigma / d E_{T}^{\mathrm{jet} 3}$ & $\begin{array}{l} \pm \text { stat. } \\
\qquad(\mathrm{pb} / \mathrm{G}\end{array}$ & $\begin{array}{l} \pm \text { syst. } \\
\text { V) }\end{array}$ & \pm E-scale & had & corr. & MP & corr. \\
\hline \multicolumn{11}{|c|}{$25 \leq M_{3 j}<50 \mathrm{GeV}$} \\
\hline 6.0 & - & 8.5 & 644 & \pm 2 & $\begin{array}{l}+68 \\
-57\end{array}$ & $\begin{array}{l}+76 \\
-76\end{array}$ & 0.799 & \pm 0.011 & 1.53 & \pm 0.28 \\
\hline 8.5 & - & 11.2 & 63.2 & \pm 0.6 & $\begin{array}{l}+3.5 \\
-2.8\end{array}$ & $\begin{array}{l}+8.5 \\
-8.5\end{array}$ & 0.859 & \pm 0.011 & 1.30 & \pm 0.08 \\
\hline 11.2 & - & 14.2 & 3.82 & \pm 0.14 & $\begin{array}{l}{ }_{-0.70}^{+0.82} \\
-0.70\end{array}$ & $\begin{array}{l}+0.68 \\
-0.68\end{array}$ & 0.887 & \pm 0.017 & 1.24 & \pm 0.02 \\
\hline 14.2 & - & 17.6 & 0.096 & \pm 0.034 & $\begin{array}{l}+0.053 \\
-0.090 \\
\end{array}$ & $\begin{array}{l}+0.050 \\
-0.050 \\
\end{array}$ & 0.834 & \pm 0.058 & 1.09 & \pm 0.21 \\
\hline \multicolumn{11}{|c|}{$M_{3 j} \geq 50 \mathrm{GeV}$} \\
\hline 6.0 & . & 8.5 & 94 & \pm 1 & $\begin{array}{l}+20 \\
{ }_{-20}\end{array}$ & ${ }_{-11}^{+11}$ & 0.767 & \pm 0.010 & 1.15 & \pm 0.14 \\
\hline 8.5 & - & 11.2 & 43.1 & \pm 0.5 & $\begin{array}{l}+5.1 \\
-4.4\end{array}$ & $\begin{array}{l}+4.4 \\
-4.4\end{array}$ & 0.864 & \pm 0.010 & 1.08 & \pm 0.09 \\
\hline 11.2 & - & 14.2 & 15.3 & \pm 0.3 & $\begin{array}{l}+1.5 \\
{ }_{-1.3}\end{array}$ & $\begin{array}{l}+1.7 \\
{ }_{-1.7}\end{array}$ & 0.914 & \pm 0.015 & 1.06 & \pm 0.07 \\
\hline 14.2 & - & 17.6 & 5.0 & \pm 0.1 & $\begin{array}{l}+1.0 \\
-1.0\end{array}$ & $\begin{array}{l}+0.5 \\
-0.5\end{array}$ & 0.915 & \pm 0.020 & 1.04 & \pm 0.05 \\
\hline 17.6 & - & 21.5 & 1.08 & \pm 0.06 & $\begin{array}{l}+0.15 \\
{ }_{-0.15}\end{array}$ & $\begin{array}{l}+0.16 \\
{ }_{-0.16}\end{array}$ & 0.919 & \pm 0.016 & 1.04 & \pm 0.06 \\
\hline 21.5 & - & 26.0 & 0.289 & \pm 0.026 & $\begin{array}{l}+0.086 \\
{ }_{-0.068}\end{array}$ & $\begin{array}{l}+0.034 \\
{ }_{-0.034}\end{array}$ & 0.898 & \pm 0.032 & 1.00 & \pm 0.04 \\
\hline 26.0 & - & 31.2 & 0.065 & \pm 0.012 & $\begin{array}{l}+0.030 \\
{ }_{-0.034}\end{array}$ & $\begin{array}{l}+0.006 \\
{ }_{-0.006}\end{array}$ & 0.887 & \pm 0.145 & 1.00 & \pm 0.08 \\
\hline 31.2 & - & 40.0 & 0.0185 & \pm 0.0053 & $\begin{array}{l}+0.0085 \\
{ }_{-0.0078} \\
\end{array}$ & $\begin{array}{l}+0.0037 \\
{ }_{-0.0037}\end{array}$ & 0.921 & \pm 0.054 & 1.05 & \pm 0.15 \\
\hline
\end{tabular}

Table 10: The measured three-jet differential cross-section $d \sigma / d E_{T}^{\mathrm{jet} 3}$ in both the low- and high-mass regions. Other details as described in the caption to Table 2. 


\begin{tabular}{|c|c|c|c|c|c|c|}
\hline \multicolumn{3}{|c|}{$\begin{array}{c}E_{T}^{\mathrm{jet} 1} \text { range } \\
(\mathrm{GeV})\end{array}$} & $d \sigma / d E_{T}^{\mathrm{jet}}$ & $\begin{array}{l}\text { 土stat. } \\
\qquad(\mathrm{pb} / \mathrm{C}\end{array}$ & $\begin{array}{l}\text { 土syst. } \\
\text { V) }\end{array}$ & \pm E-scale \\
\hline \multicolumn{7}{|c|}{$25 \leq M_{4 j}<50 \mathrm{GeV}$} \\
\hline 6.0 & & 8.5 & 9.6 & \pm 0.2 & $\begin{array}{l}+1.4 \\
-1.6\end{array}$ & $\begin{array}{l}+1.7 \\
-1.7\end{array}$ \\
\hline 8.5 & - & 11.2 & 19.6 & \pm 0.3 & $\begin{array}{l}+1.9 \\
-2.0\end{array}$ & $\begin{array}{l}+3.7 \\
-3.7\end{array}$ \\
\hline 11.2 & - & 14.2 & 9.3 & \pm 0.2 & $\begin{array}{l}+1.4 \\
{ }_{-1.1}\end{array}$ & $\begin{array}{l}+1.8 \\
{ }_{-1.8}\end{array}$ \\
\hline 14.2 & - & 17.6 & 2.66 & \pm 0.10 & $\begin{array}{l}+0.40 \\
-0.52\end{array}$ & ${ }_{-0.50}^{+0.50}$ \\
\hline 17.6 & - & 21.5 & 0.29 & \pm 0.03 & $\begin{array}{l}+0.12 \\
-0.06 \\
\end{array}$ & $\begin{array}{l}+0.06 \\
-0.06 \\
\end{array}$ \\
\hline \multicolumn{7}{|c|}{$M_{4 j} \geq 50 \mathrm{GeV}$} \\
\hline 6.0 & . & 8.5 & 1.00 & \pm 0.16 & $\begin{array}{l}+0.48 \\
-0.55\end{array}$ & $\begin{array}{l}+0.13 \\
-0.13\end{array}$ \\
\hline 8.5 & - & 11.2 & 6.1 & \pm 0.2 & ${ }_{-1.7}^{+1.8}$ & $\begin{array}{l}+0.9 \\
{ }_{-0.9}\end{array}$ \\
\hline 11.2 & - & 14.2 & 8.3 & \pm 0.2 & $\begin{array}{l}+1.4 \\
-1.4\end{array}$ & $\begin{array}{l}+1.1 \\
-1.1\end{array}$ \\
\hline 14.2 & - & 17.6 & 6.46 & \pm 0.16 & ${ }_{-0.56}^{+0.71}$ & ${ }_{-0.95}^{+0.95}$ \\
\hline 17.6 & - & 21.5 & 3.93 & \pm 0.11 & $\begin{array}{l}+0.43 \\
{ }_{-0.29}\end{array}$ & $\begin{array}{l}+0.62 \\
{ }_{-0.62}\end{array}$ \\
\hline 21.5 & - & 26.0 & 1.93 & \pm 0.07 & $\begin{array}{l}+0.29 \\
{ }_{-0.21}\end{array}$ & $\begin{array}{l}+0.33 \\
{ }_{-0.33}\end{array}$ \\
\hline 26.0 & - & 31.2 & 0.74 & \pm 0.04 & $\begin{array}{l}+0.09 \\
-0.09\end{array}$ & ${ }_{-0.14}^{+0.14}$ \\
\hline 31.2 & - & 37.0 & 0.289 & \pm 0.022 & $\begin{array}{l}+0.044 \\
-0.052\end{array}$ & $\begin{array}{l}+0.051 \\
-0.051\end{array}$ \\
\hline 37.0 & - & 43.9 & 0.100 & \pm 0.014 & $\begin{array}{l}+0.028 \\
-0.023\end{array}$ & $\begin{array}{l}+0.020 \\
-0.020\end{array}$ \\
\hline 43.9 & - & 51.8 & 0.016 & \pm 0.004 & $\begin{array}{l}+0.017 \\
-0.011\end{array}$ & $\begin{array}{l}+0.004 \\
-0.004\end{array}$ \\
\hline 51.8 & - & 60.8 & 0.0022 & \pm 0.0014 & $\begin{array}{l}+0.0040 \\
-0.0022 \\
\end{array}$ & $\begin{array}{l}+0.0010 \\
-0.0010 \\
\end{array}$ \\
\hline
\end{tabular}

Table 11: The measured four-jet differential cross-section $d \sigma / d E_{T}^{\text {jet1 }}$ in both the low- and high-mass regions. Other details as described in the caption to Table 2. 


\begin{tabular}{|c|c|c|c|c|c|c|}
\hline \multicolumn{3}{|c|}{$\begin{array}{c}E_{T}^{\text {jet2}} \text { range } \\
(\mathrm{GeV})\end{array}$} & $d \sigma / d E_{T}^{\mathrm{jet} 2}$ & $\begin{array}{l} \pm \text { stat. } \\
\qquad(\mathrm{pb} / \mathrm{C}\end{array}$ & $\begin{array}{l} \pm \text { syst. } \\
\text { eV) }\end{array}$ & \pm E-scale \\
\hline \multicolumn{7}{|c|}{$I_{4 j}<50 \mathrm{GeV}$} \\
\hline 6.0 & - & 8.5 & 27.0 & \pm 0.3 & $\begin{array}{l}+3.1 \\
-3.6\end{array}$ & $\begin{array}{l}+4.9 \\
-4.9\end{array}$ \\
\hline 8.5 & - & 11.2 & 15.3 & \pm 0.3 & $\begin{array}{l}+2.2 \\
-1.8\end{array}$ & $\begin{array}{l}+2.9 \\
{ }_{-2.9}\end{array}$ \\
\hline 11.2 & - & 14.2 & 2.04 & \pm 0.10 & $\begin{array}{l}+0.50 \\
{ }_{-0.30}\end{array}$ & $\begin{array}{l}+0.33 \\
{ }_{-0.33}\end{array}$ \\
\hline 14.2 & - & 17.6 & 0.066 & \pm 0.017 & $\begin{array}{l}+0.050 \\
-0.061 \\
\end{array}$ & $\begin{array}{l}+0.004 \\
-0.004 \\
\end{array}$ \\
\hline \multicolumn{7}{|c|}{$M_{4 j} \geq 50 \mathrm{GeV}$} \\
\hline 6.0 & - & 8.5 & 5.7 & \pm 0.2 & $\begin{array}{l}+1.9 \\
-1.5\end{array}$ & $\begin{array}{l}+0.7 \\
-0.7\end{array}$ \\
\hline 8.5 & - & 11.2 & 12.7 & \pm 0.3 & $\begin{array}{l}+1.8 \\
-1.4\end{array}$ & $\begin{array}{l}+1.9 \\
-1.9\end{array}$ \\
\hline 11.2 & - & 14.2 & 8.4 & \pm 0.2 & ${ }_{-0.7}^{+0.5}$ & ${ }_{-1.4}^{+1.4}$ \\
\hline 14.2 & - & 17.6 & 3.40 & \pm 0.13 & $\begin{array}{l}+0.48 \\
-0.25\end{array}$ & $\begin{array}{l}+0.48 \\
{ }_{-0.48}\end{array}$ \\
\hline 17.6 & - & 21.5 & 1.55 & \pm 0.08 & ${ }_{-0.51}^{+0.26}$ & ${ }_{-0.24}^{+0.24}$ \\
\hline 21.5 & - & 26.0 & 0.55 & \pm 0.05 & $\begin{array}{l}+0.17 \\
{ }_{-0.09}\end{array}$ & $\begin{array}{l}+0.08 \\
{ }_{-0.08}\end{array}$ \\
\hline 26.0 & - & 31.2 & 0.152 & \pm 0.021 & $\begin{array}{l}+0.043 \\
{ }_{-0.032}\end{array}$ & $\begin{array}{l}+0.036 \\
-0.036\end{array}$ \\
\hline 31.2 & - & 37.0 & 0.058 & \pm 0.016 & $\begin{array}{l}+0.036 \\
{ }_{-0.029}\end{array}$ & $\begin{array}{l}+0.013 \\
{ }_{-0.013}\end{array}$ \\
\hline 37.0 & - & 43.9 & 0.017 & \pm 0.005 & $\begin{array}{l}+0.014 \\
-0.009 \\
\end{array}$ & $\begin{array}{l}+0.005 \\
{ }_{-0.005} \\
\end{array}$ \\
\hline
\end{tabular}

Table 12: The measured four-jet differential cross-section $d \sigma / d E_{T}^{\mathrm{jet} 2}$ in both the low- and high-mass regions. Other details as described in the caption to Table 2. 


\begin{tabular}{|c|c|c|c|c|c|c|}
\hline \multicolumn{3}{|c|}{$\begin{array}{c}E_{T}^{\text {jet3 }} \text { range } \\
(\mathrm{GeV})\end{array}$} & \multirow{2}{*}{\multicolumn{4}{|c|}{$\begin{array}{cc}d \sigma / d E_{T}^{\text {jet3 }} & \begin{array}{c} \pm \text { stat. } \\
(\mathrm{pb} / \mathrm{GeV}\end{array} \\
25 \leq M_{4 j}<50 \mathrm{GeV}\end{array}$}} \\
\hline \multicolumn{3}{|c|}{$25 \leq M_{4 j}<50 \mathrm{GeV}$} & & & & \\
\hline 6.0 & & 8.5 & 40.8 & \pm 0.4 & $\begin{array}{l}+4.7 \\
-4.0\end{array}$ & $\begin{array}{l}+7.7 \\
-7.7\end{array}$ \\
\hline 8.5 & - & 11.2 & 4.72 & \pm 0.14 & $\begin{array}{l}+0.99 \\
-0.72\end{array}$ & ${ }_{-0.85}^{+0.85}$ \\
\hline 11.2 & - & 14.2 & 0.054 & \pm 0.019 & $\begin{array}{l}+0.060 \\
-0.047 \\
\end{array}$ & $\begin{array}{l}+0.005 \\
-0.005 \\
\end{array}$ \\
\hline \multicolumn{7}{|c|}{$M_{4 j} \geq 50 \mathrm{GeV}$} \\
\hline 6.0 & & 8.5 & 17.5 & \pm 0.4 & $\begin{array}{l}+3.7 \\
-2.6\end{array}$ & $\begin{array}{l}+2.6 \\
-2.6\end{array}$ \\
\hline 8.5 & - & 11.2 & 13.1 & \pm 0.3 & $\begin{array}{l}+1.4 \\
{ }_{-1.0}\end{array}$ & ${ }_{-1.7}^{+1.7}$ \\
\hline 11.2 & - & 14.2 & 4.3 & \pm 0.1 & $\begin{array}{l}+0.7 \\
{ }_{-1.5}\end{array}$ & $\begin{array}{l}+0.6 \\
{ }_{-0.6}\end{array}$ \\
\hline 14.2 & - & 17.6 & 0.99 & \pm 0.07 & $\begin{array}{l}+0.21 \\
{ }_{-0.22}\end{array}$ & $\begin{array}{l}+0.10 \\
-0.10\end{array}$ \\
\hline 17.6 & - & 21.5 & 0.191 & \pm 0.031 & $\begin{array}{l}+0.075 \\
{ }_{-0.049}\end{array}$ & $\begin{array}{l}+0.051 \\
{ }_{-0.051}\end{array}$ \\
\hline 21.5 & - & 26.0 & 0.035 & \pm 0.009 & $\begin{array}{l}+0.017 \\
-0.015 \\
\end{array}$ & $\begin{array}{l}+0.007 \\
-0.007 \\
\end{array}$ \\
\hline
\end{tabular}

Table 13: The measured four-jet differential cross-section $d \sigma / d E_{T}^{\mathrm{jet} 3}$ in both the low- and high-mass regions. Other details as described in the caption to Table 2.

\begin{tabular}{|c|c|c|c|c|c|c|}
\hline \multicolumn{3}{|c|}{$\begin{array}{c}E_{T}^{\text {jet4 }} \text { range } \\
(\mathrm{GeV})\end{array}$} & $d \sigma / d E_{T}^{\mathrm{jet} 4}$ & $\begin{array}{l} \pm \text { stat. } \\
\qquad(\mathrm{pb} / \mathrm{C}\end{array}$ & $\begin{array}{l} \pm \text { syst. } \\
\text { eV) }\end{array}$ & \pm E-scale \\
\hline \multicolumn{7}{|c|}{$50 \mathrm{GeV}$} \\
\hline 6.0 & - & 8.5 & 45.4 & \pm 0.4 & $\begin{array}{l}+5.3 \\
-2.4\end{array}$ & $\begin{array}{l}+8.6 \\
-8.6\end{array}$ \\
\hline 8.5 & - & 11.2 & 0.53 & \pm 0.05 & $\begin{array}{l}+0.15 \\
-0.11 \\
\end{array}$ & $\begin{array}{l}+0.11 \\
-0.11 \\
\end{array}$ \\
\hline \multicolumn{7}{|c|}{$M_{4 j} \geq 50 \mathrm{GeV}$} \\
\hline 6.0 & & 8.5 & 32.0 & \pm 0.5 & $\begin{array}{l}+4.5 \\
-3.8\end{array}$ & $\begin{array}{l}+4.9 \\
-4.9\end{array}$ \\
\hline 8.5 & 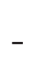 & 11.2 & 5.02 & \pm 0.17 & $\begin{array}{l}+0.37 \\
-0.45\end{array}$ & ${ }_{-0.71}^{+0.71}$ \\
\hline 11.2 & - & 14.2 & 0.81 & \pm 0.07 & $\begin{array}{r}+0.59 \\
-0.24\end{array}$ & $\begin{array}{l}+0.09 \\
{ }_{-0.09}\end{array}$ \\
\hline 14.2 & - & 20.0 & 0.086 & \pm 0.014 & $\begin{array}{l}+0.044 \\
-0.034 \\
\end{array}$ & $\begin{array}{l}+0.004 \\
-0.004 \\
\end{array}$ \\
\hline
\end{tabular}

Table 14: The measured four-jet differential cross-section $d \sigma / d E_{T}^{\text {jet4 }}$ in both the low- and high-mass regions. Other details as described in the caption to Table 2. 


\begin{tabular}{|c|c|c|c|c|c|c|c|c|c|}
\hline$\eta^{\text {jet1 }}$ & range & $d \sigma / d \eta^{\mathrm{jet} 1}$ & \pm stat & $\begin{array}{l} \pm \mathrm{sys} \\
\text { o) }\end{array}$ & \pm E-scale & $\overline{\mathrm{had}}$ & corr. & \multicolumn{2}{|c|}{ MPI corr. } \\
\hline \multicolumn{10}{|c|}{$25 \leq M_{3 j}<50 \mathrm{GeV}$} \\
\hline-1.686 & - $\quad-1.371$ & 3.3 & \pm 0.4 & $\begin{array}{l}+1.4 \\
-1.7\end{array}$ & $\begin{array}{l}+0.5 \\
-0.5\end{array}$ & 0.324 & \pm 0.012 & 1.15 & \pm 0.21 \\
\hline-1.371 & $\begin{array}{ll}- & -1.057\end{array}$ & 36.0 & \pm 1.4 & $\begin{array}{l}+7.8 \\
{ }_{-9.9}\end{array}$ & $\begin{array}{l}+2.9 \\
-2.9\end{array}$ & 0.538 & \pm 0.041 & 1.34 & \pm 0.23 \\
\hline-1.057 & $-\quad-0.743$ & 123 & \pm 2 & $\begin{array}{l}+18 \\
-20\end{array}$ & $\begin{array}{l}+9 \\
-9\end{array}$ & 0.686 & \pm 0.044 & 1.33 & \pm 0.18 \\
\hline-0.743 & $-\quad-0.429$ & 256 & \pm 3 & $\begin{array}{l}+40 \\
-37\end{array}$ & $\begin{array}{l}+19 \\
{ }_{-19}\end{array}$ & 0.763 & \pm 0.025 & 1.35 & \pm 0.19 \\
\hline-0.429 & - $\quad-0.114$ & 394 & \pm 4 & $\begin{array}{l}+55 \\
-51\end{array}$ & $\begin{array}{l}+33 \\
-33\end{array}$ & 0.793 & \pm 0.025 & 1.35 & \pm 0.19 \\
\hline-0.114 & - $\quad 0.200$ & 506 & \pm 4 & $\begin{array}{l}+67 \\
{ }_{-63}\end{array}$ & ${ }_{-51}^{+51}$ & 0.803 & \pm 0.014 & 1.37 & \pm 0.21 \\
\hline 0.200 & - $\quad 0.514$ & 600 & \pm 5 & $\begin{array}{l}+68 \\
-65\end{array}$ & $\begin{array}{l}+65 \\
-65\end{array}$ & 0.820 & \pm 0.009 & 1.39 & \pm 0.21 \\
\hline 0.514 & $\begin{array}{ll}- & 0.829\end{array}$ & 653 & \pm 5 & $\begin{array}{l}+65 \\
-57\end{array}$ & $\begin{array}{l}+74 \\
-74\end{array}$ & 0.816 & \pm 0.008 & 1.43 & \pm 0.22 \\
\hline 0.829 & - $\quad 1.143$ & 631 & \pm 5 & $\begin{array}{l}+54 \\
-49\end{array}$ & $\begin{array}{l}+76 \\
{ }_{-76}\end{array}$ & 0.814 & \pm 0.004 & 1.49 & \pm 0.25 \\
\hline 1.143 & - $\quad 1.457$ & 556 & \pm 4 & $\begin{array}{l}+63 \\
-58\end{array}$ & $\begin{array}{l}+72 \\
-72\end{array}$ & 0.814 & \pm 0.007 & 1.55 & \pm 0.28 \\
\hline 1.457 & - $\quad 1.771$ & 573 & \pm 4 & ${ }_{-50}^{+58}$ & $\begin{array}{l}+85 \\
{ }_{-85}\end{array}$ & 0.821 & \pm 0.003 & 1.64 & \pm 0.31 \\
\hline 1.771 & - 2.086 & 697 & \pm 6 & $\begin{array}{l}+97 \\
-84\end{array}$ & $\begin{array}{l}+103 \\
-103\end{array}$ & 0.829 & \pm 0.002 & 1.75 & \pm 0.36 \\
\hline 2.086 & $-\quad 2.400$ & 790 & \pm 9 & $\begin{array}{l}+186 \\
-186 \\
\end{array}$ & $\begin{array}{l}+107 \\
-107 \\
\end{array}$ & 0.843 & \pm 0.005 & 1.90 & \pm 0.42 \\
\hline \multicolumn{10}{|c|}{$M_{3 j} \geq 50 \mathrm{GeV}$} \\
\hline-1.686 & - $\quad-1.371$ & 2.4 & \pm 0.5 & $\begin{array}{l}+1.7 \\
-1.6\end{array}$ & $\begin{array}{l}+0.6 \\
-0.6\end{array}$ & 0.300 & \pm 0.040 & 1.19 & \pm 0.25 \\
\hline-1.371 & $\begin{array}{ll}- & -1.057\end{array}$ & 14.7 & \pm 1.1 & $\begin{array}{l}+5.5 \\
{ }_{-4.0}\end{array}$ & $\begin{array}{l}+2.0 \\
{ }_{-2.0}\end{array}$ & 0.498 & \pm 0.022 & 1.20 & \pm 0.15 \\
\hline-1.057 & $\begin{array}{ll}- & -0.743\end{array}$ & 42 & \pm 2 & ${ }_{-11}^{+12}$ & $\stackrel{+}{-4}_{-4}$ & 0.648 & \pm 0.030 & 1.13 & \pm 0.10 \\
\hline-0.743 & $\begin{array}{ll}- & -0.429\end{array}$ & 67 & \pm 2 & $\begin{array}{l}+16 \\
-15\end{array}$ & $\begin{array}{l}+6 \\
-6\end{array}$ & 0.757 & \pm 0.019 & 1.10 & \pm 0.10 \\
\hline-0.429 & $\begin{array}{ll}- & -0.114\end{array}$ & 84 & \pm 2 & ${ }_{-16}^{+18}$ & $\begin{array}{l}+7 \\
{ }_{-7}^{+}\end{array}$ & 0.830 & \pm 0.019 & 1.08 & \pm 0.09 \\
\hline-0.114 & - $\quad 0.200$ & 90 & \pm 2 & $\begin{array}{l}+11 \\
-10\end{array}$ & $\begin{array}{l}+8 \\
-8\end{array}$ & 0.863 & \pm 0.010 & 1.06 & \pm 0.06 \\
\hline 0.200 & - $\quad 0.514$ & 99 & \pm 2 & ${ }_{-16}^{+14}$ & $\begin{array}{l}+9 \\
{ }_{-9}^{9}\end{array}$ & 0.867 & \pm 0.008 & 1.06 & \pm 0.07 \\
\hline 0.514 & $\begin{array}{l}-\quad 0.829 \\
\end{array}$ & 92 & \pm 2 & $\begin{array}{l}+10 \\
-9\end{array}$ & $\begin{array}{l}+10 \\
{ }_{-10}\end{array}$ & 0.840 & \pm 0.006 & 1.07 & \pm 0.08 \\
\hline 0.829 & - $\quad 1.143$ & 99 & \pm 2 & $\begin{array}{l}+13 \\
-13\end{array}$ & ${ }_{-11}^{+11}$ & 0.830 & \pm 0.018 & 1.08 & \pm 0.09 \\
\hline 1.143 & $-\quad 1.457$ & 115 & \pm 2 & $\begin{array}{l}+14 \\
-19\end{array}$ & $\begin{array}{l}+14 \\
-14\end{array}$ & 0.812 & \pm 0.026 & 1.11 & \pm 0.12 \\
\hline 1.457 & - $\quad 1.771$ & 145 & \pm 2 & $\begin{array}{l}+17 \\
{ }_{-21}\end{array}$ & $\begin{array}{l}+18 \\
{ }_{-18}^{+18}\end{array}$ & 0.808 & \pm 0.019 & 1.12 & \pm 0.12 \\
\hline 1.771 & - 2.086 & 200 & \pm 3 & $\begin{array}{l}+31 \\
{ }_{-34}\end{array}$ & $\begin{array}{l}+23 \\
{ }_{-23}\end{array}$ & 0.818 & \pm 0.012 & 1.16 & \pm 0.16 \\
\hline 2.086 & $-\quad 2.400$ & 283 & \pm 4 & $\begin{array}{l}+66 \\
-54 \\
\end{array}$ & $\begin{array}{l}+32 \\
-32 \\
\end{array}$ & 0.829 & \pm 0.012 & 1.22 & \pm 0.17 \\
\hline
\end{tabular}

Table 15: The measured three-jet differential cross-section $d \sigma / d \eta^{\mathrm{jet} 1}$ in both the low- and high-mass regions. Other details as described in the caption to Table 2. 


\begin{tabular}{|c|c|c|c|c|c|c|c|c|c|c|}
\hline \multicolumn{3}{|c|}{$\eta^{\text {jet2 }}$ range } & \multirow[t]{2}{*}{$d \sigma / d \eta^{\mathrm{jet} 2}$} & \multicolumn{3}{|c|}{$\begin{array}{l} \pm \text { stat. } \pm \text { syst. } \pm \text { E-scale } \\
(\mathrm{pb})\end{array}$} & \multicolumn{2}{|c|}{ had. corr. } & \multicolumn{2}{|c|}{ MPI corr. } \\
\hline \multicolumn{10}{|c|}{$25 \leq M_{3 j}<50 \mathrm{GeV}$} & \\
\hline-1.686 & - & -1.371 & 9.1 & \pm 0.8 & $\begin{array}{l}+7.4 \\
-3.4\end{array}$ & $\begin{array}{l}+1.8 \\
-1.8\end{array}$ & 0.382 & \pm 0.005 & 1.17 & \pm 0.20 \\
\hline-1.371 & - & -1.057 & 57 & \pm 2 & ${ }_{-10}^{+11}$ & $\begin{array}{l}+9 \\
-9\end{array}$ & 0.592 & \pm 0.019 & 1.35 & \pm 0.27 \\
\hline-1.057 & - & -0.743 & 168 & \pm 3 & $\begin{array}{l}+21 \\
-25\end{array}$ & $\begin{array}{l}+15 \\
-15\end{array}$ & 0.720 & \pm 0.024 & 1.40 & \pm 0.25 \\
\hline-0.743 & - & -0.429 & 282 & \pm 4 & $\begin{array}{l}+39 \\
{ }_{-30}\end{array}$ & $\begin{array}{l}+26 \\
{ }_{-26}\end{array}$ & 0.766 & \pm 0.015 & 1.42 & \pm 0.26 \\
\hline-0.429 & - & -0.114 & 408 & \pm 4 & ${ }_{-44}^{+41}$ & $\begin{array}{l}+39 \\
{ }_{-39}\end{array}$ & 0.780 & \pm 0.012 & 1.43 & \pm 0.25 \\
\hline-0.114 & - & 0.200 & 492 & \pm 4 & $\begin{array}{l}+54 \\
-46\end{array}$ & $\begin{array}{l}+50 \\
-50\end{array}$ & 0.808 & \pm 0.007 & 1.42 & \pm 0.22 \\
\hline 0.200 & - & 0.514 & 574 & \pm 5 & $\begin{array}{l}+66 \\
-57\end{array}$ & $\begin{array}{l}+67 \\
-67\end{array}$ & 0.817 & \pm 0.005 & 1.44 & \pm 0.22 \\
\hline 0.514 & - & 0.829 & 628 & \pm 5 & $\begin{array}{l}+67 \\
-61\end{array}$ & $\begin{array}{l}+73 \\
-73\end{array}$ & 0.817 & \pm 0.003 & 1.45 & \pm 0.21 \\
\hline 0.829 & - & 1.143 & 615 & \pm 5 & $\begin{array}{l}+62 \\
{ }_{-57}\end{array}$ & ${ }_{-72}^{+72}$ & 0.816 & \pm 0.003 & 1.48 & \pm 0.22 \\
\hline 1.143 & - & 1.457 & 550 & \pm 4 & $\begin{array}{l}+40 \\
-34\end{array}$ & $\begin{array}{l}+66 \\
-66\end{array}$ & 0.818 & \pm 0.013 & 1.50 & \pm 0.25 \\
\hline 1.457 & - & 1.771 & 564 & \pm 4 & $\begin{array}{l}+36 \\
-32\end{array}$ & $\begin{array}{l}+77 \\
-77\end{array}$ & 0.819 & \pm 0.012 & 1.56 & \pm 0.29 \\
\hline 1.771 & - & 2.086 & 686 & \pm 6 & $\begin{array}{l}+79 \\
-82\end{array}$ & $\begin{array}{l}+96 \\
-96\end{array}$ & 0.833 & \pm 0.015 & 1.63 & \pm 0.33 \\
\hline 2.086 & - & 2.400 & 767 & \pm 8 & $\begin{array}{l}+183 \\
{ }_{-181}\end{array}$ & $\begin{array}{r}+96 \\
{ }_{-96}\end{array}$ & 0.844 & \pm 0.015 & 1.75 & \pm 0.38 \\
\hline \multicolumn{11}{|c|}{$M_{3 j} \geq 50 \mathrm{GeV}$} \\
\hline-2.000 & - & -1.686 & 0.48 & \pm 0.16 & $\begin{array}{l}+0.44 \\
-0.27\end{array}$ & $\begin{array}{l}+0.18 \\
-0.18\end{array}$ & 0.085 & \pm 0.007 & 1.00 & \pm 0.18 \\
\hline-1.686 & - & -1.371 & 8.2 & \pm 0.7 & $\begin{array}{l}+2.5 \\
-2.5\end{array}$ & $\begin{array}{l}+0.9 \\
{ }_{-0.9}\end{array}$ & 0.347 & \pm 0.021 & 1.20 & \pm 0.22 \\
\hline-1.371 & - & -1.057 & 43 & \pm 2 & $\begin{array}{l}+16 \\
{ }_{-19}\end{array}$ & $\begin{array}{l}+5 \\
-5\end{array}$ & 0.571 & \pm 0.025 & 1.20 & \pm 0.17 \\
\hline-1.057 & - & -0.743 & 70 & \pm 2 & ${ }_{-18}^{+20}$ & ${ }_{-7}^{+7}$ & 0.710 & \pm 0.038 & 1.18 & \pm 0.14 \\
\hline-0.743 & - & -0.429 & 92 & \pm 2 & $\begin{array}{l}+22 \\
-24\end{array}$ & $\begin{array}{l}+11 \\
-11\end{array}$ & 0.783 & \pm 0.014 & 1.14 & \pm 0.12 \\
\hline-0.429 & - & -0.114 & 97 & \pm 2 & $\begin{array}{l}+20 \\
-15\end{array}$ & $\begin{array}{l}+10 \\
{ }_{-10}\end{array}$ & 0.822 & \pm 0.013 & 1.12 & \pm 0.09 \\
\hline-0.114 & - & 0.200 & 96 & \pm 2 & $\begin{array}{l}+12 \\
-12\end{array}$ & $\begin{array}{l}+10 \\
-10\end{array}$ & 0.845 & \pm 0.006 & 1.10 & \pm 0.10 \\
\hline 0.200 & - & 0.514 & 104 & \pm 2 & ${ }_{-13}^{+12}$ & ${ }_{-11}^{+11}$ & 0.852 & \pm 0.007 & 1.09 & \pm 0.08 \\
\hline 0.514 & - & 0.829 & 106 & \pm 2 & $\begin{array}{l}+16 \\
-14\end{array}$ & $\begin{array}{l}+12 \\
-12\end{array}$ & 0.858 & \pm 0.001 & 1.09 & \pm 0.09 \\
\hline 0.829 & - & 1.143 & 108 & \pm 2 & $\begin{array}{l}+14 \\
-17\end{array}$ & ${ }_{-11}^{+11}$ & 0.851 & \pm 0.009 & 1.09 & \pm 0.10 \\
\hline 1.143 & - & 1.457 & 103 & \pm 2 & $\begin{array}{l}+16 \\
-16\end{array}$ & $\begin{array}{l}+11 \\
-11\end{array}$ & 0.846 & \pm 0.011 & 1.09 & \pm 0.10 \\
\hline 1.457 & - & 1.771 & 113 & \pm 2 & $\begin{array}{l}+19 \\
-14\end{array}$ & $\begin{array}{l}+13 \\
-13\end{array}$ & 0.827 & \pm 0.018 & 1.10 & \pm 0.11 \\
\hline 1.771 & - & 2.086 & 157 & \pm 3 & $\begin{array}{l}+26 \\
{ }_{-20}\end{array}$ & ${ }_{-17}^{+17}$ & 0.829 & \pm 0.013 & 1.12 & \pm 0.13 \\
\hline 2.086 & - & 2.400 & 232 & \pm 4 & $\begin{array}{l}+51 \\
-49 \\
\end{array}$ & $\begin{array}{l}+23 \\
-23 \\
\end{array}$ & 0.839 & \pm 0.010 & 1.14 & \pm 0.15 \\
\hline
\end{tabular}

Table 16: The measured three-jet differential cross-section $d \sigma / d \eta^{\text {jet2 }}$ in both the low- and high-mass regions. Other details as described in the caption to Table 2. 


\begin{tabular}{|c|c|c|c|c|c|c|c|c|c|}
\hline \multicolumn{2}{|c|}{$\eta^{\text {jet3 }}$ range } & \multirow[t]{2}{*}{$d \sigma / d \eta^{\mathrm{jet} 3}$} & \multicolumn{3}{|c|}{$\begin{array}{l} \pm \text { stat. } \pm \text { syst. } \pm \text { E-scale } \\
(\mathrm{pb})\end{array}$} & \multicolumn{2}{|c|}{ had. corr. } & \multicolumn{2}{|c|}{ MPI corr. } \\
\hline \multicolumn{9}{|c|}{$25 \leq M_{3 j}<50 \mathrm{GeV}$} & \\
\hline-2.000 & $-\quad-1.686$ & 0.33 & \pm 0.23 & $\begin{array}{l}+0.49 \\
-0.33\end{array}$ & $\begin{array}{l}+0.08 \\
-0.08\end{array}$ & 0.090 & \pm 0.045 & 1.42 & \pm 0.82 \\
\hline-1.686 & - $\quad-1.371$ & 15.2 & \pm 1.0 & $\begin{array}{l}+3.4 \\
-3.5\end{array}$ & $\begin{array}{l}+1.3 \\
-1.3\end{array}$ & 0.388 & \pm 0.019 & 1.30 & \pm 0.33 \\
\hline-1.371 & $-\quad-1.057$ & 80 & \pm 2 & $\begin{array}{l}+16 \\
-13\end{array}$ & $\begin{array}{l}+7 \\
-7\end{array}$ & 0.631 & \pm 0.004 & 1.33 & \pm 0.33 \\
\hline-1.057 & $-\quad-0.743$ & 187 & \pm 3 & $\begin{array}{l}+25 \\
-24\end{array}$ & ${ }_{-17}^{+17}$ & 0.738 & \pm 0.007 & 1.38 & \pm 0.34 \\
\hline-0.743 & $\begin{array}{ll}- & -0.429\end{array}$ & 308 & \pm 4 & $\begin{array}{l}+37 \\
-39\end{array}$ & $\begin{array}{l}+29 \\
-29\end{array}$ & 0.791 & \pm 0.002 & 1.41 & \pm 0.31 \\
\hline-0.429 & - $\quad-0.114$ & 396 & \pm 4 & $\begin{array}{l}+46 \\
-35\end{array}$ & $\begin{array}{l}+42 \\
-42\end{array}$ & 0.800 & \pm 0.006 & 1.44 & \pm 0.30 \\
\hline-0.114 & - $\quad 0.200$ & 474 & \pm 4 & $\begin{array}{l}+49 \\
-44\end{array}$ & $\begin{array}{l}+53 \\
-53\end{array}$ & 0.826 & \pm 0.009 & 1.46 & \pm 0.27 \\
\hline 0.200 & - $\quad 0.514$ & 560 & \pm 5 & $\begin{array}{l}+67 \\
-60\end{array}$ & $\begin{array}{l}+67 \\
{ }_{-67}\end{array}$ & 0.829 & \pm 0.015 & 1.49 & \pm 0.26 \\
\hline 0.514 & - $\quad 0.829$ & 616 & \pm 5 & $\begin{array}{l}+73 \\
-74\end{array}$ & $\begin{array}{l}+72 \\
{ }_{-72}\end{array}$ & 0.818 & \pm 0.000 & 1.51 & \pm 0.22 \\
\hline 0.829 & - $\quad 1.143$ & 605 & \pm 5 & $\begin{array}{l}+67 \\
-58\end{array}$ & $\begin{array}{l}+71 \\
-71\end{array}$ & 0.807 & \pm 0.010 & 1.52 & \pm 0.21 \\
\hline 1.143 & - $\quad 1.457$ & 538 & \pm 4 & $\begin{array}{l}+38 \\
-29\end{array}$ & $\begin{array}{l}+64 \\
-64\end{array}$ & 0.806 & \pm 0.017 & 1.50 & \pm 0.19 \\
\hline 1.457 & - $\quad 1.771$ & 559 & \pm 4 & ${ }_{-30}^{+34}$ & $\begin{array}{l}+72 \\
{ }_{-72}\end{array}$ & 0.808 & \pm 0.022 & 1.52 & \pm 0.21 \\
\hline 1.771 & - 2.086 & 685 & \pm 5 & $\begin{array}{l}+79 \\
-75\end{array}$ & ${ }_{-91}^{+91}$ & 0.822 & \pm 0.032 & 1.57 & \pm 0.24 \\
\hline 2.086 & $-\quad 2.400$ & 793 & \pm 8 & $\begin{array}{l}+183 \\
-177 \\
\end{array}$ & $\begin{array}{l}+103 \\
-103 \\
\end{array}$ & 0.835 & \pm 0.030 & 1.66 & \pm 0.29 \\
\hline \multicolumn{10}{|c|}{$M_{3 j} \geq 50 \mathrm{GeV}$} \\
\hline-2.000 & $-\quad-1.686$ & 1.9 & \pm 0.3 & $\begin{array}{l}+1.2 \\
-1.2\end{array}$ & $\begin{array}{l}+1.0 \\
-1.0\end{array}$ & 0.145 & \pm 0.014 & 1.01 & \pm 0.11 \\
\hline-1.686 & $\begin{array}{ll}- & -1.371\end{array}$ & 26.1 & \pm 1.3 & $\begin{array}{l}+9.5 \\
-6.9\end{array}$ & $\begin{array}{l}+3.1 \\
{ }_{-3.1}\end{array}$ & 0.456 & \pm 0.004 & 1.19 & \pm 0.22 \\
\hline-1.371 & - -1.057 & 70 & \pm 2 & ${ }_{-16}^{+14}$ & $\begin{array}{l}+9 \\
-9\end{array}$ & 0.673 & \pm 0.003 & 1.20 & \pm 0.22 \\
\hline-1.057 & $-\quad-0.743$ & 104 & \pm 2 & $\begin{array}{l}+26 \\
-22\end{array}$ & $\begin{array}{l}+11 \\
-11\end{array}$ & 0.788 & \pm 0.001 & 1.18 & \pm 0.19 \\
\hline-0.743 & $\begin{array}{ll}- & -0.429\end{array}$ & 100 & \pm 2 & $\begin{array}{l}+20 \\
-16\end{array}$ & $\begin{array}{l}+10 \\
-10\end{array}$ & 0.840 & \pm 0.005 & 1.14 & \pm 0.15 \\
\hline-0.429 & $\begin{array}{ll}- & -0.114\end{array}$ & 97 & \pm 2 & $\begin{array}{l}+12 \\
-16\end{array}$ & $\begin{array}{l}+10 \\
-10\end{array}$ & 0.876 & \pm 0.014 & 1.13 & \pm 0.14 \\
\hline-0.114 & $\begin{array}{l}-\quad 0.200 \\
\end{array}$ & 92 & \pm 2 & ${ }_{-13}^{+11}$ & $\begin{array}{l}+10 \\
-10\end{array}$ & 0.901 & \pm 0.033 & 1.11 & \pm 0.12 \\
\hline 0.200 & - $\quad 0.514$ & 89 & \pm 2 & $\begin{array}{l}+19 \\
-15\end{array}$ & $\begin{array}{l}+9 \\
-9\end{array}$ & 0.900 & \pm 0.036 & 1.10 & \pm 0.11 \\
\hline 0.514 & - $\quad 0.829$ & 98 & \pm 2 & $\begin{array}{l}+17 \\
-16\end{array}$ & $\begin{array}{l}+11 \\
-11\end{array}$ & 0.856 & \pm 0.022 & 1.12 & \pm 0.10 \\
\hline 0.829 & - $\quad 1.143$ & 95 & \pm 2 & $\begin{array}{l}+16 \\
-14\end{array}$ & $\begin{array}{l}+10 \\
-10\end{array}$ & 0.840 & \pm 0.002 & 1.11 & \pm 0.09 \\
\hline 1.143 & - $\quad 1.457$ & 89 & \pm 2 & $\begin{array}{l}+11 \\
-12\end{array}$ & $\begin{array}{l}+10 \\
{ }_{-10}\end{array}$ & 0.819 & \pm 0.012 & 1.12 & \pm 0.08 \\
\hline 1.457 & - 1.771 & 103 & \pm 2 & $\begin{array}{l}+16 \\
{ }_{-15}\end{array}$ & ${ }_{-12}^{+12}$ & 0.815 & \pm 0.023 & 1.11 & \pm 0.06 \\
\hline 1.771 & - 2.086 & 138 & \pm 3 & $\begin{array}{l}+22 \\
-21\end{array}$ & $\begin{array}{l}+16 \\
-16\end{array}$ & 0.817 & \pm 0.030 & 1.11 & \pm 0.08 \\
\hline 2.086 & $\begin{array}{l}-\quad 2.400 \\
\end{array}$ & 222 & \pm 4 & $\begin{array}{l}+44 \\
-49 \\
\end{array}$ & $\begin{array}{l}+19 \\
{ }_{-19}^{+19}\end{array}$ & 0.820 & \pm 0.042 & 1.12 & \pm 0.07 \\
\hline
\end{tabular}

Table 17: The measured three-jet differential cross-section $d \sigma / d \eta^{\text {jet3 }}$ in both the low- and high-mass regions. Other details as described in the caption to Table 2. 


\begin{tabular}{|c|c|c|c|c|c|}
\hline \multicolumn{2}{|c|}{$\eta^{\text {jet1 }}$ range } & $d \sigma / d \eta^{\text {jet1 }}$ & \multicolumn{2}{|c|}{$\begin{array}{c} \pm \text { stat. } \pm \text { syst. } \\
\text { (pb) }\end{array}$} & \pm E-scale \\
\hline \multicolumn{6}{|c|}{$25 \leq M_{4 j}<50 \mathrm{GeV}$} \\
\hline-1.371 & $-\quad-1.057$ & 0.61 & \pm 0.09 & $\begin{array}{l}0.91 \\
{ }_{-0.36}\end{array}$ & $\begin{array}{l}+0.08 \\
{ }_{-0.08}\end{array}$ \\
\hline-1.057 & - $\quad-0.743$ & 1.76 & \pm 0.23 & $\begin{array}{l}+0.85 \\
-0.67\end{array}$ & ${ }_{-0.30}^{+0.30}$ \\
\hline-0.743 & - $\quad-0.429$ & 6.1 & \pm 0.4 & ${ }_{-1.5}^{+1.0}$ & ${ }_{-1.0}^{+1.0}$ \\
\hline-0.429 & - $\quad-0.114$ & 13.2 & \pm 0.6 & $\begin{array}{l}+2.2 \\
{ }_{-3.0}\end{array}$ & ${ }_{-2.1}^{+2.1}$ \\
\hline-0.114 & - $\quad 0.200$ & 21.9 & \pm 0.8 & $\begin{array}{l}+4.4 \\
{ }_{-3.6}\end{array}$ & $\begin{array}{l}+4.0 \\
{ }_{-4.0}\end{array}$ \\
\hline 0.200 & - $\quad 0.514$ & 36.7 & \pm 1.1 & $\begin{array}{l}+5.7 \\
-6.7\end{array}$ & $\begin{array}{l}+6.4 \\
-6.4\end{array}$ \\
\hline 0.514 & - $\quad 0.829$ & 43.3 & \pm 1.3 & $\begin{array}{l}+6.0 \\
-4.6\end{array}$ & $\begin{array}{l}+7.5 \\
-7.5\end{array}$ \\
\hline 0.829 & - 1.143 & 55 & \pm 1 & $\begin{array}{l}+12 \\
+12\end{array}$ & $\begin{array}{l}+9 \\
+9\end{array}$ \\
\hline 1.143 & - $\quad 1.457$ & 43 & \pm 1 & ${ }_{-8}^{+10}$ & $\begin{array}{l}+8 \\
-8\end{array}$ \\
\hline 1.457 & - $\quad 1.771$ & 44.5 & \pm 1.1 & $\begin{array}{l}+8.1 \\
{ }_{-4.1}\end{array}$ & $\begin{array}{l}+9.5 \\
-9.5\end{array}$ \\
\hline 1.771 & - 2.086 & 54 & \pm 2 & ${ }_{-9}^{+11}$ & ${ }_{-12}^{+12}$ \\
\hline 2.086 & $-\quad 2.400$ & 68 & \pm 3 & $\begin{array}{l}+25 \\
-24 \\
\end{array}$ & $\begin{array}{l}+13 \\
{ }_{-13}\end{array}$ \\
\hline \multicolumn{6}{|c|}{$M_{4 j} \geq 50 \mathrm{GeV}$} \\
\hline-1.371 & $-\quad-1.057$ & 1.10 & \pm 0.29 & $\begin{array}{l}+0.63 \\
{ }_{-0.70}\end{array}$ & $\begin{array}{l}+0.14 \\
-0.14\end{array}$ \\
\hline-1.057 & - $\quad-0.743$ & 4.9 & \pm 0.6 & $\begin{array}{l}+2.3 \\
-1.4\end{array}$ & ${ }_{-0.6}^{+0.6}$ \\
\hline-0.743 & - -0.429 & 10.9 & \pm 0.8 & $\begin{array}{l}+3.7 \\
-2.3\end{array}$ & $\begin{array}{l}+1.2 \\
{ }_{-1.2}\end{array}$ \\
\hline-0.429 & $\begin{array}{ll}- & -0.114\end{array}$ & 20.6 & \pm 0.9 & $\begin{array}{l}+5.1 \\
{ }_{-7.1}\end{array}$ & ${ }_{-2.5}^{+2.5}$ \\
\hline-0.114 & - $\quad 0.200$ & 20.9 & \pm 1.0 & $\begin{array}{l}+3.7 \\
{ }_{-2.8}\end{array}$ & $\begin{array}{l}+2.7 \\
-2.7\end{array}$ \\
\hline 0.200 & - 0.514 & 24.0 & \pm 1.1 & ${ }_{-2.5}^{+4.0}$ & $\begin{array}{l}+3.3 \\
{ }_{-3.3}\end{array}$ \\
\hline 0.514 & - $\quad 0.829$ & 24.4 & \pm 1.1 & $\begin{array}{l}+4.8 \\
-2.5\end{array}$ & $\begin{array}{l}+3.4 \\
-3.4\end{array}$ \\
\hline 0.829 & - $\quad 1.143$ & 27.8 & \pm 1.2 & $\begin{array}{l}+3.5 \\
-3.4\end{array}$ & $\begin{array}{l}+3.6 \\
-3.6\end{array}$ \\
\hline 1.143 & - $\quad 1.457$ & 28.0 & \pm 1.0 & $\begin{array}{l}+4.2 \\
{ }_{-4.7}\end{array}$ & $\begin{array}{l}+4.3 \\
{ }_{-4.3}\end{array}$ \\
\hline 1.457 & - $\quad 1.771$ & 37.0 & \pm 1.3 & $\begin{array}{l}+5.9 \\
{ }_{-3.7}\end{array}$ & $\begin{array}{l}+6.4 \\
{ }_{-6.4}\end{array}$ \\
\hline 1.771 & - 2.086 & 47.0 & \pm 1.7 & $\begin{array}{l}+7.6 \\
-8.9\end{array}$ & $\begin{array}{l}+8.6 \\
-8.6\end{array}$ \\
\hline 2.086 & $\begin{array}{l}-\quad 2.400 \\
\end{array}$ & 63 & \pm 2 & $\begin{array}{l}+16 \\
-17 \\
\end{array}$ & ${ }_{-11}^{+11}$ \\
\hline
\end{tabular}

Table 18: The measured four-jet differential cross-section $d \sigma / d \eta^{\text {jet1 }}$ in both the low- and high-mass regions. Other details as described in the caption to Table 2. 


\begin{tabular}{|c|c|c|c|c|c|c|}
\hline \multicolumn{3}{|c|}{$\eta^{\text {jet2 }}$ range } & $d \sigma / d \eta^{\text {jet2 }}$ & $\begin{array}{r} \pm \text { stat. } \\
(\mathrm{p}\end{array}$ & $\begin{array}{l}\text { 土syst } \\
\text { p) }\end{array}$ & \pm E-scale \\
\hline \multicolumn{7}{|c|}{$\mathrm{GeV}$} \\
\hline-1.371 & . & -1.057 & 0.67 & \pm 0.18 & $\begin{array}{l}+0.43 \\
-0.50\end{array}$ & $\begin{array}{l}+0.11 \\
{ }_{-0.11}\end{array}$ \\
\hline-1.057 & 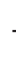 & -0.743 & 3.15 & \pm 0.37 & $\begin{array}{l}+0.87 \\
-0.73\end{array}$ & $\begin{array}{l}+0.35 \\
-0.35\end{array}$ \\
\hline-0.743 & 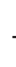 & -0.429 & 11.3 & \pm 0.5 & $\begin{array}{l}+6.5 \\
{ }_{-6.9}\end{array}$ & $\begin{array}{l}+1.0 \\
{ }_{-1.0}\end{array}$ \\
\hline-0.429 & - & -0.114 & 17.0 & \pm 0.8 & $\begin{array}{l}+2.4 \\
-2.8\end{array}$ & $\begin{array}{l}+1.9 \\
{ }_{-1.9}\end{array}$ \\
\hline-0.114 & 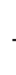 & 0.200 & 23.5 & \pm 0.9 & $\begin{array}{l}+4.1 \\
-3.6\end{array}$ & $\begin{array}{l}+3.5 \\
-3.5\end{array}$ \\
\hline 0.200 & 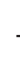 & 0.514 & 37.9 & \pm 1.2 & $\begin{array}{l}+4.9 \\
-5.8\end{array}$ & $\begin{array}{l}+6.3 \\
{ }_{-6.3}\end{array}$ \\
\hline 0.514 & . & 0.829 & 42.4 & \pm 1.3 & $\begin{array}{l}+4.9 \\
-5.7\end{array}$ & $\begin{array}{l}+7.5 \\
-7.5\end{array}$ \\
\hline 0.829 & 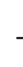 & 1.143 & 46.2 & \pm 1.3 & $\begin{array}{l}+4.2 \\
{ }_{-6.4}\end{array}$ & $\begin{array}{l}+9.0 \\
{ }_{-9.0}\end{array}$ \\
\hline 1.143 & 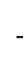 & 1.457 & 40.3 & \pm 1.1 & $\begin{array}{l}+8.7 \\
-6.9\end{array}$ & $\begin{array}{l}+8.3 \\
-8.3\end{array}$ \\
\hline 1.457 & 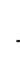 & 1.771 & 43.3 & \pm 1.1 & $\begin{array}{l}+8.7 \\
-5.5\end{array}$ & $\begin{array}{l}+9.0 \\
{ }_{-9.0}\end{array}$ \\
\hline 1.771 & 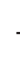 & 2.086 & 52 & \pm 1 & ${ }_{-7}^{+10}$ & ${ }_{-11}^{+11}$ \\
\hline 2.086 & - & 2.400 & 57 & \pm 2 & $\begin{array}{l}+19 \\
{ }_{-15}^{+19}\end{array}$ & $\begin{array}{l}+11 \\
{ }_{-11}^{11}\end{array}$ \\
\hline \multicolumn{7}{|c|}{$M_{4 j} \geq 50 \mathrm{GeV}$} \\
\hline-1.686 & 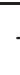 & -1.371 & 0.08 & \pm 0.04 & $\begin{array}{l}+0.21 \\
-0.08\end{array}$ & $\begin{array}{l}+0.03 \\
{ }_{-0.03}\end{array}$ \\
\hline-1.371 & . & -1.057 & 3.1 & \pm 0.3 & $\begin{array}{l}+5.2 \\
-1.3\end{array}$ & $\begin{array}{l}+0.6 \\
-0.6\end{array}$ \\
\hline-1.057 & 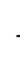 & -0.743 & 7.6 & \pm 0.7 & $\begin{array}{l}+1.9 \\
{ }_{-1.4}\end{array}$ & $\begin{array}{l}+1.0 \\
{ }_{-1.0}\end{array}$ \\
\hline-0.743 & 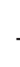 & -0.429 & 15.2 & \pm 0.9 & $\begin{array}{l}+2.3 \\
{ }_{-1.7}\end{array}$ & $\begin{array}{l}+2.5 \\
{ }_{-2.5}\end{array}$ \\
\hline-0.429 & 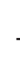 & -0.114 & 22.9 & \pm 1.2 & $\begin{array}{l}+4.2 \\
{ }_{-6.0}\end{array}$ & $\begin{array}{l}+3.5 \\
{ }_{-3.5}\end{array}$ \\
\hline-0.114 & . & 0.200 & 20.9 & \pm 1.1 & ${ }_{-2.5}^{+3.8}$ & ${ }_{-2.5}^{+2.5}$ \\
\hline 0.200 & & 0.514 & 26.4 & \pm 1.2 & $\begin{array}{l}+2.7 \\
-5.2\end{array}$ & $\begin{array}{l}+3.2 \\
-3.2\end{array}$ \\
\hline 0.514 & . & 0.829 & 33.8 & \pm 1.3 & $\begin{array}{l}+5.6 \\
{ }_{-9.4}\end{array}$ & $\begin{array}{l}+3.9 \\
-3.9\end{array}$ \\
\hline 0.829 & & 1.143 & 28.1 & \pm 1.3 & $\begin{array}{l}+5.0 \\
{ }_{-3.0}\end{array}$ & $\begin{array}{l}+3.7 \\
-3.7\end{array}$ \\
\hline 1.143 & 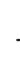 & 1.457 & 25.4 & \pm 1.1 & $\begin{array}{l}+5.5 \\
-4.7\end{array}$ & $\begin{array}{l}+3.6 \\
-3.6\end{array}$ \\
\hline 1.457 & . & 1.771 & 29.4 & \pm 1.1 & $\begin{array}{l}+4.1 \\
-3.6\end{array}$ & $\begin{array}{l}+4.4 \\
-4.4\end{array}$ \\
\hline 1.771 & 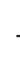 & 2.086 & 43.3 & \pm 1.6 & $\begin{array}{l}+8.4 \\
-7.0\end{array}$ & $\begin{array}{l}+6.7 \\
-6.7\end{array}$ \\
\hline 2.086 & 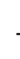 & 2.400 & 51 & \pm 2 & $\begin{array}{l}+15 \\
-12\end{array}$ & $\begin{array}{l}+10 \\
{ }_{-10}\end{array}$ \\
\hline
\end{tabular}

Table 19: The measured four-jet differential cross-section $d \sigma / d \eta^{\mathrm{jet} 2}$ in both the low- and high-mass regions. Other details as described in the caption to Table 2. 


\begin{tabular}{|c|c|c|c|c|c|}
\hline \multicolumn{2}{|c|}{$\eta^{\text {jet3 }}$ range } & $d \sigma / d \eta^{\text {jet3 }}$ & \multicolumn{3}{|c|}{$(\mathrm{pb})$} \\
\hline \multicolumn{6}{|c|}{$25 \leq M_{4 j}<50 \mathrm{GeV}$} \\
\hline-1.371 & $-\quad-1.057$ & 0.5 & \pm 0.1 & $\begin{array}{l}+1.1 \\
-0.4\end{array}$ & $\begin{array}{l}+0.3 \\
-0.3\end{array}$ \\
\hline-1.057 & $-\quad-0.743$ & 3.7 & \pm 0.4 & $\begin{array}{l}+1.1 \\
{ }_{-0.9}\end{array}$ & $\begin{array}{l}+0.9 \\
-0.9\end{array}$ \\
\hline-0.743 & $-\quad-0.429$ & 9.4 & \pm 0.6 & $\begin{array}{l}+1.9 \\
-1.5\end{array}$ & $\begin{array}{l}+1.2 \\
-1.2\end{array}$ \\
\hline-0.429 & $-\quad-0.114$ & 20.0 & \pm 0.8 & ${ }_{-7.8}^{+7.2}$ & $\begin{array}{l}+3.2 \\
{ }_{-3.2}\end{array}$ \\
\hline-0.114 & - $\quad 0.200$ & 26.2 & \pm 0.9 & ${ }_{-3.3}^{+2.6}$ & $\begin{array}{l}+4.6 \\
{ }_{-4.6}\end{array}$ \\
\hline 0.200 & - 0.514 & 37.2 & \pm 1.2 & $\begin{array}{l}+6.4 \\
-4.4\end{array}$ & $\begin{array}{l}+6.5 \\
-6.5\end{array}$ \\
\hline 0.514 & $\begin{array}{ll}- & 0.829\end{array}$ & 45.7 & \pm 1.4 & $\begin{array}{l}+4.3 \\
-5.8\end{array}$ & $\begin{array}{l}+7.8 \\
-7.8\end{array}$ \\
\hline 0.829 & - 1.143 & 47.8 & \pm 1.4 & $\begin{array}{l}+5.0 \\
-5.6\end{array}$ & $\begin{array}{l}+8.5 \\
-8.5\end{array}$ \\
\hline 1.143 & - $\quad 1.457$ & 37.8 & \pm 1.0 & $\begin{array}{l}+8.2 \\
-4.1\end{array}$ & $\begin{array}{l}+7.3 \\
-7.3\end{array}$ \\
\hline 1.457 & - $\quad 1.771$ & 40.0 & \pm 1.0 & $\begin{array}{l}+7.2 \\
-5.5\end{array}$ & $\begin{array}{l}+8.6 \\
-8.6\end{array}$ \\
\hline 1.771 & - 2.086 & 51 & \pm 1 & $\begin{array}{l}+8 \\
-6\end{array}$ & ${ }_{-11}^{+11}$ \\
\hline 2.086 & $-\quad 2.400$ & 61 & \pm 2 & $\begin{array}{l}+16 \\
-19 \\
\end{array}$ & $\begin{array}{l}+13 \\
-13\end{array}$ \\
\hline \multicolumn{6}{|c|}{$M_{4 j} \geq 50 \mathrm{GeV}$} \\
\hline-1.686 & - -1.371 & 0.59 & \pm 0.20 & $\begin{array}{l}+0.97 \\
-0.59\end{array}$ & $\begin{array}{l}+0.28 \\
-0.28\end{array}$ \\
\hline-1.371 & $-\quad-1.057$ & 6.1 & \pm 0.6 & $\begin{array}{l}+2.0 \\
-2.0\end{array}$ & $\begin{array}{l}+1.4 \\
+1.4\end{array}$ \\
\hline-1.057 & $-\quad-0.743$ & 19 & \pm 1 & $\begin{array}{l}+5 \\
-10\end{array}$ & $\begin{array}{l}+3 \\
{ }_{-3}^{3}\end{array}$ \\
\hline-0.743 & $\begin{array}{ll}- & -0.429\end{array}$ & 20.4 & \pm 1.1 & $\begin{array}{l}+4.6 \\
{ }_{-4.3}\end{array}$ & $\begin{array}{l}+4.6 \\
{ }_{-4.6}\end{array}$ \\
\hline-0.429 & $-\quad-0.114$ & 21.0 & \pm 1.1 & $\begin{array}{l}+4.0 \\
{ }_{-3.4}^{4}\end{array}$ & $\begin{array}{l}+3.9 \\
-3.9\end{array}$ \\
\hline-0.114 & - 0.200 & 22.7 & \pm 1.2 & $\begin{array}{l}+4.8 \\
-4.3\end{array}$ & $\begin{array}{l}+3.6 \\
-3.6\end{array}$ \\
\hline 0.200 & - $\quad 0.514$ & 24.8 & \pm 1.2 & $\begin{array}{l}+6.0 \\
-4.1\end{array}$ & $\begin{array}{l}+3.7 \\
-3.7\end{array}$ \\
\hline 0.514 & - $\quad 0.829$ & 27.6 & \pm 1.3 & $\begin{array}{l}+3.8 \\
-3.4\end{array}$ & $\begin{array}{l}+4.1 \\
{ }_{-4.1}^{+}\end{array}$ \\
\hline 0.829 & - 1.143 & 27.3 & \pm 1.3 & $\begin{array}{l}+6.3 \\
{ }_{-4.1}\end{array}$ & $\begin{array}{l}+4.1 \\
{ }_{-4.1}\end{array}$ \\
\hline 1.143 & - $\quad 1.457$ & 24.0 & \pm 1.1 & $\begin{array}{l}+4.1 \\
-2.7\end{array}$ & $\begin{array}{l}+3.9 \\
-3.9\end{array}$ \\
\hline 1.457 & - $\quad 1.771$ & 26.3 & \pm 1.0 & $\begin{array}{l}+4.3 \\
-2.7\end{array}$ & $\begin{array}{l}+3.9 \\
-3.9\end{array}$ \\
\hline 1.771 & - 2.086 & 33.5 & \pm 1.4 & $\begin{array}{l}+4.3 \\
-2.9\end{array}$ & $\begin{array}{l}+4.8 \\
-4.8\end{array}$ \\
\hline 2.086 & $\begin{array}{l}-\quad 2.400 \\
\end{array}$ & 55 & \pm 2 & ${ }_{-13}^{+11}$ & $\stackrel{+5}{+5}$ \\
\hline
\end{tabular}

Table 20: The measured four-jet differential cross-section $d \sigma / d \eta^{\text {jet3 }}$ in both the low- and high-mass regions. Other details as described in the caption to Table 2. 


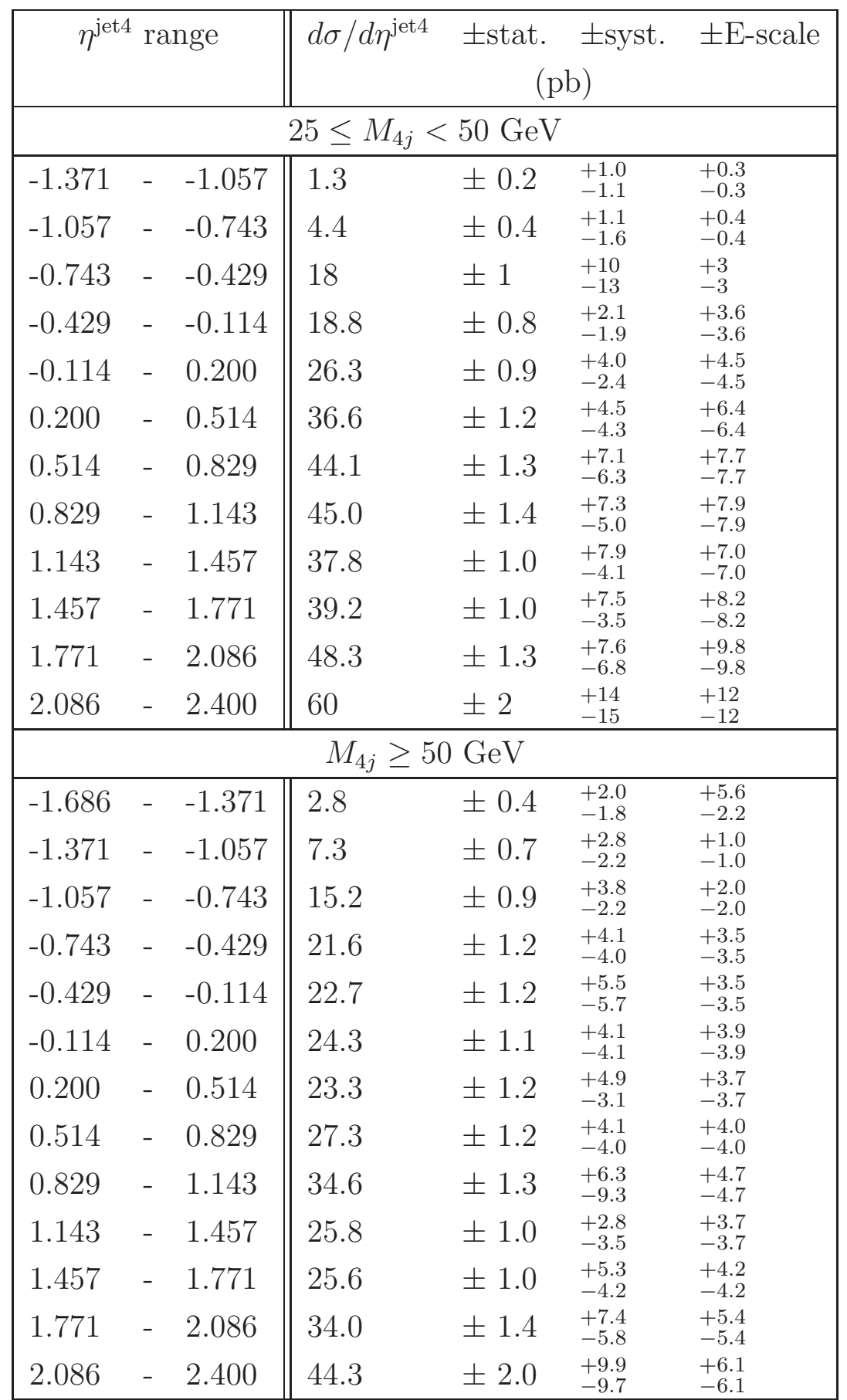

Table 21: The measured four-jet differential cross-section $d \sigma / d \eta^{\mathrm{jet} 4}$ in both the low- and high-mass regions. Other details as described in the caption to Table 2. 


\begin{tabular}{|c|c|c|c|c|c|c|c|c|c|c|}
\hline \multicolumn{3}{|c|}{$\cos \left(\psi_{3}\right)$ range } & \multirow[t]{2}{*}{$d \sigma / d \cos \left(\psi_{3}\right)$} & \multicolumn{3}{|c|}{$\begin{array}{l} \pm \text { stat. } \pm \text { syst. } \pm \text { E-scale } \\
(\mathrm{pb})\end{array}$} & \multicolumn{2}{|c|}{ had. corr. } & \multicolumn{2}{|c|}{ MPI corr. } \\
\hline \multicolumn{10}{|c|}{$25 \leq M_{3 j}<50 \mathrm{GeV}$} & \\
\hline-1.00 & - & -0.88 & 1494 & \pm 13 & $\begin{array}{l}+217 \\
-175\end{array}$ & $\begin{array}{l}+188 \\
-188\end{array}$ & 0.864 & \pm 0.012 & 1.76 & \pm 0.43 \\
\hline-0.88 & - & -0.72 & 856 & \pm 9 & $\begin{array}{l}+117 \\
-105\end{array}$ & $\begin{array}{l}+107 \\
-107\end{array}$ & 0.821 & \pm 0.017 & 1.51 & \pm 0.28 \\
\hline-0.72 & - & -0.56 & 804 & \pm 8 & ${ }_{-77}^{+77}$ & $\begin{array}{l}+99 \\
{ }_{-99}\end{array}$ & 0.793 & \pm 0.019 & 1.43 & \pm 0.20 \\
\hline-0.560 & - & -0.336 & 766 & \pm 7 & $\begin{array}{l}+75 \\
{ }_{-76}\end{array}$ & $\begin{array}{l}+94 \\
{ }_{-94}\end{array}$ & 0.776 & \pm 0.008 & 1.43 & \pm 0.19 \\
\hline-0.336 & - & -0.112 & 759 & \pm 7 & $\begin{array}{l}+70 \\
-64\end{array}$ & $\begin{array}{l}+94 \\
-94\end{array}$ & 0.763 & \pm 0.005 & 1.42 & \pm 0.20 \\
\hline-0.112 & - & 0.112 & 746 & \pm 6 & $\begin{array}{l}+70 \\
-57\end{array}$ & $\begin{array}{l}+92 \\
-92\end{array}$ & 0.761 & \pm 0.006 & 1.41 & \pm 0.19 \\
\hline 0.112 & - & 0.336 & 812 & \pm 7 & $\begin{array}{l}+80 \\
{ }_{-80}\end{array}$ & $\begin{array}{l}+98 \\
{ }_{-98}\end{array}$ & 0.767 & \pm 0.012 & 1.42 & \pm 0.20 \\
\hline 0.336 & - & 0.560 & 851 & \pm 7 & ${ }_{-98}^{+101}$ & $\begin{array}{l}+99 \\
{ }_{-99}\end{array}$ & 0.780 & \pm 0.015 & 1.48 & \pm 0.22 \\
\hline 0.56 & - & 0.72 & 886 & \pm 9 & $\begin{array}{l}+99 \\
-103\end{array}$ & ${ }_{-100}^{+100}$ & 0.809 & \pm 0.017 & 1.48 & \pm 0.22 \\
\hline 0.72 & - & 0.88 & 898 & \pm 9 & $\begin{array}{l}+114 \\
-107\end{array}$ & $\begin{array}{l}+102 \\
-102\end{array}$ & 0.839 & \pm 0.013 & 1.51 & \pm 0.27 \\
\hline 0.88 & - & 1.00 & 1475 & \pm 13 & ${ }_{-196}^{+212}$ & $\begin{array}{r}+173 \\
-173 \\
\end{array}$ & 0.894 & \pm 0.006 & 1.64 & \pm 0.38 \\
\hline \multicolumn{11}{|c|}{$M_{3 j} \geq 50 \mathrm{GeV}$} \\
\hline-1.00 & - & -0.88 & 542 & \pm 9 & $\begin{array}{l}+99 \\
-94\end{array}$ & $\begin{array}{l}+55 \\
-55\end{array}$ & 0.824 & \pm 0.018 & 1.15 & \pm 0.15 \\
\hline-0.88 & - & -0.72 & 263 & \pm 5 & $\begin{array}{l}+44 \\
-45\end{array}$ & $\begin{array}{l}+29 \\
-29\end{array}$ & 0.812 & \pm 0.031 & 1.11 & \pm 0.11 \\
\hline-0.72 & - & -0.56 & 215 & \pm 5 & $\begin{array}{l}+38 \\
-40\end{array}$ & $\begin{array}{l}+25 \\
-25\end{array}$ & 0.807 & \pm 0.021 & 1.10 & \pm 0.10 \\
\hline-0.560 & - & -0.336 & 164 & \pm 3 & $\begin{array}{l}+26 \\
-24\end{array}$ & $\begin{array}{l}+19 \\
{ }_{-19}^{19}\end{array}$ & 0.790 & \pm 0.026 & 1.10 & \pm 0.09 \\
\hline-0.336 & - & -0.112 & 156 & \pm 3 & $\begin{array}{l}+31 \\
{ }_{-30}\end{array}$ & $\begin{array}{l}+18 \\
{ }_{-18}\end{array}$ & 0.793 & \pm 0.012 & 1.10 & \pm 0.10 \\
\hline-0.112 & - & 0.112 & 149 & \pm 3 & $\begin{array}{l}+33 \\
-27\end{array}$ & $\begin{array}{l}+17 \\
-17\end{array}$ & 0.785 & \pm 0.013 & 1.11 & \pm 0.11 \\
\hline 0.112 & - & 0.336 & 143 & \pm 3 & $\begin{array}{l}+25 \\
-22\end{array}$ & $\begin{array}{l}+15 \\
-15\end{array}$ & 0.784 & \pm 0.009 & 1.12 & \pm 0.11 \\
\hline 0.336 & - & 0.560 & 151 & \pm 3 & $\begin{array}{l}+25 \\
-28\end{array}$ & $\begin{array}{l}+16 \\
-16\end{array}$ & 0.802 & \pm 0.017 & 1.12 & \pm 0.11 \\
\hline 0.56 & - & 0.72 & 169 & \pm 4 & $\begin{array}{l}+32 \\
-34\end{array}$ & ${ }_{-17}^{+17}$ & 0.823 & \pm 0.015 & 1.10 & \pm 0.11 \\
\hline 0.72 & - & 0.88 & 217 & \pm 5 & $\begin{array}{l}+39 \\
{ }_{-45}\end{array}$ & $\begin{array}{l}+22 \\
{ }_{-22}\end{array}$ & 0.847 & \pm 0.006 & 1.10 & \pm 0.11 \\
\hline 0.88 & - & 1.00 & 370 & \pm 7 & $\begin{array}{l}+67 \\
+61\end{array}$ & $\begin{array}{l}+38 \\
-38\end{array}$ & 0.865 & \pm 0.009 & 1.12 & \pm 0.12 \\
\hline
\end{tabular}

Table 22: The measured three-jet differential cross-section $d \sigma / d \cos \left(\psi_{3}\right)$ in both the low- and high-mass regions. Other details as described in the caption to Table 2. 


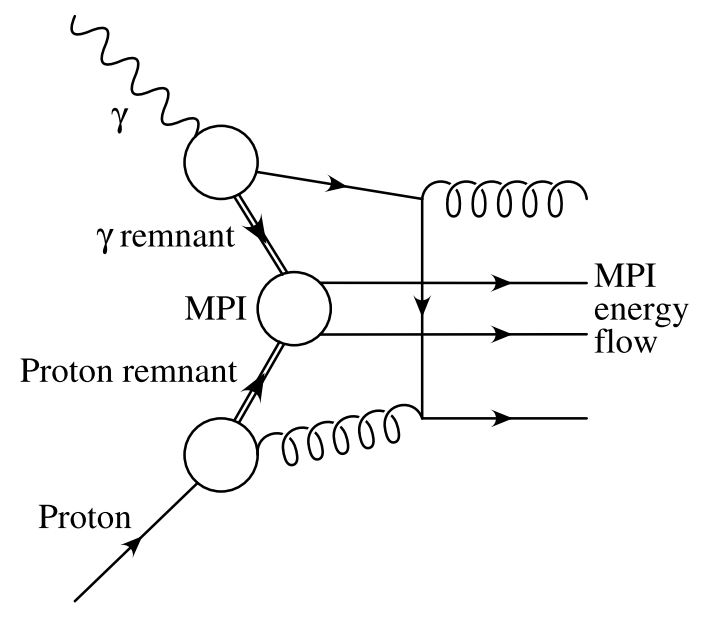

Figure 1: A schematic representation of an event exhibiting a secondary scatter (MPI).

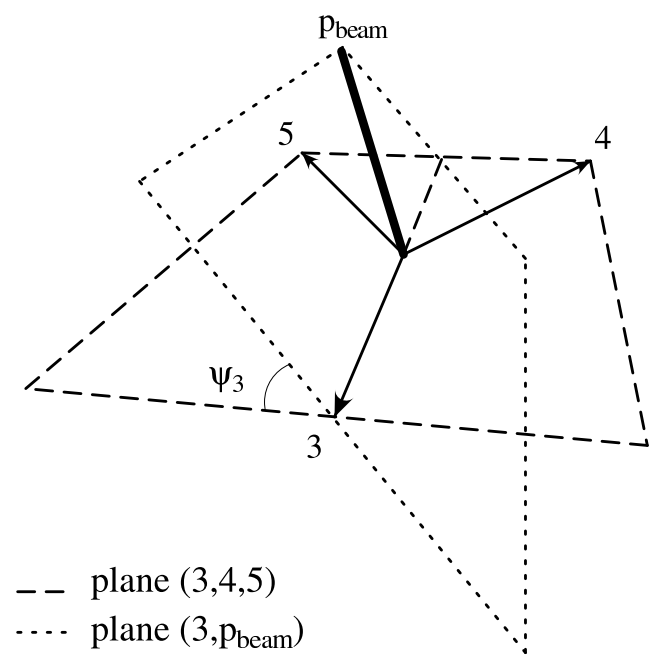

Figure 2: A schematic representation of the three-jet centre-of-mass system and the $\psi_{3}$ angle. 


\section{ZEUS}
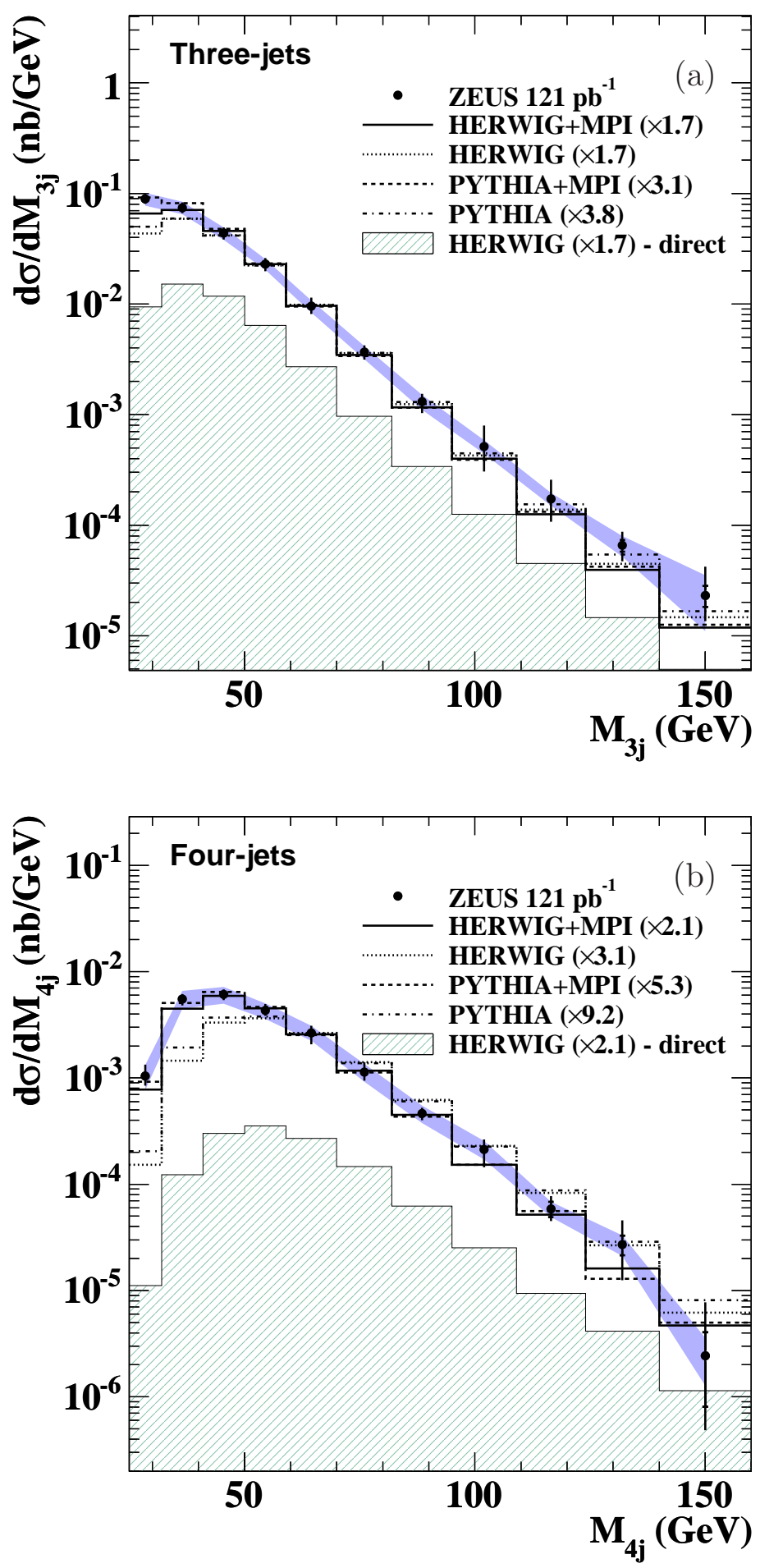

Figure 3: $\quad$ Measured cross section as a function of (a) $M_{3 j}$ and (b) $M_{4 j}$ for the three- and four-jet samples (solid circles). The inner error bars represent the statistical uncertainty. The outer error bars represent the statistical plus systematic uncertainties added in quadrature. The shaded band represents the calorimeter energy scale uncertainty. The predictions from the HERWIG and PYTHIA models are also shown both with and without MPIs, as is the direct component of the HeRwig cross sections. Each Monte Carlo cross section has been area normalised to the high-mass $\left(M_{n j} \geq 50 \mathrm{GeV}\right)$ measured cross section by scaling the predictions by the factors indicated in the legend. 


\section{ZEUS}
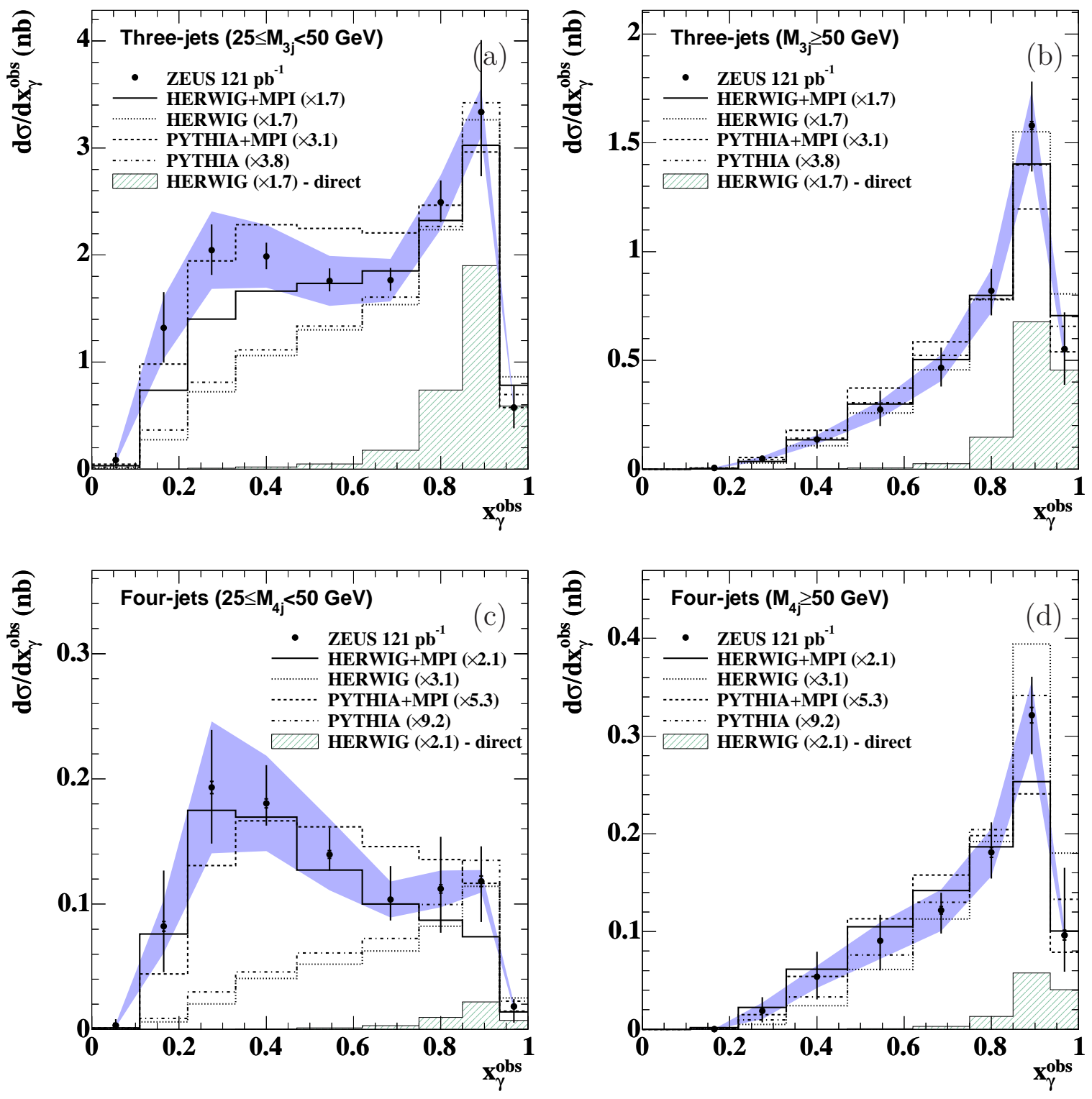

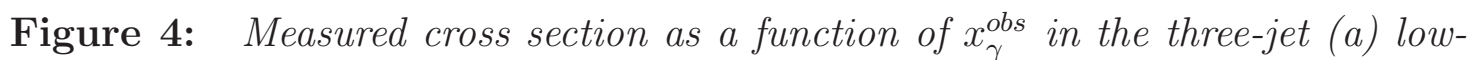
and (b) high-mass samples and the four-jet, (c) low-and (d) high-mass samples. Other details as in the caption to Fig. 3. 


\section{ZEUS}
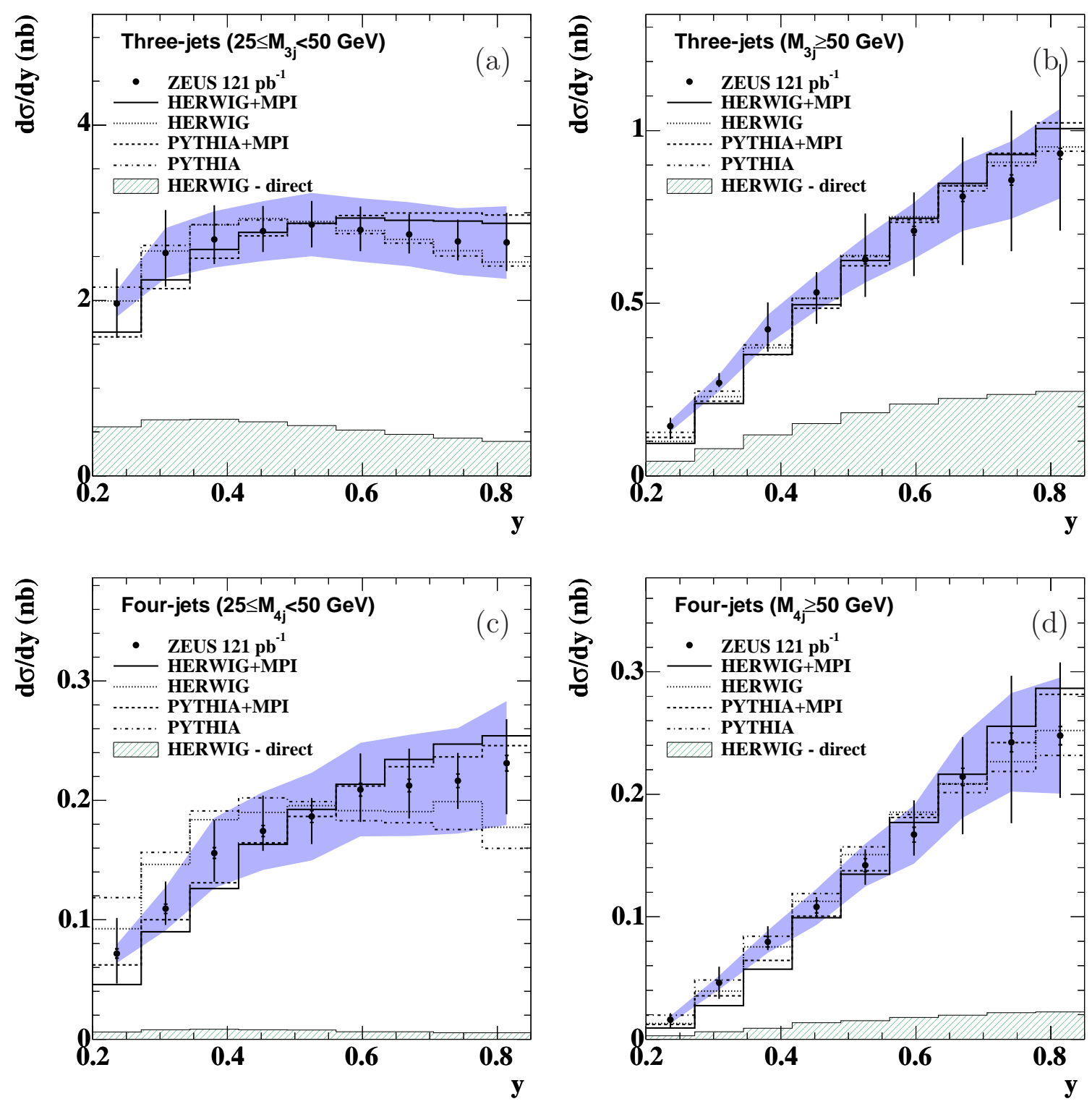

Figure 5: Measured cross section as a function of $y$ in the three-jet (a) lowand (b) high-mass samples and the four-jet, (c) low- and (d) high-mass samples. The predictions from the HERWIG and PYTHIA models are also shown both with and without MPIs, as is the direct component of the HERWIG cross sections. Each Monte Carlo cross section has been area normalised to the data. Other details as in the caption to Fig. 3. 


\section{ZEUS}
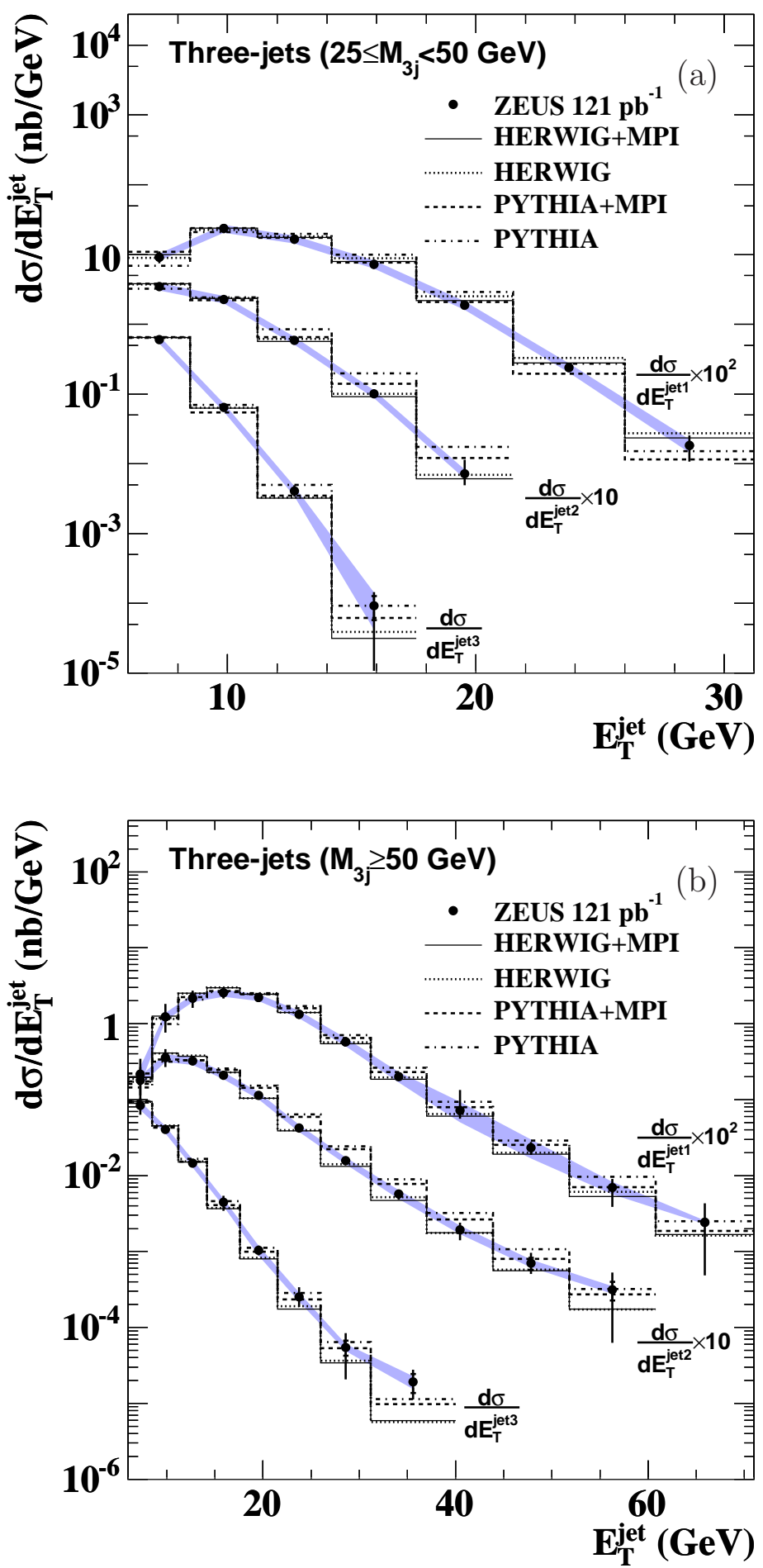

Figure 6: Measured cross section as a function of $E_{T}^{\text {jet }}$ in the three-jet (a) lowand (b) high-mass samples. The jets are ordered such that $E_{T}^{\text {jet } 1}>E_{T}^{\text {jet } 2}>E_{T}^{\text {jet3 }}$. Each cross section has been multiplied by $10^{n}$, where $n$ is given on the plot, to aid visibility. Other details as in the caption to Fig. 5. 


\section{ZEUS}
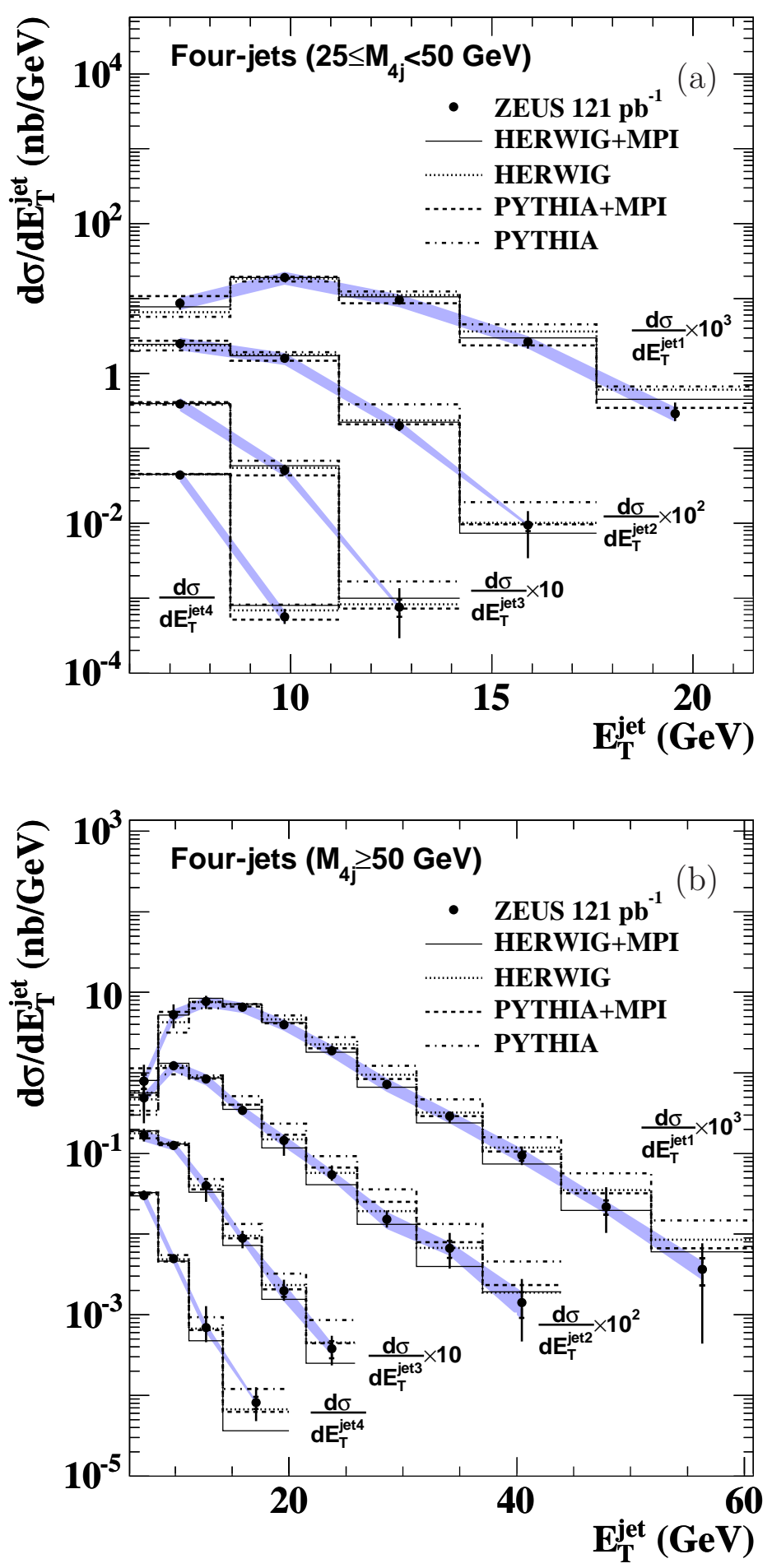

Figure 7: Measured cross section as a function of $E_{T}^{\text {jet }}$ in the four-jet (a) lowand (b) high-mass samples. The jets are ordered such that $E_{T}^{\text {jet } 1}>E_{T}^{\text {jet } 2}>E_{T}^{\text {jet } 3}>$ $E_{T}^{\text {jet } 4}$. Each cross section has been multiplied by $10^{n}$, where $n$ is given on the plot, to aid visibility. Other details as in the caption to Fig. 6. 


\section{ZEUS}
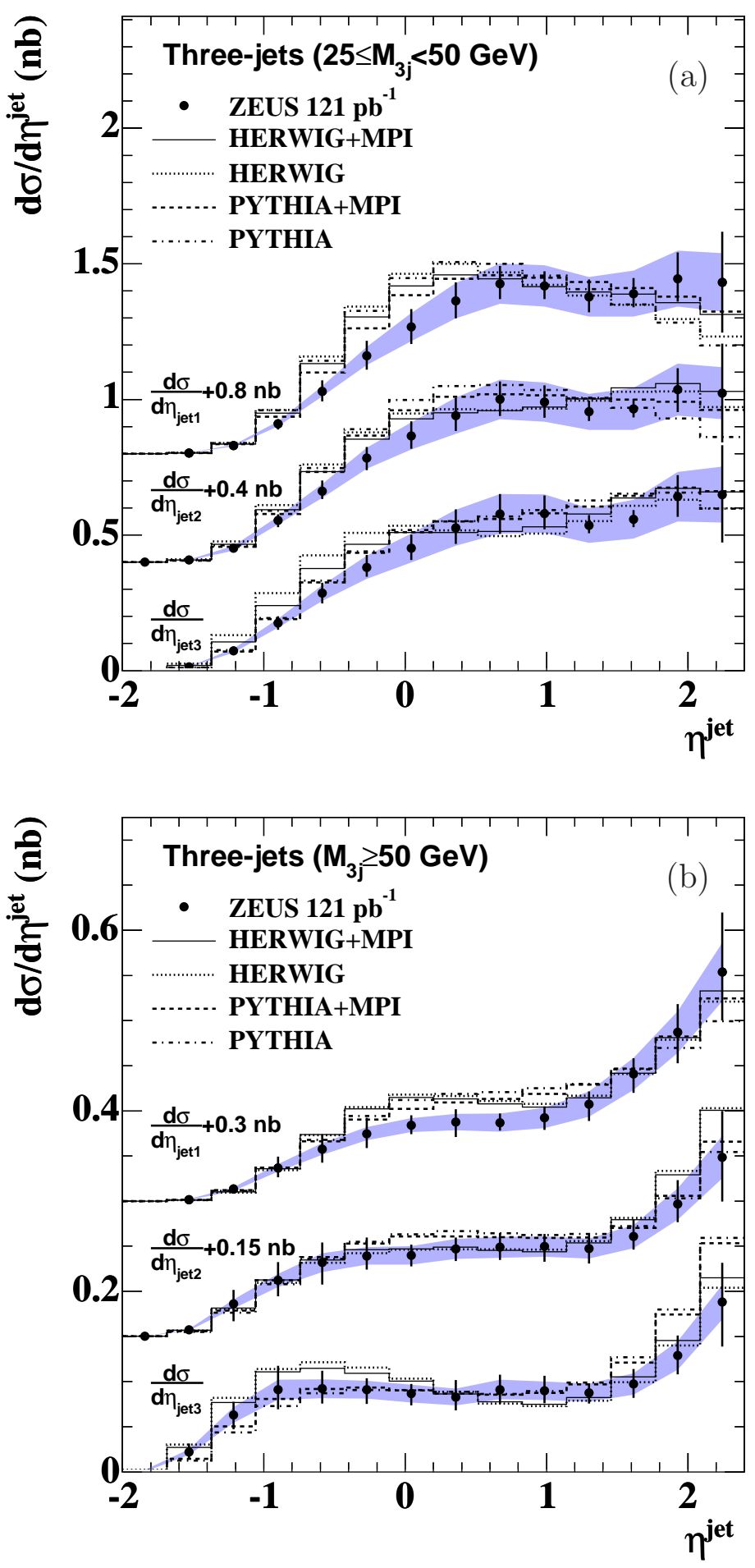

Figure 8: Measured cross section as a function of $\eta^{\text {jet }}$ in the three-jet (a) low-and (b) high-mass samples. Each cross section has been shifted upwards by the amount given on the plot, to aid visibility. Other details as in the caption to Fig. 6. 


\section{ZEUS}
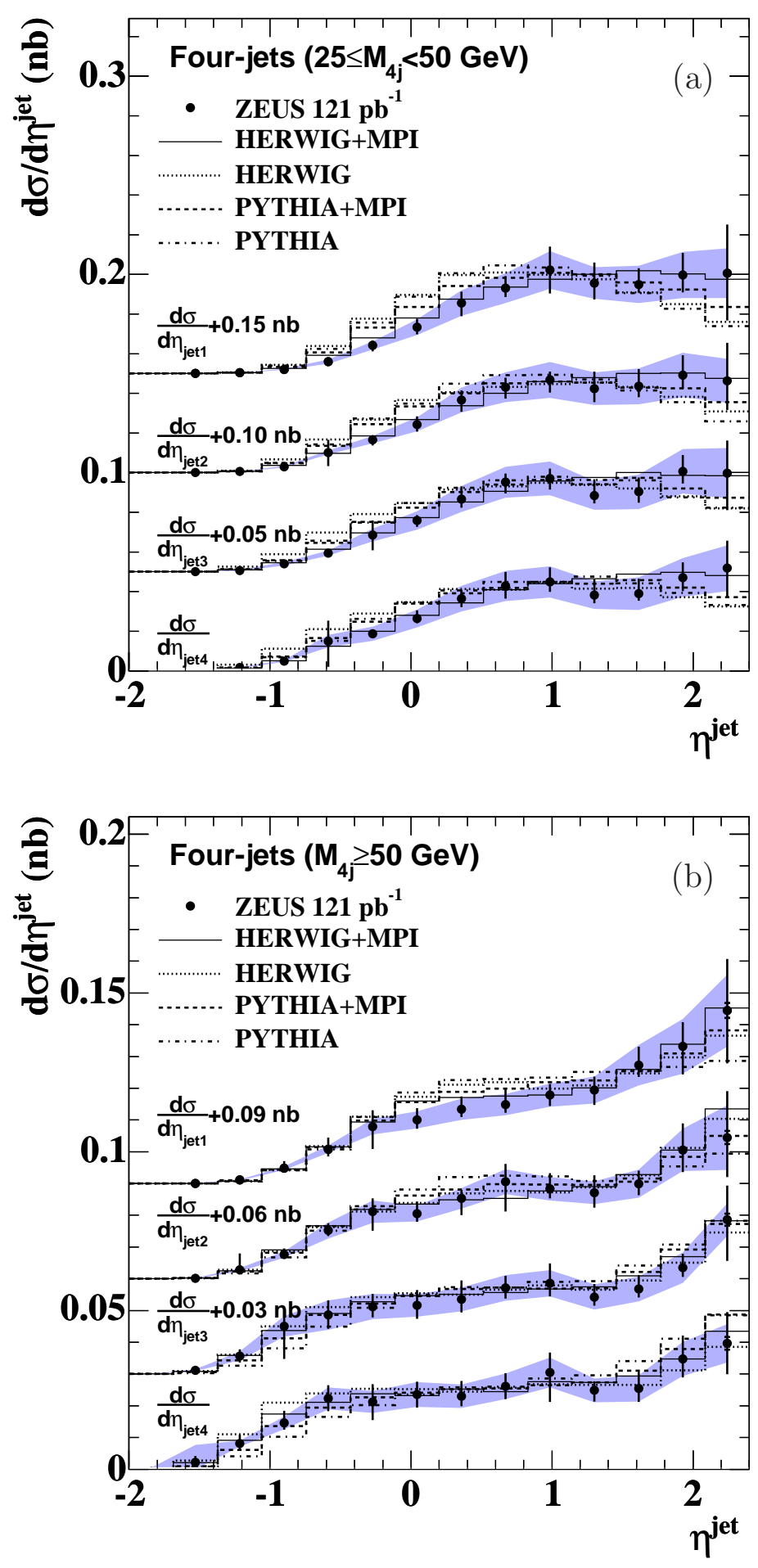

Figure 9: Measured cross section as a function of $\eta^{\text {jet }}$ in the four-jet (a) lowand (b) high-mass samples. Other details as in the caption to Fig. 8. 


\section{ZEUS}
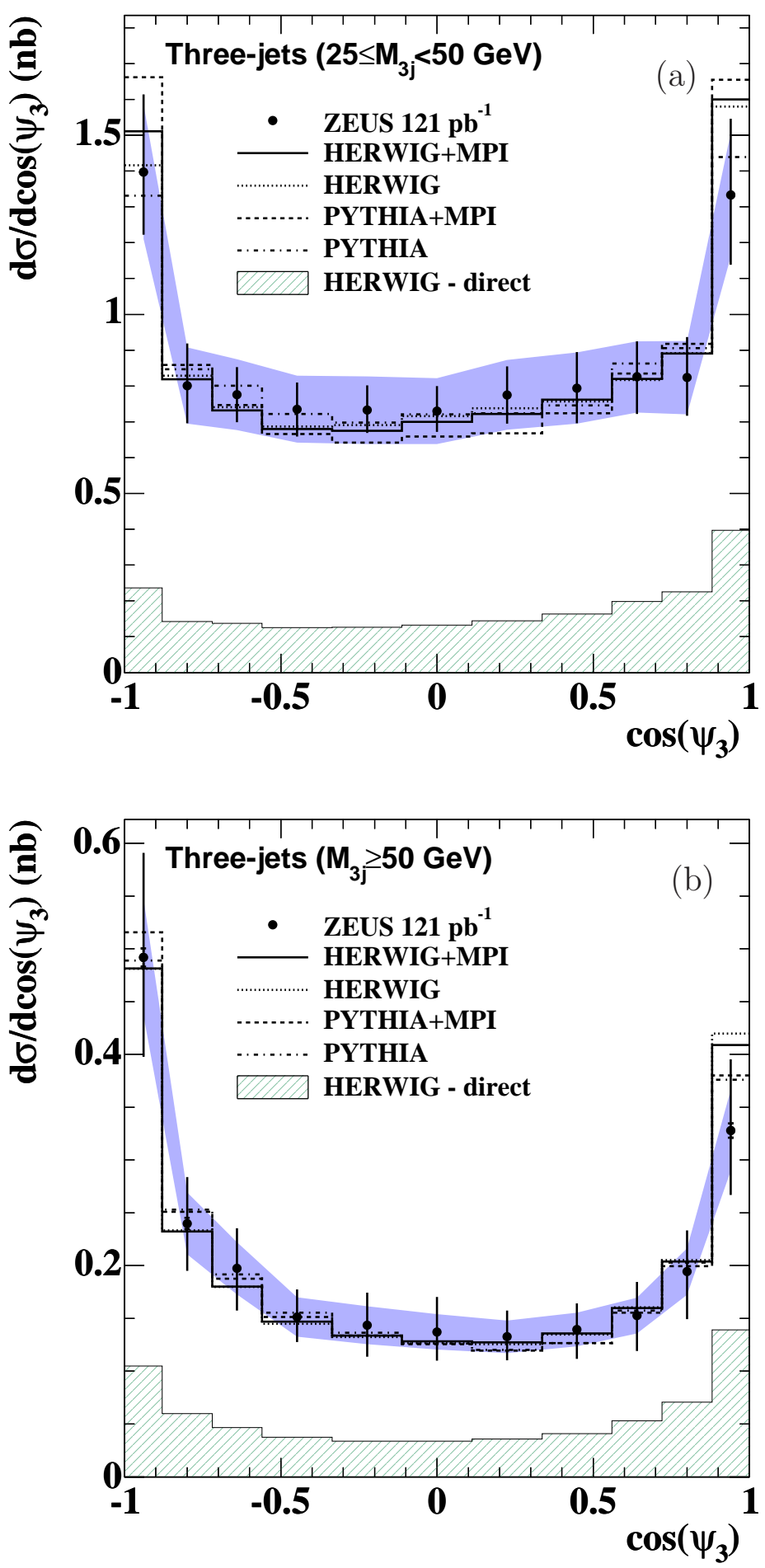

Figure 10: Measured cross section as a function of $\cos \left(\psi_{3}\right)$ in the three-jet (a) low- and (b) high-mass samples. Other details as in the caption to Fig. 5. 
ZEUS

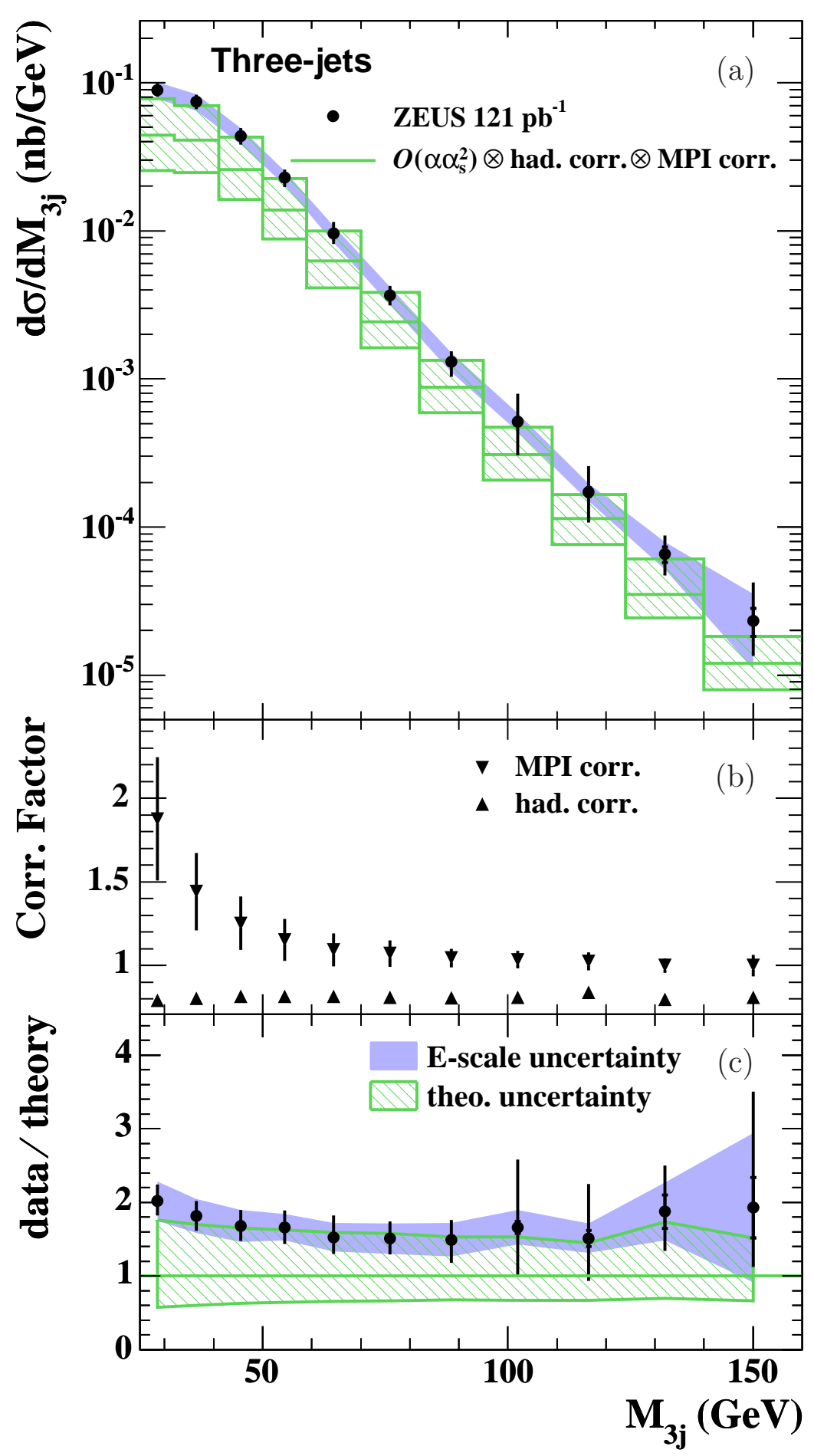

Figure 11: (a) Measured cross section as a function of $M_{3 j}$ in the three-jet sample compared with an $\mathcal{O}\left(\alpha \alpha_{s}^{2}\right)$ prediction, corrected for hadronisation and MPI effects. (b) The hadronisation and MPI corrections as a function of $M_{3 j}$. (c) The ratio of the $M_{3 j}$ cross section divided by the corrected $\mathcal{O}\left(\alpha \alpha_{s}^{2}\right)$ prediction. The theoretical uncertainty is represented by the dashed bands. Other details as in the caption to Fig. 3. 


\section{ZEUS}
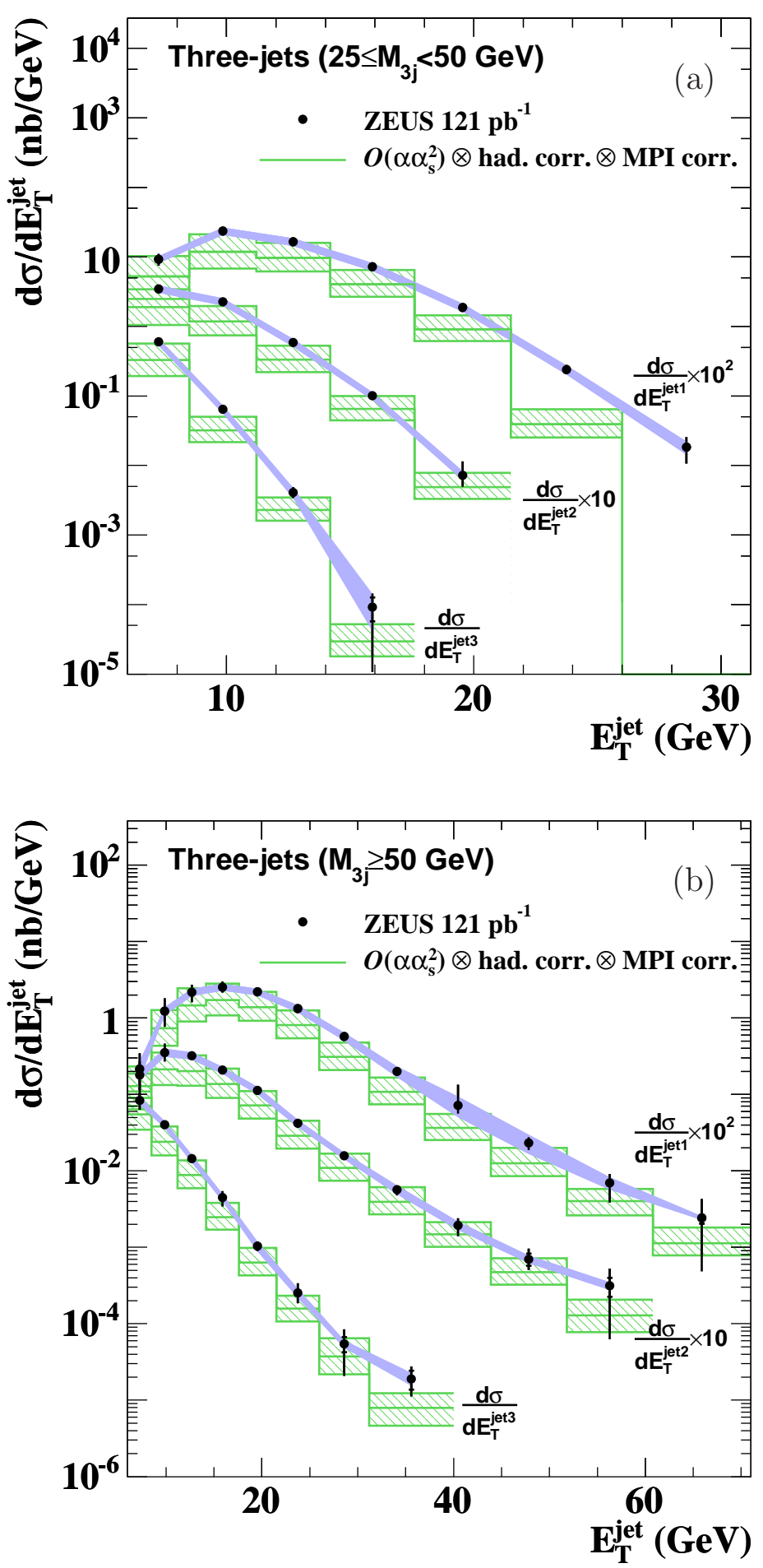

Figure 12: Measured cross section as a function of $E_{T}^{\text {jet }}$ for each jet in the three-jet (a) low- and (b) high-mass samples compared with $\mathcal{O}\left(\alpha \alpha_{s}^{2}\right)$ predictions, corrected for both hadronisation and MPI effects. Each cross section has been multiplied by $10^{n}$, where $n$ is given on the plot, to aid visibility. Other details as in the caption to Fig. 11. 


\section{ZEUS}
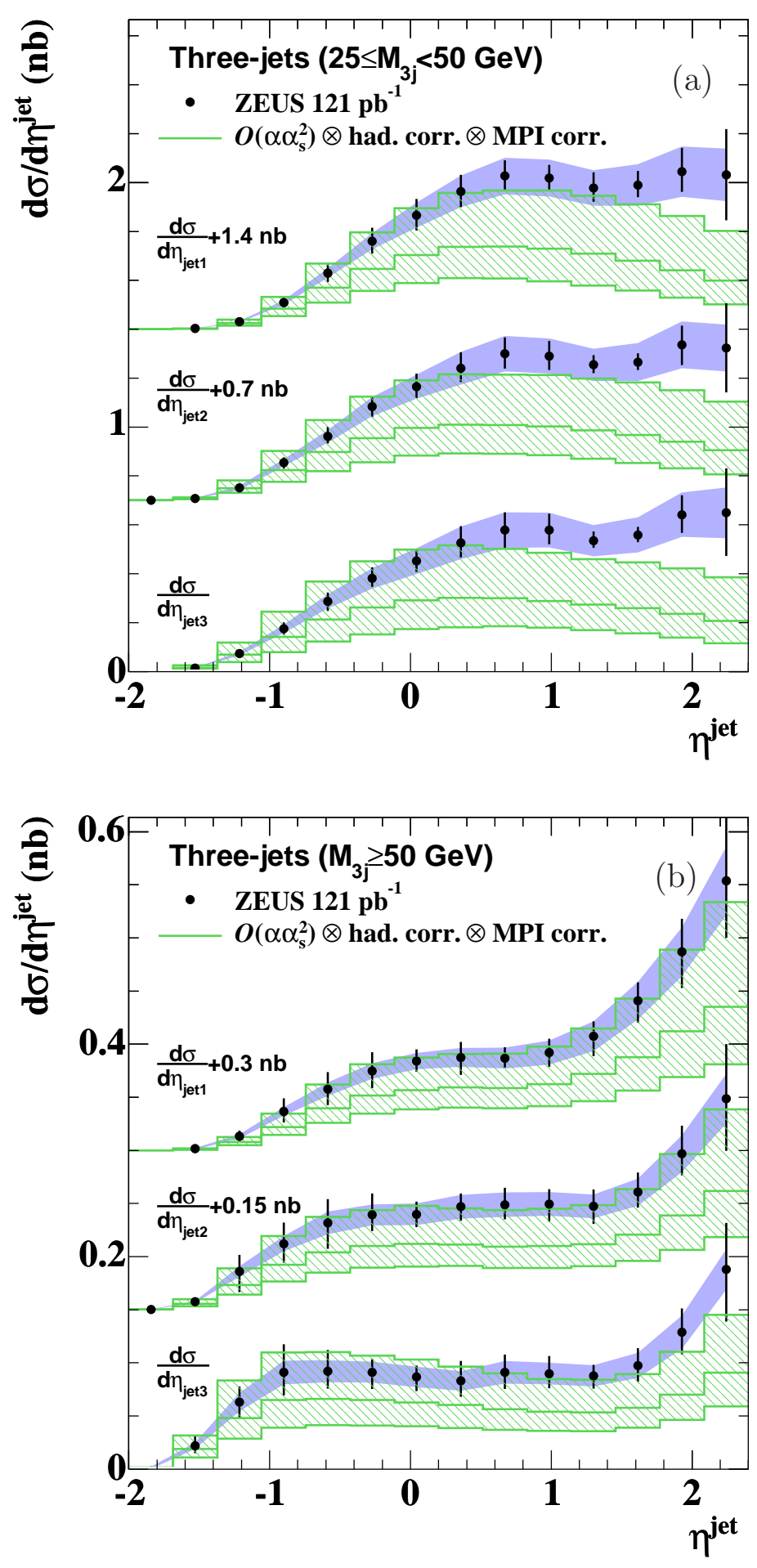

Figure 13: Measured cross section as a function of $\eta^{\text {jet }}$ for each jet in the three-jet (a) low- and (b) high-mass samples compared with $\mathcal{O}\left(\alpha \alpha_{s}^{2}\right)$ predictions, corrected for both hadronisation and MPI effects. Each cross section has been shifted upwards by the amount given on the plot, to aid visibility. Other details as in the caption to Fig. 11. 
ZEUS

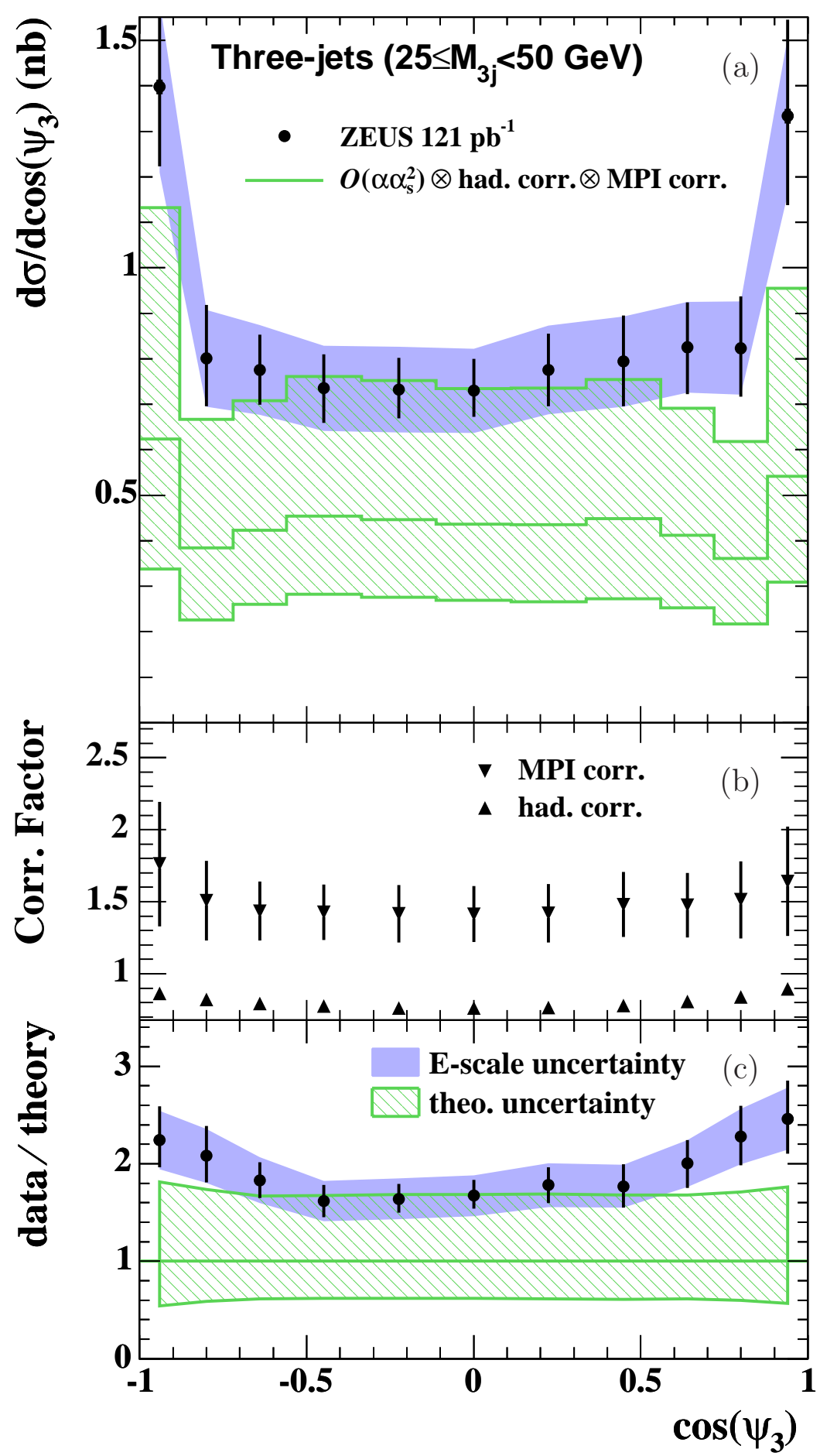

Figure 14: (a) Measured cross section as a function of $\cos \left(\psi_{3}\right)$ in the low-mass three-jet sample. Other details as in the caption to Fig. 11. 


\section{ZEUS}

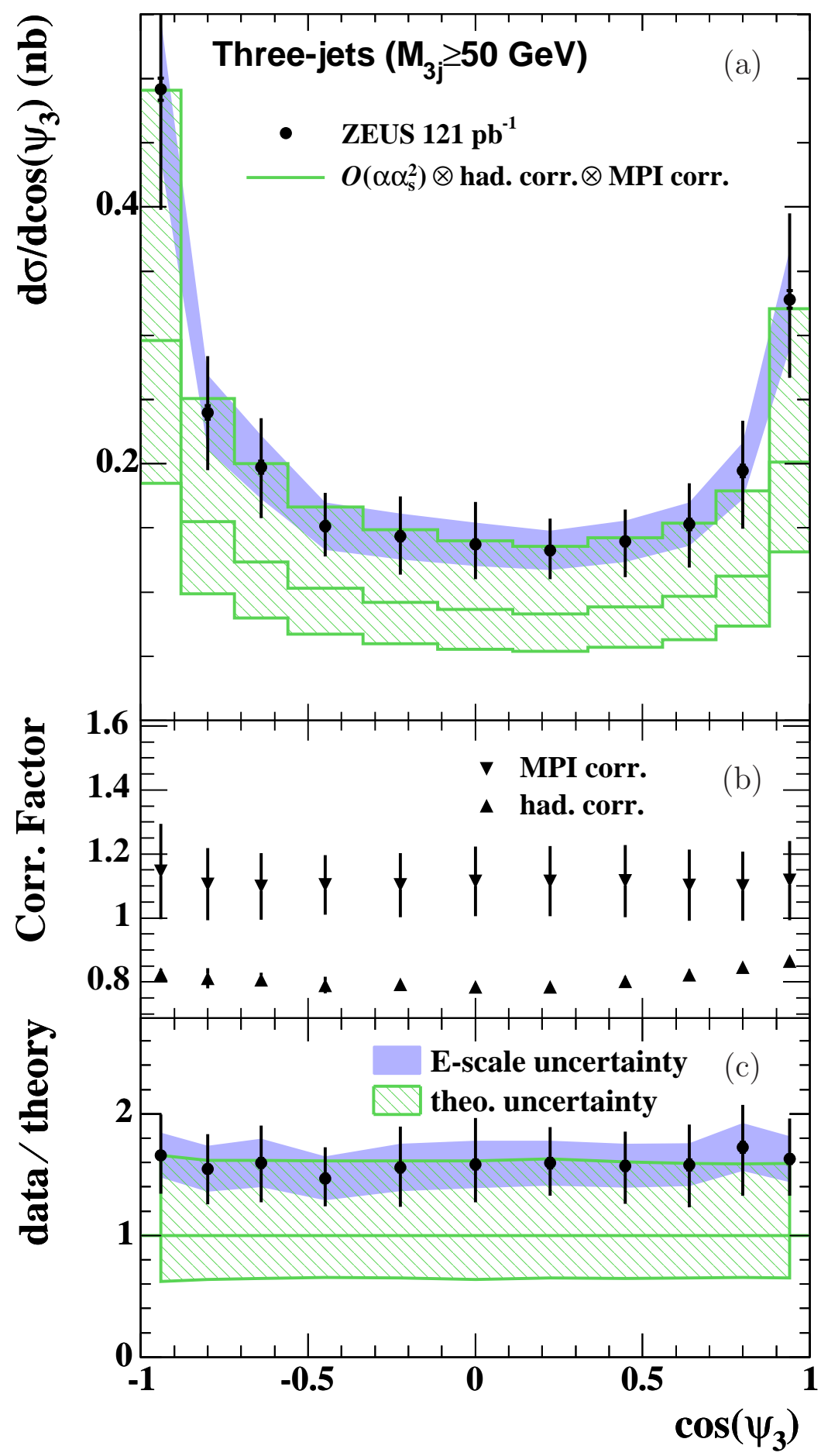

Figure 15: (a) Measured cross section as a function of $\cos \left(\psi_{3}\right)$ in the high-mass three-jet sample. Other details as in the caption to Fig. 11. 